\title{
DIE OBERE GRENZE DER DAUERSIEDLUNGEN IM SIMMENTAL IN IHRER ABHANGIGKEIT VON BODENGESTALT UND LANDWIRTSCHAFT
}

\author{
Von Paul Köchli
}

Mit 11 Figuren, 4 Abbildungen und 2 Kartenbeilagen

\section{Vorwort}

Der Versuch, die obere Grenze der Dauersiedlungen im Simmental in ihrer Abhängigkeit von Bodengestalt und Landwirtschaft zu untersuchen, ist auf Anregung von Herrn Prof.Dr.F.Nussbaum, o. Prof. für Geographie an der Universität Bern, entstanden. Ich möchte ihm hier für seine Anteilnahme am Gelingen der Arbeit wie für die gütige Ueberlassung von persönlichen Karten und Notizen über die eiszeitliche Vergletscherung des Simmentales bestens danken. Zu Dank verpflichtet bin ich ebenfalls Herrn Dr. Th. Ischer in Bern für die eingehenden Hinweise auf die historische Literatur über das Simmental, Herrn E. GENGE in Erlenbach für die Ueberprüfung der Zuordnung der verschiedenen Terrassen in die von Dr. P. BECK gegebenen Systeme. Herr E. GENGE, der sich seit Jahren mit diesem Problem im Simmental beschäftigt, wird darüber eine eingehende Untersuchung veröffentlichen. Ferner sei all jenen Bewohnern des Simmentales, die mir trotz der großen Inanspruchnahme durch die Landarbeit, durch kriegswirtschaftliche Aufträge und Kontrollen bereitwillig und entgegenkommend Auskunft gegeben haben, meine Dankbarkeit bezeugt. Zuletzt sei der Eidg. Landestopographie und der Firma Kümmerly \& Frey, Bern, der beste Dank für ihren Beitrag an die Druckkosten ausgesprochen.

\section{A. EINLEITUNG}

\section{ZUM BEGRIFF DER HÖHENGRENZEN}

In den Gebirgen kann in vertikaler Gliederung eine ähnliche Erscheinung festgestellt werden, wie sie auf den Kontinenten mit der Zunahme der geographischen Breite auftritt. Je mehr sich das Gebiet den Polen nähert, desto geringer wird die Erwärmung des Landes und der Luft durch die Sonneneinstrahlung. Eine Folge davon ist, daß die Auswahl an Pflanzenarten und die Wuchsformen immer kleiner wird. Schließlich verschwinden bestimmte Arten vollständig, so daß sich Grenzen ihrer Verbreitung ziehen lassen. So folgt auf die Zone des Laubwaldes mit Buche, Eiche und Linde diejenige des subarktischen Nadelwaldes, auf diese die der baumlosen Tundra. In den Gebirgen lassen sich nun mit zunehmender Höhe verschiedene aufeinanderfolgende Höhengürtel unterscheiden. Ihre obern Grenzen werden im allgemeinen durch die immer ungünstiger werdenden klimatischen Verhältnisse, namentlich durch die Abnahme der Temperatur, bedingt. Im einzelnen hingegen wird die Ausdehnung dieser Gürtel durch die örtlichen, klimatischen und orographischen Gegebenheiten beeinflußt. Unter diesen spielen die nördliche Exposition mit starker Beschattung, Steilheit der Berghänge, Steinschlag und Lawinen bestrichene Lage, stärkere Schneebedeckung infolge von Schneeverwehungen oder die Zunahme der Niederschläge, hervorgerufen durch die Geländegestaltung, und die Abnahme der Niederschläge aus der gleichen Ursache eine wesentliche Rolle.

Seitdem A. von Humboldr auf die Bedeutung solcher Höhengrenzen hingewiesen hat, sind in zahlreichen Gebirgen der Erde diesbezügliche Beobachtungen gemacht 
worden. Die Werte solcher Höhengrenzen sind in der geographischen Literatur manchmal verwendet worden, um gewisse charakteristische Merkmale der betreffenden Gebirge zum Ausdruck zu bringen.

Je nach der Aufgabe werden am zu untersuchenden Gebiet verschiedene Arten von Höhengrenzen unterschieden, nämlich einmal die rein physikalischen oder natürlichen wie die Schneegrenze, die Firngrenze, sodann die pflanzengeographischen wie die Baum- und die Waldgrenze, und getrennt davon die anthropogeographischen Höhengrenzen, zu denen insbesondere die obern Grenzen der Kulturpflanzen und der Siedlungen zu rechnen sind.

\section{Natürliche Höhengrenzen}

\section{a) Die Schneegrenze}

Nach den grundlegenden Untersuchungen von Humboldt, den Gebrüdern SchliagIntweIt, von Kurowski, Richter, BRÜCKNER und JEgERLEHNER kommen hier die orographische und die klimatische Schneegrenze in Betracht. Die orographische Schneegrenze wird von den genannten Forschern als diejenige Linie definiert, die die untersten Schneeflecken miteinander verbindet, wobei die örtliche Bodengestaltung sowie die Exposition und die lokalen Klimaverhältnisse von großer Bedeutung sind. Als die klimatische Schneegrenze wird diejenige Höhenlinie verstanden, «die die untere Grenze der dauernden Schneebedeckung, unabhängig von der orographischen Begünstigung oder Benachteiligung, angibt, oder als diejenige Höhe, in welcher der im Laufe eines Jahres auf horizontalen Flächen gefallene Schnee durchschnittlich gerade noch oder gerade nicht mehr geschmolzen wird » $(27,488 \mathrm{ff}$.). Es ist hier zu berücksichtigen, daß beide Grenzen je nach dem Witterungsverlaufe jährlichen Schwankungen unterworfen sind.

JEGERLEHNER zeigt in seinen Untersuchungen, daß in den Schweizer Alpen die klimatische Schneegrenze nach den zentralen Gebieten hin in größere Höhen hinaufrückt. Am Säntis liegt sie nach seinen Angaben in 2400-2450 m Höhe, in der MonteRosa-Gruppe in $3260 \mathrm{~m}$, in den Tessiner Alpen zwischen $2700-2800 \mathrm{~m}$, in der Berninagruppe in $2900 \mathrm{~m}$. Sie steigt und sinkt längs und quer zur Richtung der Alpenketten. Im nördlichen Zuge der Schweizer Alpen hebt sie sich von der Dent de Morcles von $2800 \mathrm{~m}$ bis zum Finsteraarhorn auf $2950 \mathrm{~m}$ empor (27, 538ff.).

Dieselbe Tatsache stellte RICHTER bereits früher in den Ostalpen fest. Er schreibt in seinem Werke über «die Gletscher der Ostalpen» (16, $277 \mathrm{ff}$.), daß gerade die innern Teile des Gebirges und die mit der größten Massenerhebung den höchsten Stand der Schneegrenze aufweisen. Auch bei Jegerlekrner wird dieses Ansteigen der Schneegrenze nach den zentralen Gebieten hin als eine Folge der Massenerhebung gedeutet.

Der Begriff der Massenerhebung wird definiert als die gesamte Erhebung eines Gebirges über eine angenommene Niveaufläche. Ragt das Gebiet in breiten und massigen Formen über diese Niveaufläche hinaus, so soll dadurch die Temperaturabnahme langsamer als in der freien Atmosphäre geschehen. Die Gegenden erhielten dadurch ein milderes Klima, als ihnen eigentlich zu käme, was zu höheren Werten der obern Grenzen führe.

\section{b) Die Waldgrenze}

FrITZSCH und IMHOF - die ältere Literatur zu dieser Frage ist bei IMHof auf den Seiten 254 und 255 angegeben - haben bestimmt, daß mit dem Begriff «Wald» ein größerer Bezirk zu verstehen sei, in dem voll ausgewachsene Bäume in ungefähr gleichem Abstande voneinander stehen. Aus einiger Entfernung muß er sich als geschlossene Masse darstellen. Dort, wo der Wald sich aufzulockern beginnt und die Bäume verkrüppelte Formen annehmen, ist die klimatische, obere Waldgrenze. 
Die Waldgrenzen liegen im Wallis und Engadin im Mittel in $2150 \mathrm{~m}$ Höhe, in den Voralpen in $1650 \mathrm{~m}$, in den nördlichen Hochalpen in $1800 \mathrm{~m}$, in den südlichen in $1950 \mathrm{~m}$ Höhe. Der Unterschied zwischen der Schneegrenze und der Waldgrenze beträgt je nach der Oertlichkeit zwischen 700-1000 m. Die Massenerhebung zeigt hier wieder dieselbe Wirkung wie bei der Schneegrenze, nämlich ein Ansteigen des Waldes gegen die zentralen Alpengebiete hin (28, 307 ff.).

\section{Anthropogeographische Höhengrenzen}

Dazu gehören die obern Grenzen der temporär und der dauernd bewohnten Siedlungen, die des Ackerbaus und des Obstbaus. Sie stehen zueinander in Wechselbeziehung, d. h., den Dauersiedlungen folgt im allgemeinen der Ackerbau, und umgekehrt geht die Siedlung nur dorthin, wo meistens noch der Anbau von Ackerfrüchten möglich ist.

In diesen Beziehungen ist das Verhältnis zwischen den dauernd bewohnten Niederlassungen und der Getreidegrenze am eingehendsten untersucht worden.

Die zeitweise bewohnten Siedlungen stehen in den Weidegebieten und werden im Sommer aufgesucht. Die Weidegebiete stellen eine Erweiterung des nutzbaren Bodens dar und ermöglichen damit in den Alpentälern oft die Entstehung von zahlreichen Dauersiedlungen.

\section{a) Grenzen des Ackerbaus und des Obstbaus}

Für die Schweiz sind bei FrüH (76, II., 94 ff.) einige Angaben über die höchsten Vorkommen von Ackerfrüchten enthalten.

Der Weizen gedeiht bis auf $1400 \mathrm{~m}$ bei Ardez, $1410 \mathrm{~m}$ bis $1600 \mathrm{~m}$ bei Valcava im Münstertal; der Spelz wächst bis $1210 \mathrm{~m}$ und $1240 \mathrm{~m}$ am Thunersee in Südexposition, $1100 \mathrm{~m}$ und $1150 \mathrm{~m}$ bei Guggisberg, bis $1300 \mathrm{~m}$ in südwestlicher Lage bei Adelboden, was die ungefähre obere Grenze bedeutet.

Die Gerste reift in Samnaun in $1670 \mathrm{~m}$, in Tschamut in $1640 \mathrm{~m}$, in Lü in $1900 \mathrm{~m}$ und in den Berner Alpen bis $1520 \mathrm{~m}$ hinauf. Der Hafer wird in Celerina in $1800 \mathrm{~m}$ Höhe angebaut, und der Roggen bei Tschamut bis 1740 m, bei Lü bis 1918 m, bei FindelenZermatt bis $2100 \mathrm{~m}$.

Daraus ergibt sich, daß mit der Massenerhebung der Gebirge die obere Grenze des Anbaus hinaufrückt.

Dasselbe ist auch bei der Kartoffel und bei den Gemüsen festgestellt worden, wobei an der obern Grenze des Anbaus allerdings Frostschäden auftreten können. Die Kartoffel steigt in der Nordschweiz durchschnittlich auf $1650 \mathrm{~m}$ hinauf, im Engadin auf $1700 \mathrm{~m}$, in Arosa auf $1850 \mathrm{~m}$, im Wallis bis auf $1900 \mathrm{~m}$.

In Arosa gedeihen in 1800-1850 m noch 16 Gemüsearten wie 5 Salatsorten, Lauch, Rotkraut, Spinat, Karotten, Kohl, Buschbohnen usw. Der Rhabarber wird sogar noch in $2000 \mathrm{~m}$ Höhe angepflanzt.

FRÜH weist darauf hin, daß beim Obstbau die Kirschen oft die obere Grenze der Dauersiedlungen kennzeichnen. Der Kirschbaum kommt auf der Nordseite der Alpen in 1200-1300 m Höhe vor, im Wallis in $1650 \mathrm{~m}$, in Graubünden in $1790 \mathrm{~m}$. Das Kernobst bleibt gewöhnlich $150 \mathrm{~m}$ darunter zurück (76, II., 117 ff.).

\section{b) Die obere Grenze der Siedlungen}

Wir unterscheiden zwischen den periodisch und dauernd bewohnten Siedlungen. Dieses sind die Heimgüter, jenes die Sennhütten, die auf den Alpweiden stehen, oder die Vorsassen, die im Frühling und Herbst, manchmal sogar bis weit in den Winter hinein, bezogen werden. 
FLÜCKIGER hat die obere Grenze der zeitweise bewohnten Siedlungen in der Schweiz auf Grund der Verbreitung der Alphütten abgeleitet. Er benützte dazu den Topographischen Atlas der Schweiz (Siegfried-Karte). Bei der Erläuterung über die Lageverhältnisse in den verschiedenen Talgebieten berücksichtigte er in erster Linie die Exposition, weniger die Geländeform, in der die Siedlungen liegen.

Aus der FlüCKIGERS Arbeit beigelegten Karte ist ersichtlich, daß mit zunehmender Massenerhebung die periodisch bewohnten Siedlungen in größere Höhen hinaufsteigen. Es handelt sich dabei um Siedlungen, die in unmittelbarer Beziehung zur Alpwirtschaft stehen und nur im Sommer während 1-2 Monaten bewohnt werden. Die höchsten derartigen Siedlungszonen liegen im Einzugsgebiet des Inn (Engadin), im Oberwallis und im südlichen Wallis. In den Voralpen verlaufen die Kurven in geringeren Höhen(22).

Damit ergab sich eine gewisse Uebereinstimmung seiner Verbindungslinien der zeitweise benützten Siedlungen mit der Schnee- und Waldgrenze, obgleich diese Kurven nicht parallel zueinander verlaufen. Die Kurve der Alphütten liegt meistens zwischen der obern Waldgrenze und der Schneegrenze.

Aus dem über die Höhengrenzen Gesagten muß gefolgert werden, daß die obere Grenze der Dauersiedlungen durch Umstände bedingt sein wird, die den Bewohnern erlauben, am Standort ihres Wohnhauses während des ganzen Jahres ihr Leben zu fristen.

\section{DIE OBERE GRENZE DER DAUERSIEDLUNGEN}

Die Literatur über dieses Fachgebiet ist nicht sehr umfangreich. Grundlegende Arbeiten sind in den Ostalpen geleistet worden.

\section{Arbeiten über die obere Grenze der Dauersiedlungen in den Ostalpen}

Die Forscher haben ihre Untersuchungen von zwei Gesichtspunkten aus entwickelt. Die einen haben die Siedlungsgrenze in den Alpen im Zusammenhang mit den Grenzen des Getreidebaues, der Mähwiesen und des Waldes untersucht; die andern sind von der Bodengestaltung ausgegangen und haben die bevorzugten Standorte der Alpensiedlung geprüft.

SCHINDLER war der Bahnbrecher in der ersten Richtung. Seine diesbezüglichen Arbeiten sind in der Zeitschrift des Deutsch-Oesterreichischen Alpenvereins in den Jahren 1888, 1890 und 1893 erschienen. Es ergeben sich als wichtigste Tatsachen, daß nirgends der Einfluß, den der Klimawechsel und das Bodenrelief auf alle wirtschaftlichen Unternehmungen ausüben, in so prägnanten Zügen hervortritt wie gerade in den Alpen. Licht und Schatten, Höhe und Tiefe, Kälte und Wärme wechseln hier auf kleinem Raum in bedeutend stärkerem Maße ab als im Flachland.

Er findet bezüglich der obern Grenze der Dauersiedlungen, daß sie bis zur Höhe steige, in der sich noch Getreidefelder an den Gehängen ausbreiten. Die Ursache dazu sei, daß die Brotbeschaffung, die die Hauptsorge des bäuerlichen Lebens darstelle, noch heute (1888) auf eigenem Grund und Boden geschehe (39, $74 \mathrm{ff}$.$) .$

SCHINDLER gelangt zu folgenden Höhenwerten für die obere Dauersiedlungsgrenze in den Hohen Tauern (39, 77 ff.):

Gebiet

Gastrein-Tal . . . . . . . . . . . . . .

Rauriser Tal . . . . . . . . . . . . . . .

Kapruner Tal . . . . . . . . . . . . . . .

Fusch . . . . . . . . . . . . . . . . . .

Pinzgau, Sonnseite .. . . . . . . . . . . .

Pinzgau, Schattseite . . . . . . . . . . . . .

Möll- und Kalsertal . . . . . . . . . . . . . . .

\begin{tabular}{ccc} 
Abdachung & \multicolumn{2}{c}{ Obere Dauersiedlungsgrenze } \\
Nord & Mittel & $1200 \mathrm{~m}$ \\
Nord & Mittel & $1240 \mathrm{~m}$ \\
Nord & Mittel & $900 \mathrm{~m}$ \\
Nord & Mittel & $1075 \mathrm{~m}$ \\
Nord & Höchstwert & $1300 \mathrm{~m}$ \\
Nord & Mittel & $900 \mathrm{~m}$ \\
Süd & Mittel & $1524 \mathrm{~m}$
\end{tabular}


Die gleiche Richtung wie SCHINDLER vertritt auch FRITZSCH in seiner umfangreichen Arbeit «Ueber die Höhengrenzen in den Ortleralpen». Er weist einleitend darauf hin, «daß das Ziel der Arbeit mit dem Wechsel von der deduktiven zur induktiven Methode ein neues geworden ist, indem man nicht mehr darauf ausgeht, Mittelwerte für weite, oft in ihren einzelnen Teilen unter ganz verschiedenen Bedingungen stehende Gebiete zu gewinnen, in denen dann die einzelnen Ursachen sich gegenseitig verschleiern und sich somit einer klaren Erkenntnis entziehen, sondern daß man die tatsächlichen Höhengrenzen mit all ihren Aus- und Einbuchtungen festzulegen versucht» (24, 109 ff.).

FrITZSCH stellt bei seinen Aufnahmen im Ortlergebiet einen großen Höhenunterschied bei den Dauersiedlungen zwischen der Nord- und der Südabdachung fest. Nach seiner Auffassung liegt der Grund im Zurückbleiben der obern Grenze der Dauersiedlung auf der Südabdachung der Tauern in ethnographischen und nicht in orographischen oder klimatischen Verhältnissen. Im Norden wird die Siedlungsgrenze durch Einzelhöfe gegeben, im Süden durch geschlossene Ortschaften, weil der italienische Volkscharakter dem Einzelwohnen abhold ist. Durch diesen Umstand werde auf der Südflanke des Gebirges die obere Grenze hinuntergedrückt $(24,265)$.

Außerdem hält er fest, daß im Suldental (Ortlergebiet) bei den Gampenhöfen in $1881 \mathrm{~m}$ Höhe die Getreide- und Dauersiedlungsgrenze nicht zusammenfallen. Die Existenz der dort ansässigen Bauern gründet ausschließlich auf derViehzucht und einem geringen Anbau von Kartoffeln und Rüben, die zur Eigenversorgung dienen $(24,265)$.

Um mit den schweizerischen Verhältnissen über Höhenlagen vergleichen zu können, führen wir noch einige Mittelwerte der obern Grenze der Dauersiedlung auf (24, 286 ff.):

Gebiet

Prad-Bormio... . . . . . . . . . . . . . . . . . .

Val Turva.

Pont di Legno-Pejo . . . . . . . . . . . . . . . . . .

Rabbi. . . . . . . . . . ............

Ulten . . . . . . . . . . . . . . . . . . . . . .

Martell . . . . . . . . . . . . . . . . . . . .

Vintschgau . . . . : . . . . . . . . . . . . . . . . .

Sulden

\begin{tabular}{|c|c|c|}
\hline Nach Talschaften & Nach & Expositior \\
\hline $1373 \mathrm{~m}$ & NW & $1186 \mathrm{~m}$ \\
\hline $1590 \mathrm{~m}$ & W & $1504^{\circ} \mathrm{m}$ \\
\hline $1452 \mathrm{~m}$ & SW & $1664 \mathrm{~m}$ \\
\hline $1421 \mathrm{~m}$ & $\mathrm{~S}$ & $1584 \mathrm{~m}$ \\
\hline $1583 \mathrm{~m}$ & SE & $1499 \mathrm{~m}$ \\
\hline $1429 \mathrm{~m}$ & $\mathrm{E}$ & $1257 \mathrm{~m}$ \\
\hline $1167 \mathrm{~m}$ & NE & $1177 \mathrm{~m}$ \\
\hline $1743 \mathrm{~m}$ & $N$ & $1147 \mathrm{~m}$ \\
\hline
\end{tabular}

Löws hat mit seiner Arbeit «Siedlungsarten in den Hochalpen» die morphologische Richtung in denUntersuchungen über die obere Dauersiedlungsgrenze eingeleitet $(32,403)$.

Er stellt an den Beginn der Untersuchung die These, daß drei Dinge jede dauernde Niederlassung im Hochgebirge bestimmen, nämlich:

1. ein gesicherter Ort für die Gründung der Heimstätte;

2. Erwerbsquellen für den Ansiedler;

3. eine nie oder doch nur ausnahmsweise unterbrochene Zugänglichkeit.

LöwL beschäftigt sich hauptsächlich mit der ersten der drei genannten Bedingungen. Er teilt die Siedlungen nach morphologischen Bezeichnungen ein. Wir geben davon einen gedrängten Auszug.

Die Schuttkegel eignen sich in der Regel vortrefflich zur Besiedlung. Sie sind viel sanfter geböscht als die Sturzhalden, bestehen nicht wie diese aus ungemischtem, grobem Gehängeschutte, sondern auch aus feinerem Gruse und selbst aus erdigen Massen und können durch den periklinen Abfall ihrer Oberfläche mit dem aus der Runse fließenden Wasser berieselt werden. Zu diesen drei, schon in der Bildungsart, gegebenen Vorzügen gesellt sich noch eine klimatische Begünstigung von hohem Werte. Der Rücken mächtiger, hochansteigender Schuttkegel ist den kalten Luftschichten entzogen, die sich im Herbst und Winter auf dem Boden schlecht ventilierter Täler ansammeln.

Die Murkegel weisen die gleichen Vorteile wie die Schuttkegel auf, trotzdem sie auf andere Art entstanden sind. Auf ihrem fruchtbaren Schwemmlande scharen sich ebenfalls die bäuerlichen Heimstätten. 
Beide Siedlungsarten bezeichnet LöwL als Schuttkegelsiedlungen.

Die Hangsiedlungen entstehen auf gleichmäßig abgeschrägten Hängen, deren Böschung unter ein gewisses $\mathrm{Maß}$, in der Regel unter den Winkel von $30^{\circ}$, herabsinkt. Das anstehende Gestein muß entweder selbst eine ergiebige Bodenkrume liefern oder von den Gletschern mit fruchtbarem Geschiebelehm bekleidet worden sein.

Staffelsiedlungen sind nach Löws nur in den untern bewohnten Abschnitten der Täler vorhanden. Allerdings sei hier die Besiedlung zumeist durch die Verteilung des Gehängeschuttes und fast nie durch das Auftreten echter Stufen bedingt. Stoße man aber doch einmal auf eine Felsstaffel, so sei die Plattform gewiß mit Halden und Schuttkegeln besetzt, welche sämtliche Niederlassungen an sich heranzögen.

Bodensiedlungen liegen auf einem durch Auftragung erweiterten und erhöhten Talboden. Sie stehen den Beckensiedlungen sehr nahe. Solche Siedlungen sind dem Hochwasser meistens schutzlos preisgegeben. Der agronomische Wert des Bodens bleibt hier weit hinter dem der Muren zurück.

Am dichtesten stehen nach Löwss Untersuchungen die Ansiedlungen auf jenen Terrassen, welche von den Gletschern der Diluvialzeit aufgeschüttet oder wenigstens mit Grundmoränenmaterial überzogen worden sind. Die Grundmoränenablagerungen bieten ähnliche günstige Bedingungen für den Anbau wie das Material der Muren.

Leistensiedlungen sitzen auf schmalen Terrassen, die die Ueberreste alter Talböden sind und flach aus dem Gehänge vorspringen. Sie sind meistens mit Moränenschutt bedeckt. Die obern Leisten sind in der Regel, weil viel länger der Verwitterung und der Denudation ausgesetzt, weniger gut erhalten als die untern, die jüngern.

Als letzten Siedlungstypus erwähnt LöwL die Rundhöckersiedlungen, die auf Rundhöckern in ehemals vergletscherten Gebieten liegen (32, 406 ff.).

In der gleichen Forschungsrichtung bewegt sich HAMMER, wobei er besonders den Einfluß der Eiszeit auf die Besiedlung der Alpentäler studiert hat. Seine Untersuchungsergebnisse bestätigen die Tatsache, daß die diluvialen Gletscher die Bodenform des Gebirgslandes umgestaltet und in den Tälern eine in ihrer Mächtigkeit schwankende Decke von Moränenmaterial zurückgelassen haben. Diese ist, je nach dem Einzugsgebiet des Gletschers, ärmer oder reicher zusammengesetzt, wodurch sie der Pflanzendecke ein verschiedenwertiges Nährmaterial bietet.

Seinen Ausführungen ist ferner zu entnehmen, daß schmälere, ausgeschliffene Terrassen in den Alpentälern, in denen die deutsche Einzelhofsiedlung herrscht, an den sonnseitigen Hängen dicht mit Gehöften besät sind.

HAMMER hat beobachtet, dảß in den Kalkalpen die Gesteinsart in hohem Maße die Siedlungsverteilung beeinflußt. Die Siedlungen folgen den Zügen der leichter verwitterbaren, wasserreichen Mergel-, Sandstein- und Schieferzonen und steigen wenig hoch empor, weil das an Wasser und Humus arme Kalkgebirge für die Besiedlung wenig günstig ist $(6,77)$.

$\mathrm{Zu}$ den gleichen Feststellungen ist auch GASTL in ihrer Arbeit über die Allgäuer Alpen und deren Besiedlung gelangt (25).

$\mathrm{Zu}$ den genannten Autoren, die die obere Grenze der Dauersiedlungen nach geographischen Gesichtspunkten erörtert haben, gesellt sich noch MAYER, der auf die historisch ökonomischen Gesichtspunkte in der Darstellung der alpinen Siedlungsgrenzen hinweist $(33,133 \mathrm{ff}$.$) .$

\section{Arbeiten über die obere Grenze der Dauersiedlungen in der Schweiz}

In den Arbeiten schweizerischer Forscher werden nur ausnahmsweise einzelne Gebiete eingehend auf die Siedlungsgrenzen untersucht.

BURKY schreibt in seiner Arbeit über das Rhonequertal, daß mit der Zunahme der Massenerhebung von den Voralpen zu den Kalkhochalpen und kristallinischen Massiven die Höhengrenze der menschlichen Siedlung ansteigt. Die höchstgelegenen Ein- 
zelhöfe stehen in diesem Rhonetalabschnitt in $1250 \mathrm{~m}$ Höhe. Größere, geschlossene Siedlungen, wie die obern Teile der Dörfer Mex und Morcles südlich St-Maurice, erreichen nur $1150 \mathrm{~m}$ bzw. $1180 \mathrm{~m}$ Höhe, während nördlich die bestgelegenen Ortschaften wie Miex, Vers le Doy und das obere Viertel von Corbeyrier um $1000 \mathrm{~m}$ Höhe bleiben und allein Torgon in ganz vorteilhafter Lage auf $1110 \mathrm{~m}$ gelangt (21).

RINGWALD kommt in seiner Dissertation "Wirtschaft und Besiedlung des Kantons Obwalden» zum Ergebnis, daß in diesem Kanton als einem Ausschnitt der Voralpenzone die Siedlungsgrenze relativ niedrig liegt. Die höchsten Dauersiedlungen gehen hier nirgends über die Höhenlinie von $1200 \mathrm{~m}$ hinaus. Eine Hauptursache ist, neben natürlichen Faktoren, die Erweiterung des Alpareals nach unten. Früher gab es Dauersiedlungen in $1300 \mathrm{~m}$ Höhe; heute sind sie nur noch zeitweilig bewohnt oder völlig ausgelöscht. Man wird also nicht fehlgehen, wenn man eine allgemeine Herabsetzung der Grenze der Dauersiedlungen um $100 \mathrm{~m}$ bis $200 \mathrm{~m}$ annimmt (38).

Aus der Arbeit von OTr über die Siedlungsverhältnisse beider Appenzell ist zu entnehmen, daß die, obersten Dauersiedlungen auf $1200 \mathrm{~m}$ liegen. Im allgemeinen schwankt die Grenze zwischen 900 bis $1000 \mathrm{~m}$ Höhe (35).

J. BühLER hat das Entlebuch in siedlungsgeographischer Hinsicht untersucht. Hier sind, abgesehen vom Haupttal, die Talsohlen relativ schmal und bieten der Ansiedlung wenig Raum. Diese steigt deshalb an den Talflanken empor. J. BüHLER gibt folgende Höchstwerte an: Napfgebiet $1250 \mathrm{~m}$, an der Beichlen $1229 \mathrm{~m}$, im Hilferntal $1291 \mathrm{~m}$, am Hilfernpaß $1376 \mathrm{~m}$, am Feuerstein $1401 \mathrm{~m}$, in Sörenberg $1222 \mathrm{~m}$ usw. (20). Err weist darauf hin, daß die obere Grenze schwierig zu bestimmen sei, weil der Charakter vieler Besitzungen in wenigen Jahren wechseln könne, je nach den persönlichen Verhältnissen des Grundbesitzerș.

Stellen wir diesen Arbeiten aus den Voralpen eine aus den Hochalpen gegenüber, und zwar die ausgezeichnete, geographische Monographie von A. BüHLER über das Meiental im Kanton Uri (19). A. BüHLER findet im Meiental für die obere Grenze der Dauersiedlungen ein Mittel von $1750 \mathrm{~m}$ für die Sonnseite und von $1540 \mathrm{~m}$ für die Schattseite. Die Hauptsiedlungen liegen in $1360 \mathrm{~m}$ bzw. in $1300 \mathrm{~m}$ Höhe, also dort, wo in den Voralpen die obersten Höfe anzutreffen sind.

Aus den erwähnter Arbeiten ergeben sich recht verschiedene Höhenwerte für die obere Grenze der Dauersiedlungen in den einzelnen Gebieten. Im allgemeinen liegt die Grenzlinie in den Voralpen tief, weil hier das Gesamtgebiet, namentlich die Talsohlen und ihre anstoßenden Gehänge, im Vergleich zum Meiental, zum Engadin und zu einigen Walliser Tälern eine bedeutend geringere Meereshöhe und Massenerhebung besitzt. Dazu kommen in jedem Gebiete seine ihm eigentümlichen klimatischen und wirtschaftlichen Verhältnisse. Außerdem wird in den höhernLagender Einfluß der orographischen Bedingungen immer ausgeprägter, wie es Löws schon 1888 nachgewiesen hat.

\section{B. DIE OBERE GRENZE}

\section{DER DAUERSIEDLUNGEN IM SIMMENTAL}

\section{NATYÜRLLIICiHE VERHÄ!LTNISSE DES SIMMENTAILES}

\section{Orographischer Ueberblick}

Das Simmental liegt in der Zone zwischen dem Thuner- und dem Genfersee vor den eigentlichen Berner.Hochalpen und gehört mit Ausnahme der Wildhorn-Wildstrubel-Gruppe den Voralpen an. Unser Untersuchungsgebiet, das sich nicht nach der politischen, sondern nach der topographischen Begrenzung richtet, umfaßt $600,84 \mathrm{~km}^{2}$. Die Gemeinden Spiez, Wimmis, Ober- und Niederstocken und Reutigen sind weggelassen, weil sie an der eigentlichen Talschaft keinen Anteil haben. 
Die natürliche Umgrenzung der untersuchten Landschaft wird im Norden durch die westöstlich verlaufende Stockhornkette gebildet, deren höchste, meist aus steil gestellten Kalkschichten aufgebaute Gipfel sich einer in 2170 bis $2200 \mathrm{~m}$ Höhe gelegenen Gipfelflur unterordnen, so das Stockhorn mit 2192 m, der Gantrisch mit 2178 m, der Ochsen mit $2192 \mathrm{~m}$ und die Kaiseregg mit $2185 \mathrm{~m}$.

Die letztgenannte Gruppe senkt sich südwärts über das Bäderhorn, $2010 \mathrm{~m}$, auf $1510 \mathrm{~m}$ Höhe zum Jaunpaß. Von hier verläuft die Wasserscheide über den sanfter geformten Flyschkamm des Hundsrück hinab zum niedrigen Längspaß der Saanenmöser $(1283 \mathrm{~m})$, dem Einzugsgebiet der Kleinen Simme.

Südwärts dieser für Siedlung und Verkehr wichtigen Einsattelung steigt die Wasserscheide zwischen Simme und Saane vorerst zu der etwas über $2000 \mathrm{~m}$ hohen Hornfluhgruppe an, die durch ihre schönen Alpweiden berühmt ist, und verläuft dann über den auffallend sanft geformten Amselgrat nach dem schärfer modellierten, $2360 \mathrm{~m}$ hohen Wistätthorn, hierauf zu der als Uebergangsstelle bekannten Tauben (2040 m); sodann steigt der Kamm wieder stark zu den Stüblenen und dem $2277 \mathrm{~m}$ hohen Rothorn an, worauf nochmals im Bereich weicher Gesteine eine Einsattelung auf $2085 \mathrm{~m}$ folgt. Damit endet das nach Formgestaltung und Höhenentwicklung charakterisierte, ausgedehnte Voralpengebiet des Simmentales, und man steht am Nordfuß der bekanntlich unvermittelt steil und hoch aufragenden Hochalpenkette. Diese besteht hier aus der stark vergletscherten, bis auf $3172 \mathrm{~m}$ hoch ansteigenden Wildhorngruppe und setzt sich ostwärts und jenseits des Rawilpasses über die nur wenige Meter höhere Wildstrubelgruppe fort. Beide Gebirgsgruppen bilden mit ihren Gletschern, ihren zahlreichen Lawinenrunsen und Quellen das Ursprungsgebiet der Großen Simme. Ihr Gesamtgebiet wird im Osten durch die am Wildstrubel beginnende Seitenkette begrenzt, die sich über Ammerten- und Pommerngrat und den Hahnenmoossattel $(1954 \mathrm{~m})$ vorerst $7 \mathrm{~km}$ in nördlicher Richtung bis zu dem $2766 \mathrm{~m}$ hohen Albristhorn erstreckt, um sich hier nord-nord-ostwärts zu wenden und als stark gegliederte Kette sich $19 \mathrm{~km}$ weit in gleicher Richtung bis zum Endgipfel des Niesens auszudehnen. Charakteristisch ist für diese vollständig aus Flyschgesteinen bestehende Kette die ausgesprochen typische Modellierung der meist pyramidenförmigen Gipfel, der vielen Sättel und der zahlreichen tiefen Bacheinschnitte durch die abtragenden Kräfte, sowie die gleichsinnige Abnahme der Gipfelhöhe in nordöstlicher Richtung. Die Gipfelhöhe senkt sich vom genannten Albristhorn und dem benachbarten Gsür, $2712 \mathrm{~m}$, erst auf $2609 \mathrm{~m}$ im Winterhorn und dann rasch auf $2497 \mathrm{~m}$ im Ladholzhorn, um sodann auf längere Erstreckung hin zwischen $2400 \mathrm{~m}$ und $2350 \mathrm{~m}$ zu bleiben.

Der Niesengrat weist zudem zahlreiche Karbildungen, deren Böden in 1900 bis 2100 m. Höhe liegen, auf. Die Kare enthalten noch heute kleine Seen, Tümpel oder Sümpfe. Sie sind die Sammelbecken für das Regenwasser und den verwehten und abgerutschten Schnee und bilden dadurch den Quellort vieler Bäche.

Vom Gsür zweigt westwärts die durch ihre wilden Kalkberge berüchtigte Spillgertengruppe ab, die sich im Süden noch auf $2479 \mathrm{~m}$, also $1429 \mathrm{~m}$ über die Talsohle von Lenk, erhebt, um sich nordwärts über Frohmattgrat und Seehorn, 2285 m, zum 2080 m hohen Niederhorn zu senken. Von hier verläuft, durch mehrere Einsattelungen gegliedert, der das untere Simmental im Süden begrenzende Kamm in nordöstlicher Richtung, der im Thurnen und Pfaffen wieder auf $2083 \mathrm{~m}$ ansteigt, um sodann mit dem abgeflachten Bergzug des $1855 \mathrm{~m}$ hohen Abendberges und dem niedrigeren Tschuggen oberhalb Diemtigen zu enden.

Zwischen der Spillgertengruppe und der Niesenkette liegt das $131 \mathrm{~km}^{2}$ umfassende Einzugsgebiet des Kirelbaches, des Hauptgewässers des Diemtigtales, dessen oberer Teil durch mehrere größere Seitentäler gegliedert ist. Diese Gliederung wird u. a. durch eine weitere Abzweigung der Niesenkette hervorgerufen, die, beim erwähnten Winterhorn beginnend, zunächst die Männlifluh und weiter nordwestwärts über den Gurbsgrat das $2308 \mathrm{~m}$ hohe, isoklinalgebaute Twirienhorn mit seinen Ausläufern bildet. 
Die ganze Gebirgslandschaft zwischen der Niesenkette und dem Simmental ist mannigfaltig gestaltet, je nachdem die Gesteine liegen und beschaffen sind. Kalkberge mit steilen Felswänden und scharfen Zacken, wie die Spillgertengruppe, das Twirienhorn, das Seehorn usw., wechseln mit sanfter abfallenden Rücken und flachen Seitenkämmen ab, die meist aus Flysch oder schiefrigen, flachgelagerten Gesteinen bestehen.

\section{Der geologische Aufbau des Simmengebietes}

Wie bereits angedeutet, ist die mannigfaltige Gestaltung der Gebirgslandschaft des Simmentales in weitgehendem Maße durch den geologischen Aufbau bedingt. Dessen Verschiedenartigkeit und der Wechsel von durchlässigen und undurchlässigen Gesteinen, verbunden mit den unterschiedlichen Lagerungsverhältnissen, erzeugen den lebhaften Szeneriewechsel von steilen Felswänden und zackigen Bergformen im Gegensatz zu den häufig wiederkehrenden, sanfter geböschten Hängen, rundlichen Rücken und flachen Einsattelungen.

Außerdem haben auch die während des Eiszeitalters erfolgten verschiedenartigen Abtragungsvorgänge Anteil an der unterschiedlichen Formgestaltung des Haupttales und der zahlreichen größeren und kleineren Nebentäler.

Die geologische Beschaffenheit des Untersuchungsgebietes ist wie in den übrigen Teilen der schweizerischen Nordalpen durch den Deckenbau und das Vorhandensein von großen Ueberschiebungsdecken gekennzeichnet.

Nach den Untersuchungen von Schardt, Lugeon, Rabowski, Beck, Bieri, Bornhauser, Al. Heim u. a. setzt sich das simmentalische Voralpengebiet aus lepontinischen und helvetischen Decken zusammen, während die Hochalpenzone aus ultrahelvetischen Deckenelementen besteht, nämlich aus der Plaine-Morte- und der Wildhorndecke $(1-5,7-10,15,17)$.

a) Die Stockhornkette, die alle Merkmale eines Faltengebirges besitzt, gehört der sogenannten Klippendecke an, die sich aus zahlreichen, vorherrschend kalkigen Schichten der Trias-, der Jura- und der. Kreideformation zusammensetzt. Die aus obern Jurakalkschichten bestehenden Isoklinalkämme und -gipfel weisen steile, hohe Felsabstürze und zackige Gipfel auf. Zwischen ihnen ziehen sich durch weichere Gesteine bedingte Synklinal- und Antiklinaltäler hin. Aus ihnen fließen Bäche; welche sich. schluchtartig quer durch die aufgerichteten Kalkschichten gefressen haben, der Simme zu.

In südlicher Richtung folgen nun die Simmendecke und die Hornfluhdecke aufeinander. Dieser gehört auch die Spillgertengruppe an.

b) Die Simmendecke besteht fast ausschließlich aus dem Flysch, der die ganze Mulde des Niedersimmentales ausfüllt und oberhalb Boltigen sogar die gesamte Landschaft des Jaunpasses und des Hundsrück bildet. In der Decke kommen noch Radiolarite und Aptychenkalke vor, die in der sonst formenarmen Landschaft kleinere Steilstufen erzeugen und sich durch ihre relative Unfruchtbarkeit auszeichnen.

c) Die Hornfluhdecke ist fast einheitlich aus mesozoischen Brekzien zusammengesetzt, die der Verwitterung einen etwas größeren Widerstand als der Flysch entgegensetzen. Außerdem enthält sie noch Kalkschichten der Juraformation, die besonders in der Spillgertengruppe, im Flühwaldgebiet, am Rinderberg, an der Saanerslochfluh, an der Hornfluh und in der Umgebung von Bettelried anstehend sind.

d) Die Niesenkette, die zum größten Teil aus undurchlässigen, leicht verwitterbaren Brekzien und Schiefern der Flyschformation besteht und als Bestandteil der sogenannten Niesendecke angesprochen wird, weist in untergeordnetem Maße auch Kalkbänke und andere Gesteine auf. Im Liegenden enthält die grobe Flyschbrekzie auch Einschlüsse von Dolomit und kristallinen Gesteinen, van feiner Brekzie, von Sandstein und Schiefer. 
e) In der Zone des Cols finden wir nach den Angaben von Al. Heim $(7,586)$ die Trüttlisbergschuppe mit Rauhwacke, Liasbrekzien, Liasglanzschiefern, Dogger, Oxford und Flysch; also durchwegs weiche Gesteine. Daher treten dort auch vorherrschend sanftere Böschungen und gerundete Rücken auf. Im obersten Teilstück des Simmentales. und im Iffigentale, soweit sie in dia Plaine-Morte-Decke eingegraben sind, wechseln leicht verwitterbare Schiefer mit widerstandsfähigen Kalkbänken ab. Diese bedingen die gewaltigen Felsabstürze der Hochalpenzone.

\section{Tal- und Terrassenbildung}

Die Simme hat sich in ihrem Oberlaufe ein Quertal geschaffen und dabei die Wildhorndecke, die Sattelzone, die Niesenflyschzone und die Préalpes in der Hornfluhzone durchschnitten. Dann biegt sie nach $\mathrm{E}$ um und hat ihren Lauf in die weichen Flyschschichten der Simmendecke eingegraben, bis sie diese bei der Burgfluh in relativ junger Epigenese verläßt (7).

Die Eintiefung bis zur heutigen Talsohle erfolgte nicht in einem Zuge, sondern war getrennt durch mehrere Stillstände, in denen die Simme mehr oder weniger stark seitwärts erodierte und dementsprechende Talböden schuf. Diese Talböden sind heute noch in Ueberresten vorhanden und bilden die ausgedehnteren Terrassen des Simmentales.

Kleinere Terrassen, die sich in keines der von BECK gefundenen Terrassensysteme, die für die Lage der Dauersiedlungen wichtig sind, einordnen lassen, müssen teilweise durch den Simmegletscher und die Lokalgletscher ausgeschliffen worden sein. Auch diese Terrassen sind oft von Einzelhöfen besetzt.

BECK (1) unterscheidet im Simmental eine Anzahl Terrassensysteme. Er erwähnt jeweils nur einige dazu gehörende Oertlichkeiten in seinen Schriften. Wenn wir uns im folgenden an seine Einteilung halten, so sind wir uns bewußt, daß auch unsere Angaben unvollständig sind, weil wir nur jene Terrassen aufgenommen haben, auf denen die obersten Dauersiedlungen liegen.

a) Ein oberstes Terrassensystem, das Tschuggenalpniveau, läßt sich ungefähr 700 bis $750 \mathrm{~m}$ über dem heutigen Talboden der Simme nachweisen. Dazu gehören die Tschuggenalp über Diemtigen $(1410 \mathrm{~m})$, die Jaunpaßhöhe $(1500 \mathrm{~m})$ und der Dachboden $(1650 \mathrm{~m})$ bei Matten. Zum gleichen Niveau darf auch das Weidegebiet von Lüß in 1640 m Höhe bei Matten, dem Dachboden gegenüberliegend, gezählt werden, wie auch das Pfundsbergli $(1660 \mathrm{~m})$ und der Weißenberg mit ungefähr $1650 \mathrm{~m}$ Höhenlage, das Gugernell ob Gutenbrunnen (1670 m) und das Gebiet «Hinter den Flühnen» ob Zweisimmen $(1520 \mathrm{~m})$.

b) Ein zweites Terrassensystem erstreckt sich in 500 bis $550 \mathrm{~m}$ Höhe über der heutigen Talsohle. BECK erwähnt davon den Lampernhubel (1230 m) und das Regenmoos $(1300 \mathrm{~m})$. Wir rechnen noch hinzu die Sommerau $(1280 \mathrm{~m})$, die im Aufstieg gegen den Jaunpaß zu gelegen ist; Ruhren bis Schafmoos (1280 bis $1300 \mathrm{~m}$ ), Zimmerboden $(1300 \mathrm{~m})$, Auf den Eggen (1340 m) und das Fermeltal.

c) Ein drittes. System, dessen Niveau am Thunersee in ungefähr $1000 \mathrm{~m}$ gelegen hat und das von BECK als das Burgfluhniveau bezeichnet wird, enthält folgende Ueberreste des ehemaligen Talbodens: Rücken der Wimmiserburgfluh $(970 \mathrm{~m})$, Diemtigbergli $(990 \mathrm{~m})$, Roßberg hinter dem Lampernhubel $(1120 \mathrm{~m})$, Saanenmöser $(1270 \mathrm{~m})$. In dieses Niveau kann noch Oberberg bei Erlenbach $(980 \mathrm{~m})$, Balzenbergallmend $(1010 \mathrm{~m})$, Stigenmad $(1100 \mathrm{~m})$ ob Därstetten, Heimersberg $(1230 \mathrm{~m})$ bei Zweisimmen einbezogen werden. Eine ganze Reihe von Terrassen des Diemtigtales läßt sich ebenfalls in dieses System einordnen. Werden sie ergänzt, und berechnet man das ehemalige Gefälle des Talbodens des Diemtigtales, so ergibt sich, daß es dem des gleichaltrigen 
Haupttalbodens entspricht. Es gehören dazu: die Terrasse von Entschwil $(1080 \mathrm{~m})$, Geißegg-Brunnen (1130 bis $1140 \mathrm{~m}$ ), Senggi, Grunholz, Grimmialp, Sager und Schlunegg $(1230$ bis $1250 \mathrm{~m})$ und die Leiste Moos bis Löh an der Nordwestabdachung des Niesengrates in 1080 bis $990 \mathrm{~m}$ Höhe.

d) Das Kirchetniveau, diese Bezeichnung stammt ebenfalls von BECK, mit $700 \mathrm{~m}$ Höhe am Thunersee, ist die vierte Eintiefungsstufe. Neben den von BECK angegebenen Talsohlenüberresten, wie Lochmatte $(855 \mathrm{~m})$, Rübelboden $(860 \mathrm{~m})$, Allmenden $(850 \mathrm{~m})$, möchten wir noch die Terrassen von Thal $(890 \mathrm{~m})$, Weißenburgberg $(1020 \mathrm{~m})$, Ried und Zelg $(1010 \mathrm{~m})$, Silberbühl bei Hintereggen $(1010 \mathrm{~m})$, Breiti $(1020 \mathrm{~m})$, Adlemsried $(1040 \mathrm{~m})$ und das Gebiet von Dürrenlos bis Egg ob Boltigen $(1060 \mathrm{~m})$ hinzufügen. Im Gebiet der Saanenmöser gehören nach unserer Ansicht die Leiste, die sich von Riedli nach Vorderreichenstein hinzieht (1080 bis $1170 \mathrm{~m}$ ), und die Terrasse von Oeschseite $(1160 \mathrm{~m})$ dazu. Die Ueberreste dieses Systems laufen gegen die Saanenmöser hin aus.

e) Schließlich ist von GENGE in Erlenbach im Simmental noch eine fünfte Eintiefungsstufe gefunden worden, die er in einer geplanten Veröffentlichung als das Wyler Terrassensystem bezeichnet (in seiner demnächst erscheinenden Arbeit hat er es in Erlenbacher System umbenannt). Auf ihm liegen unmittelbar oder mittelbar fast alle größeren Dorfsiedlungen des Niedersimmentales. Oberwil in $860 \mathrm{~m}$ Höhe steht auf der Terrasse selbst, während Latterbach $(700 \mathrm{~m})$, Erlenbach $(730 \mathrm{~m})$, Ringoldingen $(750 \mathrm{~m})$, Därstetten $(780 \mathrm{~m})$ und Weißenbach $(860 \mathrm{~m})$ sich auf Schuttkegeln entwickelt haben, die der Terrasse aufgesetzt sind.

Bei der besprochenen Terrassensystemeinteilung haben wir uns an die von BECK gegebene Definition über Talböden gehalten, die besagt, daß hier nicht nur ebene Böden zu verstehen seien, sondern auch unfertige hügelige oder gegen die Seiten ansteigende, deren Weiterbearbeitung durch eine neu einsetzende stärkere Erosion verunmöglicht worden ist. Tatsächlich können wir kaum mehr feststellen, wie die ehemaligen Talböden ursprünglich beschaffen gewesen sind. Die ungleiche Auflagerung von Glazialschutt, von Gehängeschutt, sowie die wieder eingetretene Zerstörung durch Denudation und die Erosion der größeren und kleineren Seitenbäche haben die ehemaligen Talböden umgeformt, so daß der Zusammenhang der entsprechenden Terrassen meist nur schwer $\mathrm{zu}$ erkennen ist.

\section{Das Haupttal}

Das Haupttal beschreibt bei $48 \mathrm{~km}$ Länge zwischen dem Räzliberg und der Port einen großen Bogen, indem es in den obersten $27 \mathrm{~km}$ in nordwestlicher Richtung verläuft, dann sich allmählich gegen NO wendet und schließlich von Oberwil an auf $14 \mathrm{~km}$ westöstliche Richtung nimmt. Die Talsohle senkt sich von Oberried im Obersimmen$\operatorname{tal}(1100 \mathrm{~m})$ auf $620 \mathrm{~m}$ bei der Port, woraus sich ein mittleres Gefälle von 7,7\% ergibt. Allerdings ist das Gefälle in den einzelnen Talabschnitten, wie später erwähnt werden wird, ungleich groß. Dabei machen sich auch Unterschiede in der Breite des Talbodens geltend, die mit dem Wechsel von Flysch- und Kalkzonen, die vom Fluß durchquert werden, in Beziehung stehen. Von Burgholz bis Oey ist die Talsohle breit entwickelt, dann nimmt sie, weil sich der Fluß in ein höheres Talniveau eingeschnitten hat, unregelmäßig ab, um sich erst oberhalb der Klamm von Simmenegg zum Becken von Boltigen zu weiten. Talaufwärts treten die Talflanken wieder näher zusammen, so daß nur wenig Platz für Fluß, Straße und Bahn vorhanden ist. In diesem Talstück schneidet sich die Simme bei der Durchquerung eincr schmalen Kalkzone in den Riegel von Laubegg ein, wobei sie in tosenden Fällen eine ungefähr $25 \mathrm{~m}$ hohe Stufe hinunterstürzt. Dann erweitert sich das Tal zum $3 \mathrm{~km}$ langen und maximal $1 \mathrm{~km}$ breiten Becken von Zweisimmen, dessen Boden in 920 bis $940 \mathrm{~m}$ Höhe liegt (siehe Profil 3). 

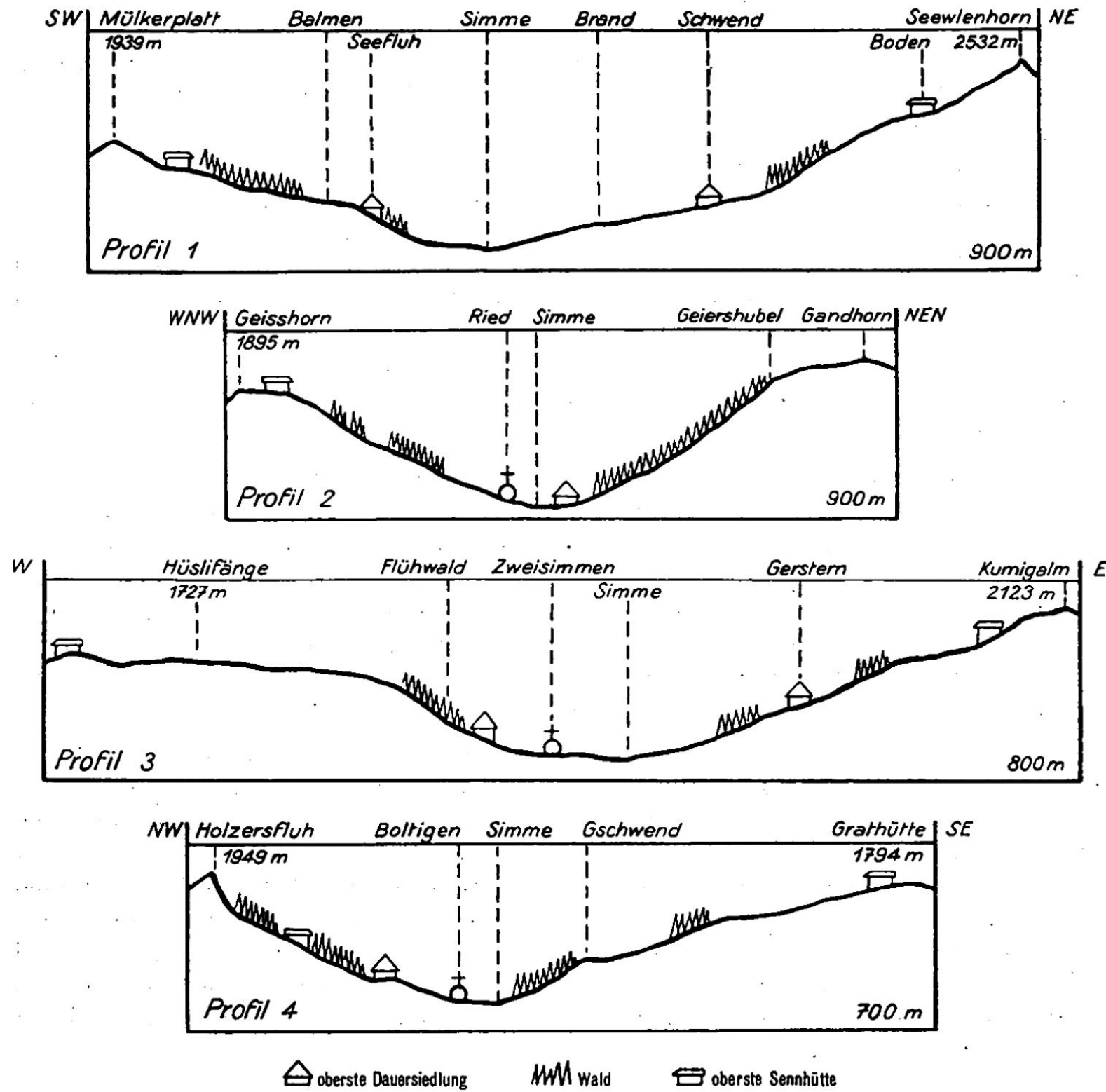

Fig. 1-4. Querprofile durch das obere und mittlere Simmental. Maßstäbe ca. 1:75000

Das Haupttal verengt sich oberhalb Zweisimmen wieder, indem der Fluß hier die Hornfluh-Spillgerten-Kalkzone durchbricht. In der schmalen Talsohle ragt der $30 \mathrm{~m}$ hohe Felsriegel von Blankenburg empor, von wo aus früher der Zugang zu St. Stephan und Lenk beherrscht worden ist. Dann öffnet sich das auf $12 \mathrm{~km}$ Länge in Flysch und mesozoische Schiefer eingeschnittene Obersimmental zu einem weiten, mehr oder weniger gut entwickelten Taltrog mit abgeschrägten Talhängen (siehe Profil 2). Die Talsohle ist stark aufgeschüttet und trotz der Simmekorrektionen noch nicht vor Ueberschwemmungen vollständig gesichert, wie die verheerenden Simmeausbrüche von 1914 und 1917 bewiesen haben.

Die Talhänge sind von Wildbachrunsen stark zerschnitten; ihre Entstehung ist durch den wasserundurchlässigen Niesenflysch begünstigt. Am untern Ende solcher Gräben entstanden große Schuttkegel, die sich in die Talsohle vorbauen. Diese Schuttkegel sind meistens dicht besiedelt, bieten sie doch Schutz vor den Ueberschwemmungen des Hauptflusses und heben die Heimwesen aus dem Bereich der stagnierenden, kalten Luftschichten der Talsohle heraus. 

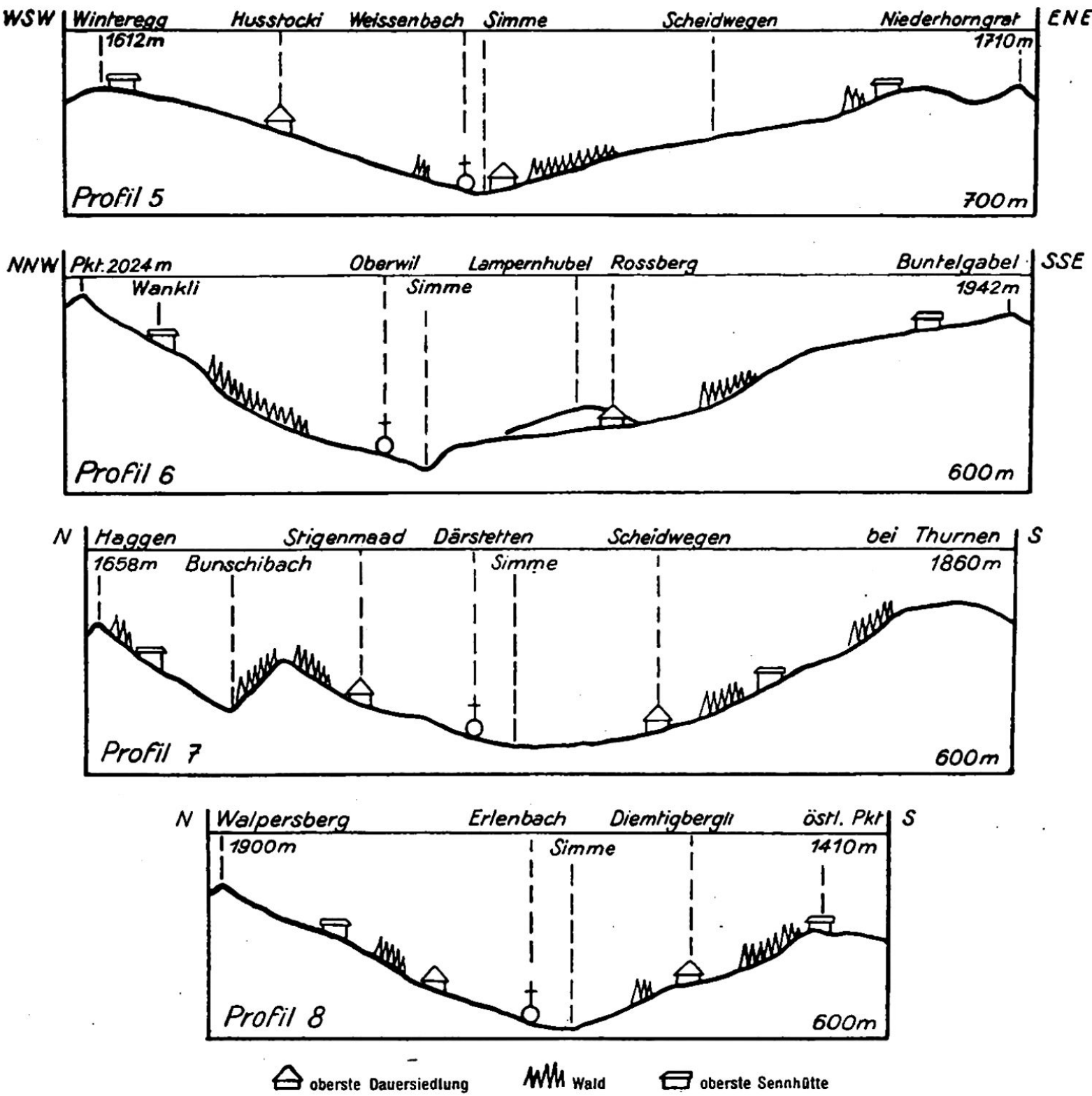

Fig. 5-8. Querprofile durch das untere Simmental. Maßstäbe ca.1:70000

Nach Oberried führt nun ein bequemer Weg an den wild daherrauschenden Simmefällen über die letzte, $280 \mathrm{~m}$ hohe Talstufe hinauf zum Räzliberg, wo das Tal durch die schroffen, über $600 \mathrm{~m}$ hohen Felsabstürze des Wildstrubelmassivs, die hier einen Trogschluß bilden, jäh abgeschlossen wird.

\section{Die Seitentäler}

Das Simmental weist mehrere größere und kleinere Seitentäler auf, von denen einige ebenfalls dauernd bewohnt sind und uns daher näher beschäftigen. Vor allem ist dies beim Diemtigtal der Fall, das bei einer Länge von ungefähr $19 \mathrm{~km}$ von SW bei Oey ins Niedersimmental einmündet, und dessen Hauptfluß, der Kirel, aus einigen Seitentälern verschiedene Bäche erhält, so daß sein gesamtes Einzugsgebiet ca. $130 \mathrm{~km}^{2}$ umfaßt.

Der vordere Teil des Tales ist infolge seiner tiefen Lage klimatisch begünstigt und gestattet eine ziemlich dichte Besiedlung bis in eine Höhe von ungefähr $1000 \mathrm{~m}$. Weiter oben im Diemtigtal ziehen sich auf beiden Seiten des schmalen Tales abwechslungs- 
weise mehr oder weniger breite, sanfter geböschte Terrassen hin, die sich ebenfalls für die Anlage von Dauersiedlungen gut eignen, wie auch die Talweitungen von Zwischenflüh - Oeyen und Schwenden.

Auf einer breiten Terrasse rechts des Kirels breitet sich am Talausgang das Dorf Diemtigen in 820 bis $850 \mathrm{~m}$ Höhe aus. Die gegenüberliegende, schmale Terrasse am Nordwestabhang der Niesenkette, die sich von Löh bis Moos erstreckt, ist schon früher erwähnt worden, wie auch die Terrasse von Entschwil, die im Mündungssporn der Täler des Kirels und des Fildrichbaches liegt, und die von Geißegg bis Brunnen.

Der Fildrichbach nimmt von links den Narrenbach auf, der das Hängetal des Mäniggrundes durchfließt. Jener entwässert mit dem Grimmibach und andern Wildbächen die stark gegliederten Nordabdachungen der Spillgerten- und der Gsürgruppe. Ihre obersten Einzugsgebiete sind durch Kare und stufenartig abfallende, glazialgeformte, kleine Hochtäler gekennzeichnet.

Auch das Fildrichtal weist wenig oberhalb der Einmündung des Narrenbaches eine bemerkenswerte, offenbar glazial bedingte Ausweitung auf, wo mehrere Wildbäche mit vorgebauten Schuttkegeln einmünden und wo deren sanftere Böschungen, ebenso wie Moränenhügel, Raum für die zerstreuten Siedlungen von Schwenden und Grimmi bieten.

Im Gegensatz zum Diemtigtal sind alle andern Seitentäler im Simmegebiet bedeutend kleiner und nur wenig gegliedert, und sie besitzen deshalb in geringerem Maße oder dann gar nicht die notwendigen Eigenschaften für eine dauernde Besiedlung. So wäre im Niedersimmental unter diesen Seitentälern dasjenige des Bunschibaches nach seiner Ausdehnung an erster Stelle zu erwähnen, da es größere Gebiete der Südabdachung der Stockhornkette entwässert; allein, es mündet mit enger, siedlungsfeindlicher Schlucht bei Weißenburg ins Haupttal ein und kann nur in den obern Abschnitten während des Sommers bewohnt werden. Aehnlich verhält es sich mit den benachbarten Tälern des Wüstenbaches und des Klusbaches, die beide ebenfalls von der Stockhornkette herabführen, ferner mit den auf der südlichen Talseite liegenden Wildbachfurchen des Oeygrabens und des Ammerzengrabens.

Auffällig zahlreich und daher für die Gehängegliederung von Bedeutung sind die Bachgräben auf der linken Talseite in der Hundsrückflyschzone zwischen Boltigen und Zweisimmen. Von den im obern Talabschnitt vorkommenden zahlreichen Bachgräben war bereits oben die Rede; sie kommen aber für die Lage von Dauersiedlungen nicht in Betracht.

Dagegen haben das Tal der Kleinen Simme, das Fermeltal und das Iffigental in dieser Hinsicht eine gewisse Bedeutung. Die bei Zweisimmen ins Haupttal sich ergießende Kleine Simme hat sich in ein ehemaliges, breites V-Tal erneut eingeschnitten und fließt in einer engen Schlucht der Simme zu. Die Siedlungen liegen hier auf dem ehemaligen Talboden oder höher oben an den schwach geböschten Hängen.

Bei Matten öffnet sich an der östlichen Talflanke das Fermeltal, ein schmales, bogenförmig verlaufendes Trogtal, das seinen Ursprung am Westhang der $2711 \mathrm{~m}$ hohen Gsürgruppe hat. In seinem mittleren Talstück stehen neben zahlreichen, der Alpwirtschaft dienenden Gebäuden auch vereinzelte Dauersiedlungen.

Bei Lenk mündet schließlich von links her das Iffigental ein, das, irr zwei Stufen ansteigend, am Nordhang des Wildhornmassivs liegt und somit zum Quellgebiet der Simme gehört. Oberhalb seiner untern Stufe findet sich in 1180-1200 m Höhe auf dem Boden des trogförmigen Hängetales Raum für eine beträchtliche Anzahl von Dauersiedlungen, die die Bäuert Pöschenried bilden.

\section{Die eiszeitliche Vergletscherung des Simmentales}

Wie die andern Alpentäler waren auch die Täler des Simmegebietes in der Eiszeit von großen Gletschern erfüllt, die an vielen Orten Moränen abgelagert haben und auch formgestaltend in den von ihnen durchflossenen Talfurchen tätig gewesen sind. Neben 
den besondèrs ansehnlichen Eisströmen des Simmen- und des Diemtigtales bestanden in den zahlreichen Tälern der Voralpen viele kleine Lokalgletscher, die sich zufolge der tiefen Lage der Schneegrenze der Eiszeit teils als Hänge-, teils als Kargletscher, ja sogar als kleine Talgletscher entwickeln konnten.

Der Simmegletscher besaß die größte Ausdehnung. Noch in der letzten Eiszeit durchzog er das ganze Tal bis in die Gegend der Porte, wo er sich mit dem Kandergletscher vereinigte, wie $\mathrm{BECK}$ (1 und 2) nachgewiesen hat.

Obwohl die Geologie des Simmegebietes durch mehrere Arbeiten bekannt ist, liegen über die genauere Ausdehnung des Simmegletschers nur wenige gedruckte Angaben vor. Nach noch nicht veröffentlichten Untersuchungen von NussBaum, die hier in freundlicher Weise zur Verfügung gestellt worden sind, kann die obere Grenze des Simmegletschers aus entsprechenden Vorkommnissen von Erratikum, wie folgt, angegeben werden:

$1680 \mathrm{~m}$ bei Reulissen westlich Matten

$1512 \mathrm{~m}$ bei Eggweid westlich St. Stephan

$1550 \mathrm{~m}$ bei Thierstein östlich Garstatt

$1470 \mathrm{~m}$ beim Bergli östlich Weißenbach

$1460 \mathrm{~m}$ bei Schwend östlich Boltigen

$1450 \mathrm{~m}$ bei Wolfsschüpfen südlich Oberwil ${ }^{1}$

$1380 \mathrm{~m}$ bei Gelbergweid südlich Ringoldingen

$1230 \mathrm{~m}$ bei Lußallmend südöstlich Oey

Auffallenderweise ist die bodengestaltende Wirkung dieses Gletschers im Niedersimmental nur wenig bemerkbar (siehe Profile 5 bis 8). Wohl kommen hier Talweitungen und Verengungen vor, und die Talhänge erscheinen stellenweise sehr steil, wie sie in glazialbearbeiteten Trogtälern häufig sind; aber alle diese Formen lassen sich auch auf die Wirkungen der fluviatilen Abtragungskräfte und auf Härteunterschiede des Gesteins zurückführen. Die geringe Erosionswirkung des Simmegletschers wird von BECK wohl mit Recht als Folge der Stauung erklärt, die dieser Gletscher durch den mächtigen Kander-Aare-Gletscher beim Talausgang der Porte erfahren hat (3).

Anders ist es aber im Obersimmental; hier tritt uns namentlich in der Gegend zwischen Bettelried und Oberried eine deutliche Trogform mit breitem Talboden und zahlreichen Hängetälern entgegen, deren Stufen eine bedeutende Uebertiefung des Haupttales als Wirkung des mächtigen Talgletschers verraten, der hier sehr lange Zeit bestehen und sich ungehemmt bewegen konnte (siehe Profil 2).

Unter diesen Hängetälern des Obersimmentales ist auch hier in erster Linie das Fermeltal zu nennen, das mit einer Stufe von $230 \mathrm{~m}$ ins Haupttal einmündet. Dieser ist der kleinste Betrag der Uebertiefung der sämtlichen hier vorkommenden Hängetäler. Wie dies bereits auch in andern Gebieten nachgewiesen wurde (12), sind in der Regel die Mündungsstufen der Hängetäler um so höher, je kleiner das betreffende Seitental ist; so weisen nach ihrer Größe die folgenden simmentalischen Hängetäler entsprechende Werte der Uebertiefung auf: Wallbachtal $260 \mathrm{~m}$, Dürrenwaldbach $400 \mathrm{~m}$, Metschbach $420 \mathrm{~m}$.

Auch das schon genannte Iffigental zeigt Stufenbau. Von den zwei Stufen ist die untere mit $100 \mathrm{~m}$ die niedrigere; die obere aber, über die der Talbach mit hoher Fallstufe herunterstürzt, beträgt rund $300 \mathrm{~m}$, und sie ist an eine widerstandsfähige Gesteinsbank gebunden, die sich hier an der richtigen tektonischen Grenzlinie zwischen den helvetischen Ueberschiebungen und der Zone des Cols einstellt.

In das unterhalb dieser hohen Stufe gelegene Talstück des Iffigenbaches mündet mit $160 \mathrm{~m}$ hoher Stufe der Kindbach aus dem Sommerwaldtal ein.

1 Die gleiche Höhe gibt auch BECK für den Ausgang des Bunschibachtales an. 
Der Gletscher reichte noch im Bühlstadium, wie Nussbaum annimmt, bis in die Gegend von Zweisimmen hinab, wo sich entsprechende Moränen vorfinden (11).

In ähnlicher Weise sind auch im Diemtigtal die Talformen angeordnet, wo ebenfalls ein größerer Talgletscher existiert hat. Seine äußersten Endmoränen lassen sich bis in die Gegend von Diemtigen hinab verfolgen, wo sie sich mit denen des Simmegletschers vermischen. Mächtiger und ausgesprochener sind die Ablagerungen des Diemtiggletschers einige Kilometer weiter talaufwärts, namentlich auf der mächtigen Terrasse von Entschwil, sowie auf denen bei Zwischenflüh und Oeyen.

Die von den beiden großen Talgletschern an Talabhängen und Terrassen abgelagerten Moränen machen sich an einzelnen Orten orographisch bemerkbar und bieten vielerorts günstige Stellen für die dauernde Besiedlung.

\section{Die Lokalvergletscherung}

Ueber die Moränenbildungen zahlreicher lokaler Gletscher in den Voralpen des Simmegebietes liegen verschiedene Angaben in der geologischen Literatur, namentlich von Gillí́ron, JaCCARD und RABOwSKI vor. Besonders eingehend sind die Spuren der Lokalvergletscherung, die sich auch im Auftreten ausgeprägter Kare zu erkennen geben, in der Stockhornkette von Nussbaum beschrieben worden (11). Ebenso sind nach diesem Autor auch die westlichen Hänge der Niesenkette von mächtigen Moränenwällen lokaler Gletscher bedeckt, die ihren Ursprung in hochgelegenen Karnischen genommen haben. Sie lassen sich an mehreren Orten bis auf $1250 \mathrm{~m}$ hinab verfolgen.

In der Regel liegen sowohl die Firnkessel der zahlreichen Lokalgletscher wie auch ihre Endmoränen verhältnismäßig sehr hoch, so daß sie meist nicht in die Zone der Dauersiedlungen herabreichen. Nur der aus dem großen Karkessel der Kaiseregg herabgeflossene Walopgletscher vermochte sich offenbar während des Bühlstadiums, als sich der Simmegletscher bereits bis in das Becken von Zweisimmen zurückgezogen hatte, bis nach Schwarzenmatt auf $927 \mathrm{~m}$ Meereshöhe hinab auszudehnen, wo er eine deutliche Endmoräne abgelagert hat. Sie bildet hier eine wellige Terrasse, in die sich der Bach eingeschnitten hat und auf der die Häuser des genannten Weilers stehen.

\section{Hydrographische Verhältnisse}

Schon die Karte zeigt uns, daß das Simmental ein dichtes Gewässernetz besitzt. Dieser Eindruck wird bei der Begehung des Tales noch verstärkt. Die häufigen Niederschläge, die vorwiegend wasserundurchlässigen Gesteinsarten und die unter der $1500-\mathrm{m}-$ Isohypse fast allgemeine Ueberkleisterung der sanfter abfallenden Talhänge mit Gletscherschutt liefern die natürlichen Bedingungen für zahlreiche Quellen und sumpfige Gebiete, die von kleinen Rinnsalen durchzogen werden. So finden wir am Lampernhubel, im Gebiet der Saanenmöser, des Hundsrück und gegen das Hahnenmoos hin, wie auch gegen den Trüttlisberg alle paar Meter eine Quelle oder ein "Lischenmoos», dem eine kleine Wasserader entfließt: Die häufigen Ortsbezeichnungen mit Moos und Ried weisen übrigens auf diesen Charakter der einzelnen Gegenden hin. Heute wird gegen die Versumpfung energisch vorgegangen, indem überall bäuerliche Genossenschaften die Drainage durchführen lassen. Die wenigen Stellen im Simmental, die an Wasserknappheit leiden, werden wir bei der Besprechung der Siedlungen aufzählen.

Das Haupttal wird durchflossen von der Simme, die am Räzliberg unter den Abstürzen des Wildstrubelmassivs in den Schichtquellen der Sieben Brunnen entspringt. Von links her empfängt sie als ersten bedeutenden Zufluß den Iffigenbach, der, wie die Simme, sein Nährgebiet in der Region des ewigen Schnees hat. Von rechts her mündet 
dann bei Matten der Fermelbach, ein ausgesprochener Wildbach, in den Hauptfluß ein. Seine Wasserführung ist wie die aller andern simmentalischer Bäche mit Ausnahme von Simme und Iffigenbach von den Niederschlägen stark abhängig. Bei ausgiebigen Gewitterregen brausen oft für kurze Zeit große Wassermassen zu Tal, die eine bis $100 \mathrm{~m}$ breite Wildbachschlucht in die Mündungsstufe des Fermeltales zu reißen vermochten. Die ganze Breite der Schlucht ist bedeckt mit großen, eckigen Gesteinsblöcken und mit kleinerem Schutt.

Ein weiterer Zufluß, der eine ziemlich konstante, aber unbedeutende Wasserführung aufweist, ist die Kleine Simme, deren Einzugsgebiet die Saanenmöser sind. Wie der Name besagt, ist dort der Boden auf weite Strecken sumpfig; das Wasser wird langsam abgegeben, was dem Wasserhaushalt der Kleinen Simme die erwähnte Ausgeglichenheit bringt.

Auf der linken Talseite folgt nun talabwärts eine ganze Reihe von Wildbachgräben, von denen die einen bis Boltigen im Flyschgebiet des Hundsrück, die andern aber in der Stockhornkette entspringen, wie der Wüstenbach und der Bunschenbach mit dem Morgetenbach. Die Wassermenge all dieser Bäche ist im allgemeinen gering; bei den letztgenannten infolge der kalkigen Beschaffenheit, bei jenen infolge der Kleinheit des Einzugsgebietes.

Auf der rechten Talseite bestehen bis zur Einmündung des Kirels dieselben Verhältnisse. Erst dieser Zufluß, der alle Bäche des Diemtigtales, wie Fildrich, GrimmibachGurbsbach, Narrenbach, und die Abflüsse der nordwestlichen Abdachung der Niesenkette aufnimmt, hat wieder eine beträchtliche Wassermenge. Aber auch sein Wasserhaus, halt ist stark dem Einfluß der Gewitter- oder langanhaltenden Landregen unterworfen.

\section{Klimaverhältnisse des Simmentales}

Die beträchtliche Länge des Tales, seine Höhenunterschiede, seine Lage inmitten verschieden hoher Bergzüge mit wechselnden Expositionen haben zur Folge, daß das Simmental kein einheitliches Klima besitzt. Leider sind die meteorologischen Angaben über dieses Gebiet sehr spärlich, weil hier keine meteorologischen Stationen - die nächste ist Saanen - bedient werden. Nur die Niederschläge werden in Wimmis, Boltigen, Zweisimmen, Jaun und bis 1935 in Lenk gemessen.

Im allgemeinen besitzt das Simmental ein günstiges Klima, das durch warme Sommer mit reichlichen Niederschlägen gekennzeichnet ist. Im Winter sind die Gegensätze zwischen der Talzone und den benachbarten Erhebungen sehr bedeutend. Das Tal genießt in merkbarer Weise den Schutz der umrahmenden Bergketten vor kalten, nördlichen Winden. In der Regel fallen auf den Erhebungen im Winter beträchtliche Schneemengen, die, verbunden mit den mit den Höhen abnehmenden Temperaturen, ausgeprägte Unterschiede zwischen Berg- und Talklima ergeben.

Ueber die einzelnen klimatischen Werte in den Gebieten des Simmentales geben die folgenden Angaben Auskunft.

\section{a) Temperatur}

Nach FRÜH (76, I., 271 ff.) weist das eigentliche Simmental mit $-2^{\circ}$ bis $-5^{\circ} \mathrm{C}$ Monatsmittel im Januar ähnliche Temperaturverhältnisse wie die benachbarten Täler der Kander und der Saane auf. Im Juli beträgt die mittlere Monatstemperatur des untern Simmentales $15^{\circ}$ bis $17^{\circ} \mathrm{C}$, während das oberste Talstück des Obersimmentales, des Diemtigtales und das Fermeltal einige Grade kühler sind. Dies wirkt sich hier in Verbindung mit den meistens stärkeren Niederschlägen nachteilig auf den Anbau gewisser Kulturpflanzen, insbesondere von Getreide, aus. 
Karten der tatsächlichen mittlern

Fig. 9 Januartemperaturen
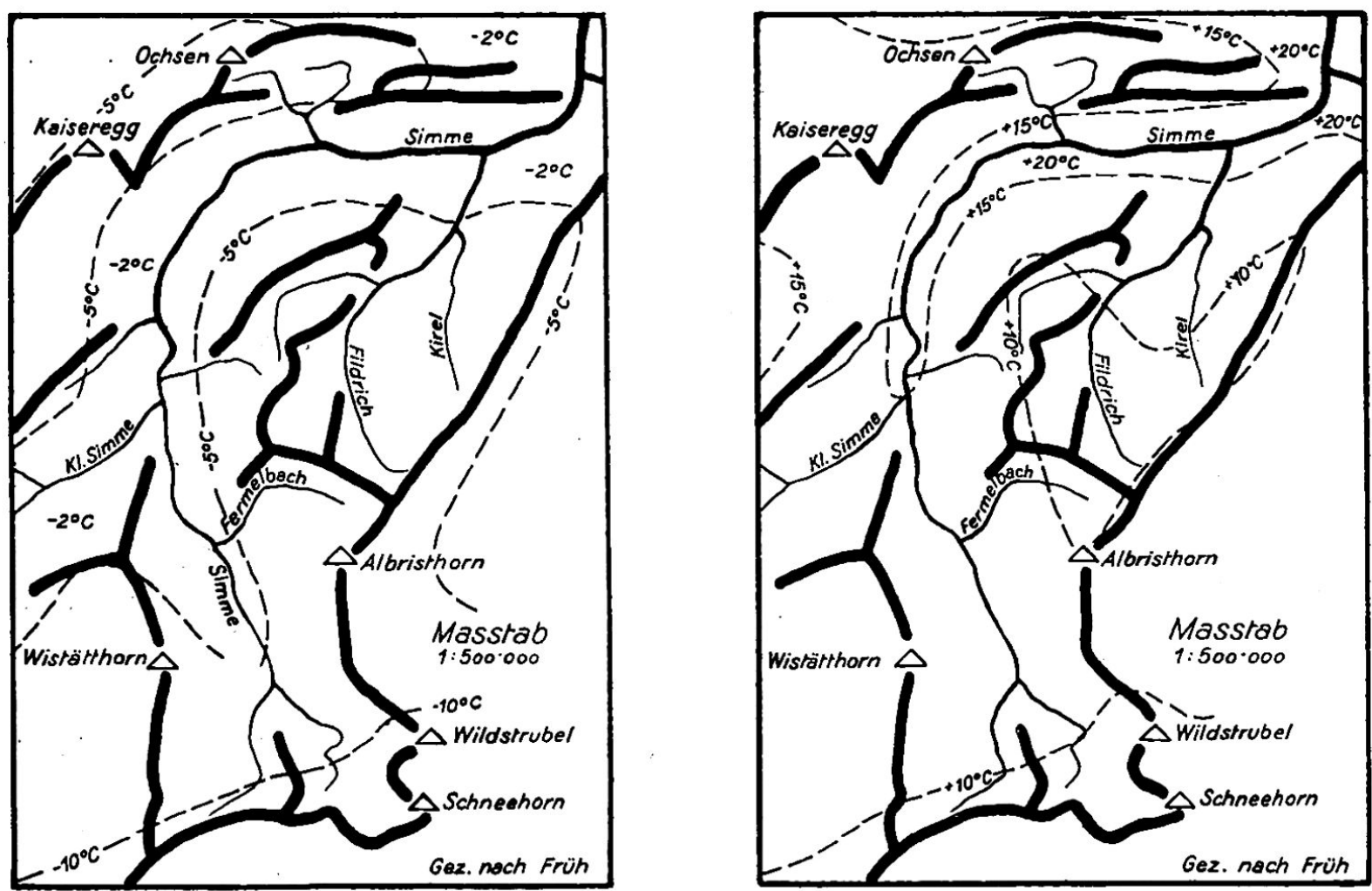

Maurer, Billiviller und Hess (78) haben errechnet, daß das Simmental, verglichen mit gleich hoch gelegenen, andern Landesteilen, einen Temperaturdurchschnitt hat, der um $0,6^{\circ} \mathrm{C}$ zu hoch ist.

b) Winde

Das Simmental nimmt an den allgemeinen Luftströmungen, die in der Schweiz vorhanden sind, teil. So herrschen in ihm die West- und Ostwinde abwechslungsweise vor. Thre Wucht wird aber durch die Berge gebrochen, so vor allem die der Bise durch Stockhornkette, Simmenfluh, Burgfluh und Niesen. Deshalb weist das Niedersimmental ein relativ mildes Klima auf.

Dagegen wirkt sich im Obersimmental der in vielen Alpentälern häufige Föhn stark aus und räumt meistens mit den im Winter vorhandenen Kälteseen von Zweisimmen und Lenk auf. Im Niedersimmental und im Diemtigtal weht er vorwiegend als schwacher Wind von den Gebirgskämmen herunter, so daß diese Talabschnitte in den Genuß seiner schneeschmelzenden Wirkung kommen, ohne jedoch die Nachteile zu erfahren, die bei seiner stürmischen Wucht oft auftreten.

Als weitere Windströmung tritt nach FRÜH (76, I., 295 ff.) der Talwind auf, der von der Port das ganze Tal und auch das Diemtigtal hinaufweht. Er stellt sich aber nur bei ruhiger Wetterlage mit ungehinderter Sonneneinstrahlung ein.

Der Bergwind ist im Simmental nur örtlich vorhanden und von geringer Stärke. Er weht hauptsächlich bei Zweisimmen und durch die Port gegen Wimmis.

Die vorherrschenden, allgemeinen Winde bringen dem Simmental auch die Gewitter. So zieht sich über Lenk die Alpengewitterstraße hin. Eine zweite Gewitterzone erstreckt sich von der Umgebung des Jaunpasses über das Niederhorn zum Hohniesen, wobei Boltigen auffallenderweise im Gewitterschatten liegt. Das Niedersimmental ist auch hierin wieder sehr begünstigt. Es hat eine sehr geringe Gewittertätigkeit, weil sich die Mehrzahl der Gewitter an der Stockhornkette entlädt, ohne ins Tal überzugreifen. 


\section{c) Niederschläge}

Die Annalen der Schweizerischen Meteorologischen Zentralanstalt geben uns die jährlichen Niederschlagsmengen von vier Stationen an. Die fünfte, Lenk, ist 1935 aufgehoben worden. Die Mittelwerte für die Jahre 1930 bis 1940 lauten:

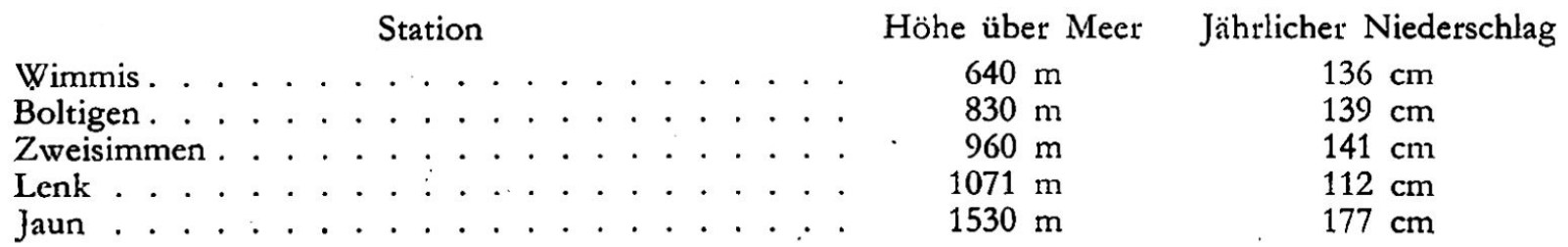

Die Niederschläge sind, wie die Durchschnitte zeigen, reichlich und nehmen mit der Höhe im allgemeinen zu. Die Regenkarte von MaUrer und Lugron lehrt, daß die Talsohlen bedeutend trockener sind als die sie einrahmenden Gebirgszüge. Die größten Niederschläge mit $200 \mathrm{~cm}$ im Jahr weist das Wildstrubelgebiet auf. Die Stockhornkette hat 180 bis $200 \mathrm{~cm}$, Jaunpaßgebiet, Niesenkette und Thurnen-Niederhorn haben 140 bis $180 \mathrm{~cm}$, die Talsohlen 120 bis $140 \mathrm{~cm}$ Niederschlag.

UtTINGER hat in den Annalen (82) eine Zusammenstellung der mittleren jährlichen Niederschlagshäufigkeit gegeben. Er hat dabei alle Tage berücksichtigt, an denen mehr als 1,0 mm Regen gefallen ist. Für die Zeitperiode von 1901 bis 1930 findet er für das Simmental einen Durchschnitt von 140 bis 150 Tagen im Jahr. Diese Niederschlagshäufigkeit setzt einen während des Jahres oft bewölkten Himmel voraus. Im Gegensatz dazu steht die geringe Zahl der Nebeltage, nämlich etwas über 20. Sie ist eine Folge des häufig auftretenden Föhns, der den Wasserdampfgehalt der Luft herabsetzt.

Naturgemäß fällt im Simmental ein Teil der jährlichen Niederschläge in der Form von Schnee. Leider fehlen nähere Angaben über die Dauer der Schneedecke. Diese nimmt talaufwärts zu. An den gegen Süden geneigten unteren Talhängen bleibt er aller-

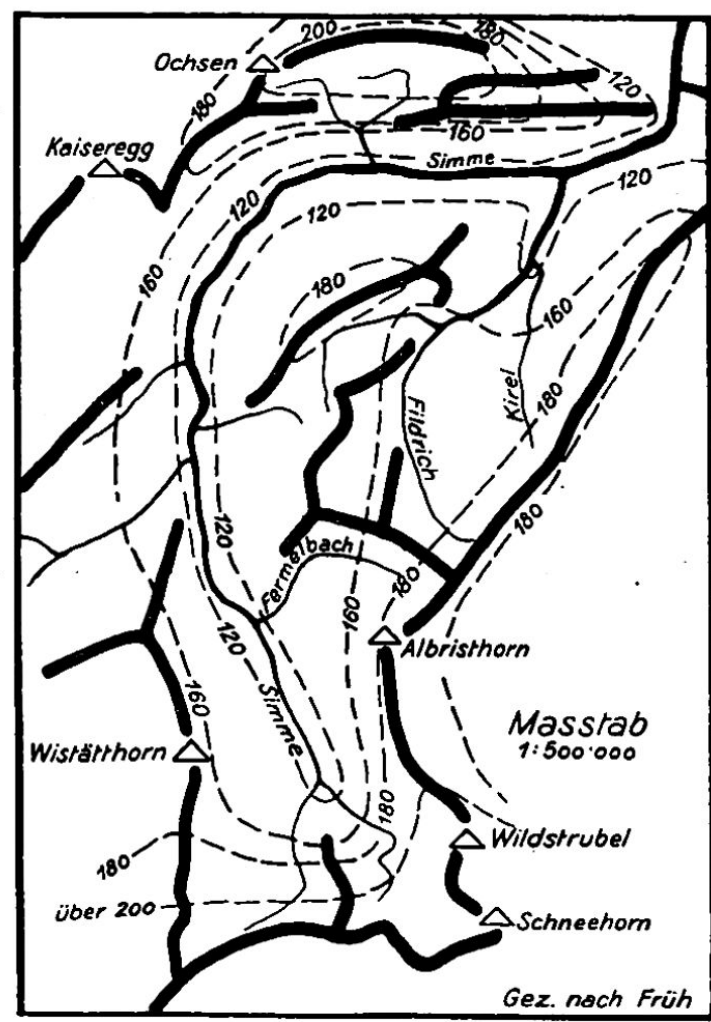

Fig. 11. Nicdcrschlagskarte des Simmentales. (Die Zahlen entsprechen der mittleren jährlichen Regensumme in Zentimetern) dings selten lange, was sich besonders im Niedersimmental mit seinen ausgeprägten Gegensätzen von Sonn- und Schattseiten bemerkbar macht. Als schneereiche Gebiete zeichnen sich die Saanenmöser, der Jaunpaß und das obere Diemtigtal aus. Angaben der Bernischen Alpen-Bahngesellschaften über die Schneeverhältnisse in den Skisportgebieten vermitteln davon ein eindrückliches Bild, wie nachstehende Tabelle zeigt:

\section{Gebiete}

Hahnenmoos

Zweisimmen

Lenk

Saanenmöser

Rinderalp

Grimmialp

$$
\begin{array}{rr}
13.12 .1935 & 19.3 .1936 \\
100 \mathrm{~cm} & \text { über } 100 \mathrm{~cm} \\
40-100 \mathrm{~cm} & 0-50 \mathrm{~cm} \\
50-100 \mathrm{~cm} & 0-80 \mathrm{~cm} \\
80-150 \mathrm{~cm} & 40-80 \mathrm{~cm} \\
60-100 \mathrm{~cm} & 5-100 \mathrm{~cm} \\
60-100 \mathrm{~cm} & 5-100 \mathrm{~cm}
\end{array}
$$

$$
\text { 24. 3. } 1936
$$

$100 \mathrm{~cm}$

$25-60 \mathrm{~cm}$

$25-60 \mathrm{~cm}$

$40-100 \mathrm{~cm}$

$30-70 \mathrm{~cm}$

$30-70 \mathrm{~cm}$

\section{über $100 \mathrm{~cm}$}

$10-80 \mathrm{~cm}$

$40-80 \mathrm{~cm}$

$60-200 \mathrm{~cm}$

$80-200 \mathrm{~cm}$

$80-200 \mathrm{~cm}$

\section{12.1937}

$30-70 \mathrm{~cm}$

$15-50 \mathrm{~cm}$

$30-50 \mathrm{~cm}$

$60-120 \mathrm{~cm}$

$30-50 \mathrm{~cm}$

$30-50 \mathrm{~cm}$
18. 3.1938

über $100 \mathrm{~cm}$

$25-80 \mathrm{~cm}$

$25-80 \mathrm{~cm}$

über $100 \mathrm{~cm}$

keine Angaben

keine Angaben

Anmerkung: Die erste Zahl bezieht sich auf die Station, die zweite auf das Hauptskigebiet. 
Aus der Zusammenstellung ist ersichtlich, daß mit der Höhe die Schneemengen rasch zunehmen. Der Verfasser hat am 5. April 1937 im Hornberg bei den Saanenmösern in $1900 \mathrm{~m}$ Höhe noch $250 \mathrm{~cm}$ Schnee gemessen, am 25. März 1933 noch $150 \mathrm{~cm}$ auf der untern Kübelialp in $1560 \mathrm{~m}$ Höhe. Während einer Woche starken Föhns schmolz diese Schneemenge auf $20 \mathrm{~cm}$ zusarnmen, ohne daß die Bäche einen merklich größern Abfluß als vorher aufwiesen.

Die Unterschiede zwischen Berg- und Talklima wirken sich naturgemäß auch in der Vegetation, in der Bewirtschaftung des Bodens und in der Lage der Siedlungen aus.

Im Frühling verschwindet der Schnee schon recht bald in der Talsohle, so daß sich hier die Vegetation der Wiesen zu entwickeln vermag, wie auch mit dem Anbau der Aecker und der Gemüsegärten begonnen werden kann. Mit zunehmender Höhe verschiebt sich der Vegetationsbeginn immer mehr gegen die wärmere Jahreszeit hin. Nach den Angaben der Einheimischen werden in der Regel im ganzen Simmental um den 20. Mai die Vorsassen bezogen. Die Ausaperung der höheren Lagen erfolgt erst später, was sich in der kurzen Weidezeit von ungefähr 70 Tagen widerspiegelt. Am Niesengrat schmelzen die letzten Schneereste erst im August. Durch diese späte Abschmelzung des Schnees in den höheren, schattigen Berglagen wird die gleichmäßige Wasserführung der Bäche und der Quellen günstig beeinflußt.

\section{II.. ANTHROPOGEOGRAPHISCHE VERHÄLTNISSE}

\section{Aus der Geschichte.der Besiedlung}

Wie andere Täler des Oberlandes ist auch das Simmental seit der prähistorischen Zeit besiedelt worden. Die Forschung hat gezeigt, daß die Besiedlung von unten her erfolgt und langsam das Tal aufwärts vorgedrungen ist. Eine dichtere Besiedlung hat wahrscheinlich erst in der alemannischen Zeit eingesetzt. Allemann schreibt diesbezüglich im Simmentaler Heimatbuch (59, 155 ff.), daß sich eine germanische Sippe geschlossen niederließ und ungefähr das Gebiet einer heutigen Bäuert zu Handen nahm. Damals sollen bereits die Weiler Reichenbach bei Därstetten, Nitfluh, Eschi, Weißenbach, Grubenwald, Bettelried, Ried bei St. Stephan entstanden sein, alles Ortschaften, die von keiner größeren Feuersbrunst heimgesucht worden sind. Die ursprünglichen Häuser sind allerdings nicht mehr vorhanden, doch reichen zahlreiche stattliche, noch heute bestehende Wohnstätten bis ins 16. Jahrhundert zurück.

Aus alten Urkunden erhalten wir einige Angaben über die damaligen höchsten Siedlungen. Wir erfahren aus der Verkaufsurkunde des Klosters Sels an das Augustinerhaus Därstetten von 1275, daß Moserried im Tal der Kleinen Simme der höchstgelegene Weiler diesseits der Saanenmöser gewesen ist. Andere Urkunden nennen uns Güter im Gugernell bei Pöschenried, Gutenbrunnen, in der Lenk. Die Dörfer Littolsbach, Underbecken, Grubenwald, Oberried, Andermatton, zur Hüsern, Grodeya, Mützenmatt (Matten bei St. Stephan), Böschenriet, Andunbleiken (an den Bleiken bei Lenk), Mannried, Heimersmaad, Steinegg, Obegg, am Tüll und Fermel werden auch erwähnt (57).

In einem Kirchenkatalog des Dompropstes Cono von Estavayer vom 15. September 1228 wird eine Anzahl Gotteshäuser im Simmental aufgezählt, was auf eine gewisse Dichte der Besiedlung hinweist. Es erscheinen darin Windemis (Wimmis), Arlinbach (Erlenbach), Tarenchat (Därstetten), Berswile (Oberwil), Boltingen und Duessimenes (Zweisimmen).

Etwas genauere Angaben gibt das Verzeichnis des Kastlans Rudolf Ougspurgers vom 7. April 1677. Er nennt einmal die schon bekannten Namen, verzeichnet aber noch einige Einzelangaben. So zählt er als neue Bäuert diejenige «im Färmel» auf und sagt darüber: "Sie besteht in etlichen Hüsern, so aber fast nur den Sommer bewohnt 
werden, ist aber kein Dörfli.» Ueber Lenk führt er aus: «In der Kirchhöre Lenk steht noch kein Dorf, sondern in den 5 Bäuerten stehen die Häuser dem Rain nach in den Gütern, das einte hie, das andere dort, und nicht fast nach bei einandern. » (66)

Diese Angaben lehren, daß schon seit Jahrhunderten das Tal ziemlich besiedelt war und daß die Siedlungen bereits hoch oben lagen, bilden doch einige der erwähnten Orte noch heute die obere Grenze der Dauersiedlungen.

\section{Die Bevölkerungsbewegung}

Genaue Zahlen, die einen Vergleich erlauben, sind erst seit 1818 erhältlich. Die seither durchgeführten Volkszählungen bestätigen auch für das Simmental die ganz allgemein in den ländlichen Gebieten des Kantons Bern festgestellte Tatsache, daß in allen Gemeinden die Bevölkerung in der Mitte des vorigen Jahrhunderts stark zugenommen hat, worauf dann in den meisten Fällen eine langsame, bis auf den heutigen Tag andauernde Abnahme der Einwohnerzahlen eingetreten ist. Einzig Zweisimmen weist von den simmentalischen Gemeinden eine beinahe beständige Zunahme auf, was offenbar auf seine günstige Verkehrslage zurückzuführen ist (siehe dazu die untenstehende Tabelle).

Dagegen hat sich die Anzahl der Haushaltungen nicht im gleichen Sinne bewegt, sondern sie hat, wie die folgende Aufstellung zeigt, im allgemeinen zugenommen. Daraus ist zu entnehmen, daß gegenüber früher die Kinderzahl der einzelnen Familien wesentlich kleiner geworden sein muß. Es ist somit im Simmental, von wenigen Ausnahmen abgesehen, trotz der allgemeinen Abnahme der Bevölkerung die Siedlungsdichte nicht geringer geworden.

\begin{tabular}{|c|c|c|c|c|c|c|c|c|c|c|}
\hline \multirow{2}{*}{\multicolumn{2}{|c|}{ Gemeinde }} & \multicolumn{4}{|c|}{ Haushaltungen } & \multicolumn{5}{|c|}{ Wohnbevölkerung } \\
\hline & & 1818 & 1850 & 1900 & 1930 & 1818 & 1850 & 1900 & 1930 & 1941 \\
\hline ach & & 231 & 295 & 348 & 327 & 1033 & 1370 & 1518 & 1301 & 1388 \\
\hline de & & 334 & 407 & 410 & 423 & 1629 & 2150 & 2014 & 1901 & 1946 \\
\hline Därs & & 167 & 209 & 201 & 216 & 823 & 1046 & 897 & 841 & 878 \\
\hline Obe & & 256 & 312 & 277 & 249 & 1205 & 1405 & 1225 & 987 & 1057 \\
\hline Bol & & 351 & 448 & 438 & 422 & 1538 & 2149 & 1933 & 1740 & 1879 \\
\hline amen & & 371 & 473 & 501 & 663 & 1753 & 2128 & 2072 & 2403 & 2492 \\
\hline ephan & & 291 & 284 & 331 & 318 & 1186 & 1454 & 1403 & 1121 & 1210 \\
\hline 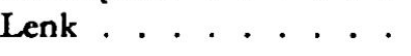 & & 439 & 534 & 447 & 472 & 2009 & 2369 & 1748 & 1750 & 1752 \\
\hline & Tot & 440 & 62 & 953 & 0 & 76 & 4071 & 12810 & 12044 & 602 \\
\hline
\end{tabular}

Zu dem gleichen Ergebnis gelangt man, wenn die Anzahl der Wohnhäuser mit der Bevölkerungszahl verglichen wird. Die Zahl der Wohnhäuser nimmt, wie die nachstehende Tabelle zeigt, fast überall zu. Damit wird der Beweis erbracht, daß der landwirtschaftliche Arbeiter darnach trachtet, im eigenen Hause zu wohnen und nicht bei seinem Arbeitgeber (84).

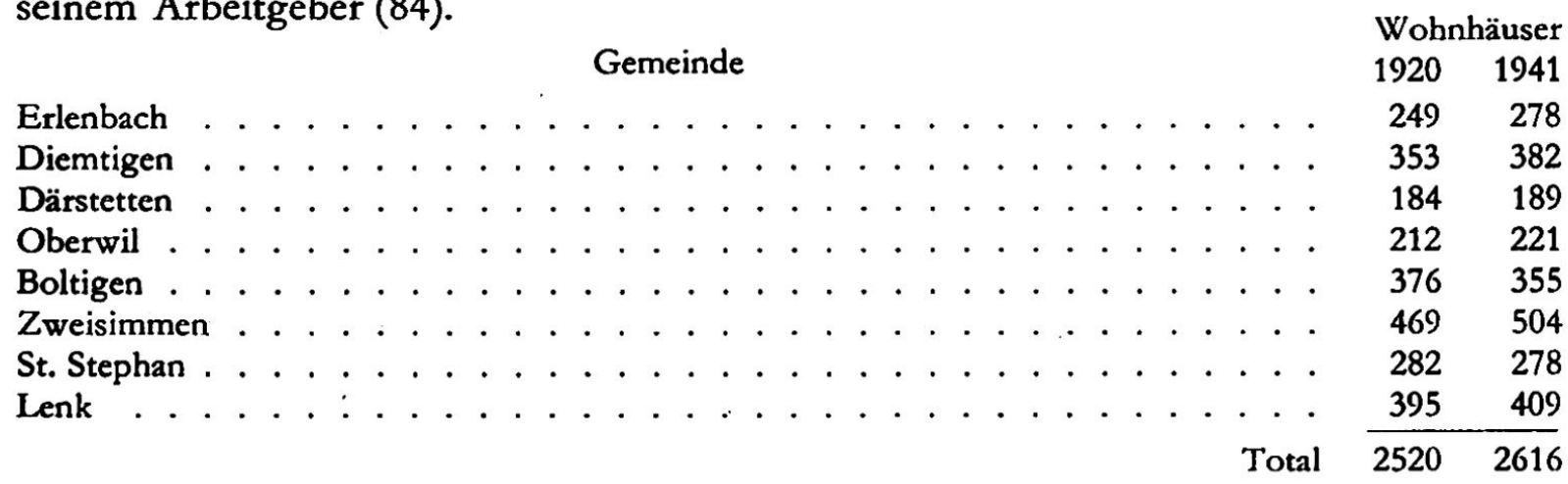

Somit bildet das Simmental gegenüber andern Alpentälern eine bemerkenswerte Ausnahme, indem hier die Gesamtzahl der Haushaltungen und der Wohnhäuser in den letzten 30-40 Jahren zugenommen hat. 
3. Land-" und alpwirtschaftliche Verhältnisse

a) Verteilung von produktivem und unproduktivem Land

Bei der Darstellung der wirtschaftlichen Verhältnisse haben wir uns auf den landwirtschaftlichen Zweig beschränkt, weil ähnliche Untersuchungen immer auf die bäuerlichen Betriebe abstellen und die durch Verkehr, Tourismus und Fremdenverkehr entstandenen dauernden Wohnstätten ausschließen ${ }^{2}$.

Die folgende Uebersicht gibt Auskunft, wie sich die produktiven und unproduktiven Areale im Simmental zueinander verhalten (86).

\begin{tabular}{|c|c|c|c|c|c|c|c|}
\hline \multirow[t]{2}{*}{ Gemeinde } & \multirow{2}{*}{$\begin{array}{c}\text { Gesamt- } \\
\text { fläche } \\
\text { ha }\end{array}$} & \multicolumn{2}{|c|}{$\begin{array}{l}\text { Unproduktiver } \\
\text { Boden }\end{array}$} & \multicolumn{2}{|c|}{$\begin{array}{l}\text { Land- und alpwirt- } \\
\text { schạftlicher Boden }\end{array}$} & \multicolumn{2}{|c|}{$\begin{array}{c}\text { Forstwirtschaftlicher } \\
\text { Boden }\end{array}$} \\
\hline & & $h_{a}$ & in $\%$ & ha & in $\%$ & ba & in $\%$ \\
\hline Erlenbach & 3629 & 241 & 6,6 & 2593 & 71,5 & 795 & 21,9 \\
\hline Diemtigen & 13071 & 2776 & 21,2 & 8193 & 62,7 & 2102 & 16,1 \\
\hline Därstetten & 3372 & 302 & 9,0 & 2297 & 68,1 & 773 & 22,9 \\
\hline Oberwil. & 4549 & 435 & 9,6 & 3291 & 72,3 & 823 & 18,1 \\
\hline Boltigen. & 7618 & 971 & 12,7 & 5325 & 69,9 & 1322 & 17,4 \\
\hline Zweisimmen . . . & 7201 & 897 & 12,5 & 5062 & 70,3 & 1242 & 17,2 \\
\hline St. Stephan . . . . & 5997 & 662 & 11,0 & 4436 & 74,0 & 899 & 15,0 \\
\hline Lenk . . . . . & 12414 & 4956 & 40,0 & 6868 & 55,3 & 590 & 4,7 \\
\hline Total & 57851 & 11240 & 19,4 & 38065 & 65,8 & 8546 & 14,8 \\
\hline
\end{tabular}

Diese Aufstellung zeigt, daß mit Ausnahme der Gemeinden Lenk und Diemtigen der Anteil des unproduktiven Areals gering ist. Der simmentalische Waldbestand bleibt fast überall unter dem schweizerischen Durchschnitt von $22,5 \%$, was auf eine intensiv ausgeübte Weideausdehnung auf Kosten der Forstwirtschaft schließen läßt.

Dies geht auch aus der folgenden Tabelle hervor, deren Zahlen aus der Arealstatistik von 1923/24 und der Anbauerhebung von 1934 errechnet worden sind. Bis 1940 sind die Hektarbeträge des Ackerbaus beinahe unverändert geblieben. Die Zahlen sind nur annähernd genau, beruhen sie doch zum Teil auf bloßer Schätzung.

\section{Gemeinde}

\begin{tabular}{|c|c|c|}
\hline & & ha \\
\hline Erlenbach & . . . . & 2593 \\
\hline Diemtigen . & ..... & 8193 \\
\hline Därstetten & .... & 2297 \\
\hline Oberwil. & ..... & 3291 \\
\hline Boltigen. & . . . & 5325 \\
\hline Zweisimmen. & ..... & 5062 \\
\hline St. Stephan & . . . & 4436 \\
\hline Lenk . . . & $\ldots$ & 6868 \\
\hline
\end{tabular}

Total der Fläche von Weiden, Wiesen, Ackerbau

\begin{tabular}{cc}
\multicolumn{2}{c}{ W'eideland } \\
ha & in \% \\
2002 & 77,2 \\
7085 & 86,4 \\
1801 & 78,4 \\
2596 & 78,8 \\
4333 & 81,4 \\
3828 & 75,6 \\
3604 & 81,3 \\
5603 & 81,6
\end{tabular}

Futtervivesen

$\begin{array}{rccc}\text { ha } & \text { in \% } & \text { ha } & \text { in \% } \\ 579,5 & 22,4 & 11,5 & 0,4 \\ 1089,5 & 13,3 & 18,5 & 0,2 \\ 487,1 & 21,2 & 8,9 & 0,4 \\ 685,7 & 20,9 & 9,3 & 0,3 \\ 979,2 & 18,4 & 12,8 & 0,2 \\ 1223,9 & 24,2 & 10,1 & 0,2 \\ 822,0 & 18,5 & 10,0 & 0,2 \\ 1253,3 & 18,1 & 11,7 & 0,2\end{array}$

Wie daraus ersichtlich ist, nimmt der Ackerbau eine verschwindend kleine Fläche ein. Die Ernteerträge werden folglich nie zur Ernährung der Bevölkerung ausreichen können. Ein Vergleich der Zahlen der Ackerfläche von 1917 (Kriegsjahr) und 1929 zeigt den starken Rückgang. 1917 wurden in Erlenbach 27,69 ha, in Diemtigen 35,99 ha, in Därstetten 16,28 ha, in Oberwil 16,09 ha, in Boltigen 21,35 ha, in Zweisimmen 18,75 ha, in St. Stephan 19,68 ha und in der Lenk 20,46 ha mit Getreide, Kartoffeln und Gemüse bepflanzt (85).

- Siehe dazu die Literatur von Ratzel, Sieger, Hammer, Gastr, Burky, Ott und anderen mehr. Nur Meissinger verlangt, daß sämtliche Siedlungen berücksichtigt werden. 
Der Getreideanbau ist sogar noch innerhalb der Gruppe Ackerbau von ganz untergeordneter Bedeutung. Dies ist insofern auffallend, als FRITZSCH, RATZEL u. a. in den Ostalpen festgestellt haben, daß der Bauer in den abgelegeneren Tälern möglichst autark lebt, d. h., er muß auf seinem Grundstück so viel Getreide anbauen, daß er von einer Ernte bis zur andern genügend davon besitzt. Leider sind die Angaben etwas ungenau, so daß eine Zufuhr von Brotgetreide nicht ausgeschlossen ist ${ }^{3}$.

Das Simmental ist in seiner Getreideversorgung nie autark gewesen, trotzdem in früheren Jahrhunderten die Milchprodukte in der Ernährung an erster Stelle gestanden haben.

Es geht dies aus folgenden Angaben hervor: Im Schreiben vom 20. März 1798 der Bauern und Bürger des Kantons Oberland an Bern heißt es u. a. : «Nous aurions préféré la réunion du Canton d'Oberland à quelque république du pays suisse allemand ,... vu que nous sommes obligés de tirer nos bleds presqu'entièrement de ces contrées-là $(62,13)$."

Im gleichen Sinne lautet die Feststellung von WYss, dem Jüngern, in seinem Streifzug im Siebenthal. Er zählt die Rubi- und die Wampflenmühle im Diemtigtal auf und fügt bei, daß aber das dort gemahlene Korn aus Bern und Thun komme $(71,314)$.

JosI und STÄHLI führen dasselbe im Simmentaler Heimatbuch aus. Sie machen darin aufmerksam, daß die Vieh- und Milchwirtschaft die hauptsächlichsten Lebensgrundlagen des Simmentaler Bauern gebildet haben, während der Ackerbau an Ausdehnung und Bedeutung immer untergeordnet gewesen sei $(59,550 \mathrm{ff}$.).

Diese Zeugnisse und andere aus der Rechtsgeschichte bestätigen die Tatsache, daß das Simmental seit jeher eine beinahe wirtschaftliche Monokultur aufgewiesen hat (68).

\section{b) Viehhaltung}

Werfen wir nun einen Blick auf die Entwicklung der Viehwirtschaft und auf die innern Verschiebungen in diesem Wirtschaftszweig.

\begin{tabular}{|c|c|c|c|c|c|c|}
\hline Jahr & & 1808 & & & 1859 & \\
\hline Bezirk & $\begin{array}{c}\text { Rindvieh } \\
\text { überhaupt }\end{array}$ & $\begin{array}{l}\text { wovon } \\
\text { Kühe }\end{array}$ & in $\%$ & $\begin{array}{l}\text { Rindvieh } \\
\text { überhaupt }\end{array}$ & $\begin{array}{l}\text { wovon } \\
\text { Kühe }\end{array}$ & in $\%$ \\
\hline $\begin{array}{l}\text { Obersimmental . } \\
\text { Niedersimmental* }\end{array}$ & $\begin{array}{l}7323 \\
6895\end{array}$ & $\begin{array}{l}3628 \\
3493\end{array}$ & $\begin{array}{l}49,5 \\
50,6\end{array}$ & $\begin{array}{l}7469 \\
6115\end{array}$ & $\begin{array}{l}3202 \\
2948\end{array}$ & $\begin{array}{l}42,8 \\
48,2\end{array}$ \\
\hline Total & 14218 & 7121 & & 13584 & 6150 & \\
\hline & & 1901 & & & 1943 & \\
\hline immental & 9133 & 2927 & 32,0 & 9703 & 3475 & 35,8 \\
\hline mental* & 9011 & 3637 & 40,3 & 10257 & 4285 & 41,7 \\
\hline sches Gcbict. & 18144 & 6564 & & 19960 & 7760 & \\
\hline
\end{tabular}

Diese Zusammenstellung läßt zwei Entwicklungen erkennen. Erstens einen bedeutenden Aufschwung der Rindviehhaltung von 1859 bis 1943, wobei eine große Zunahme bis 1901 eintritt. Diese fällt zusammen mit der allgemeinen Umstellung vom Ackerbau zur Graswirtschaft in der Schweiz, die durch die Konkurrenz des ausländischen Getreides, herangeführt durch Schiff und Bahn, und durch die Jahre des Mißwachses, hervorgerufen durch vermehrte Niederschläge in den achtziger Jahren, bewirkt worden ist (54).

Sie zeigt ferner, daß der prozentuale Anteil der Kühe im Obersimmental von $49,5 \%$ im Jahre 1808 auf $35,8 \%$ im Jahre 1943, im Niedersimmental von $50,6 \%$ auf $41,7 \%$ gesunken ist. Diese Zahlen beleuchten die Verschiebung vom Milchvieh zugunsten des Zuchtviehs. Damit ist das Simmental wirtschaftlich weniger krisenfest

${ }^{3}$ Nach der Regenkarte, die sich im Werk von KREBS über die österreichischen Alpen befindet, fallen in den Tälern der Ostalpen jährlich $800-1000 \mathrm{~mm}$ Niederschlag, was den Getreideanbau im Vergleich zum Simmental begünstigen würde. 
geworden, ist doch der Erwerb allzu einseitig an die Preisgestaltung auf dem Zuchtviehmarkt gebunden.

Dann bestätigt die Aufstellung indirekt, daß die Ernährung der Bevölkerung sich von den Milchprodukten auf eingeführte landwirtschaftliche Erzeugnisse verlagert hat.

Eine weitere Statistik soll uns in die Verhältnisse der Weidewirtschaft einführen.

$\begin{array}{lrrrrrc}\text { Gemeinde } & & \begin{array}{c}\text { Anzahl } \\ \text { der Alpen }\end{array} & \begin{array}{c}\text { Fläche } \\ \text { in ha }\end{array} & \begin{array}{c}\text { Davon produktiv } \\ \text { ha }\end{array} & \begin{array}{c}\text { Weidezeit } \\ \text { Tage }\end{array} & \begin{array}{c}\text { Stoßtage auf } 1 \text { ha } \\ \text { produktive Fläche }\end{array} \\ \text { Erlenbach . . . . . . . . . } & 32 & 1948 & 1784 & 70 & 70 \\ \text { Diemtigen . . . . . . . } & 102 & 6837 & 5816 & 68 & 64 \\ \text { Därstetten . . . . . . . . . } & 22 & 1452 & 1242 & 84 & 75 \\ \text { Oberwil. . . . . . . . . } & 22 & 2282 & 1940 & 69 & 66 \\ \text { Boltigen . . . . . . . . . } & 53 & 5838 & 4375 & 80 & 49 \\ \text { Zweisimmen . . . . . . . } & 87 & 6021 & 4995 & 70 & 44 \\ \text { St. Stephan . . . . . . . . } & 61 & 3623 & 2925 & 70 & 42 \\ \text { Lenk . . . . . . . . . . . } & 78 & 6645 & 4730 & 68 & 42\end{array}$

Im Vergleich zu andern Gemeinden ist hier die Weidezeit auf den Alpen auffallend kurz. Nur das Kandertal verzeichnet noch geringere Werte, wie Adelboden mit $59 \mathrm{Ta}$ gen, Frutigen mit 61 Tagen, Kandergrund mit 71 Tagen, während der Amtsbezirk Oberhasle mit den Gemeinden Gadmen, Guttannen, Innertkirchen, Hasleberg, Schattenhalb und Meiringen einen Durchschnitt von 93 Weidetagen ausweist. Die unter ähnlichen Bedingungen stehenden Gemeinden Lauterbrunnen, Lütschenthal und Grindelwald verzeichnen sogar 92, 110 und 100 Weidetage.

Nicht unwichtig für die Alpwirtschaft des Simmentales sind die Besitzverhältnisse. Die folgende Tabelle zeigt, daß sich die meisten Alpen in Privatbesitz befinden.

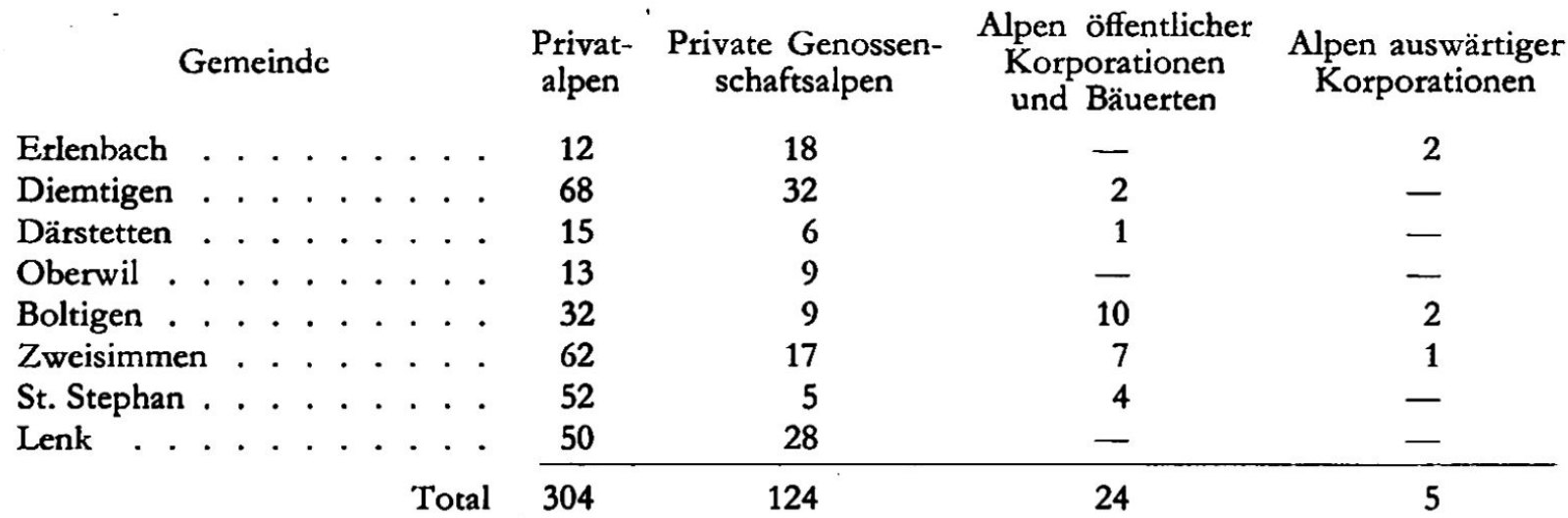

Aus einem Vergleich der Statistiken über die Verteilung des landwirtschaftlich genützten Bodens (S. 22), der Bestoßung (S. 24) und der Besitzverhältnisse der Alpen läßt sich ohne weiteres schließen, daß unmöglich alles gesömmerte Vieh im Simmental überwintert werden kann.

Die prozentuale Abnahme der Milchkühe im allgemeinen Rindviehbestand stimmt mit der Zunahme der Alpen, wie sie das Uebersömmerungsvieh verlangt, überein. Dieses besteht aus Kälbern, Rindern und Kühen, die für die Sommermonate aus dem Mittelland ins Voralpengebiet gebracht werden, um auf den Alpen das vorhandene Futter auszunützen und kräftig zu werden.

Eine weitere Zusammenstellung erläutert die Tatsache, daß die Rindviehhaltung die übrige Viehzucht weit übertrifft. Auffallend ist die geringe Anzahl der Pferde, die darauf zurückzuführen ist, daß der unbedeutende Ackerbau nicht nach ihren Kräften verlangt. 
In einer besondern Kolonne haben wir noch die Anzahl der Bienenstöcke aufgeführt, um zu zeigen, daß die Bienenzucht im Simmental noch ziemlich eingehend gepflegt wird. (Zahlen nach landwirtschaftlichem Produktionskataster des Eidg. KEA. und den Statistischen Quellenwerken der Schweiz, Heft Nr. 152.) (87)

\begin{tabular}{rcccccccc} 
Gemeinde & & $\begin{array}{c}\text { Viehbesitzer } \\
\text { im gesamten }\end{array}$ & Rindvieh & Pferde & Schweine & Schate & $\begin{array}{c}\text { Ziegen } \\
\text { Bienen- } \\
\text { stöcke }\end{array}$ \\
Erlenbach . . . . . & 194 & 1344 & 40 & 315 & 54 & 390 & 200 \\
Diemtigen . . . . & 314 & 2606 & 63 & 560 & 468 & 567 & 281 \\
Därstetten . . . . & 138 & 1150 & 24 & 204 & 70 & 208 & 150 \\
Oberwil . . . . . & 206 & 1803 & 24 & 230 & 63 & 467 & 138 \\
Boltigen . . . . . & 315 & 2246 & 40 & 374 & 236 & 1023 & 265 \\
Zweisimmen . . . & 313 & 2797 & 63 & 421 & 272 & 587 & 372 \\
St. Stephan . . . & 231 & 1749 & 18 & 186 & 176 & 438 & 175 \\
Lenk . . . . . . & 315 & 2911 & 33 & 292 & 260 & 539 & 294 \\
\hline Total & 2026 & 16606 & 305 & 2582 & 1599 & 4219 & 1875
\end{tabular}

Die überragende Stellung der Rindviehzucht im Simmental fußt auf den klimatischen Voraussetzungen, die mit ihren bedeutenden Niederschlägen die Graswirtschaft und damit die Viehzucht bedingen. Durch diese einseitige Wirtschaftsentwicklung ist das Tal allerdings nicht sehr krisenfest geworden; denn jede Schwankung in diesem Sektor wirkt sich unmittelbar auf größere Teile der Bevölkerung aus, sind doch in fast allen Gemeinden mehr als 50\% der Einwohner in der Landwirtschaft tätig, wie die folgende Zusammenstellung beweist (84).

\begin{tabular}{|c|c|c|c|c|c|c|c|}
\hline \multirow[b]{2}{*}{ Erlenbach } & Gemeinde & \multicolumn{2}{|r|}{$\begin{array}{l}\text { Zahl der Erwerbenden } \\
\text { im gesamten }\end{array}$} & \multicolumn{2}{|c|}{$\begin{array}{l}\text { In der Landwirt- } \\
\text { schaft } \\
\text { in } \%\end{array}$} & \multicolumn{2}{|c|}{$\begin{array}{c}\text { In Gewerbe, Hande } \\
\text { Verketr u.a. } m . \\
\text { in } \%\end{array}$} \\
\hline & . . . . & & 622 & 348 & 55,9 & 274 & 44,1 \\
\hline Diemtigen & ...... & - & 873 & 578 & 66,2 & 295 & 33,8 \\
\hline Därstetten & ........ & & 375 & 254 & 67,7 & 121 & 32,3 \\
\hline Oberwil . & $\ldots . . .$. & . & 483 & 355 & 73,4 & 128 & 26,6 \\
\hline Boltigen . & . : & & 795 & 505 & 63,5 & 290 & 36,5 \\
\hline Zweisimmen & . & & 1106 & 506 & 44,8 & 600 & 55,2 \\
\hline St. Stephan & $\cdots$ & & 580 & 388 & 66,8 & 192 & 33,2 \\
\hline Lenk . . . & ......... & & 842 & 586 & 69,5 & 256 & 30,5 \\
\hline
\end{tabular}

Diese wirtschaftliche Gliederung der Bevölkerung erlaubt uns, die Untersuchung auf die bäuerliche Schicht zu beschränken, um so mehr als die Gewerbe- und Handeltreibenden und die im Verkehrswesen beschäftigten Personen in der Talsohle oder ihrer unmittelbaren Nähe wohnen.

\section{DIE OBERE GRENZE DER DAUERSIEDLUNGEN IM NIEDERSIMMENTAL}

Die Gemeinden Erlenbach, Därstetten und Oberwil bilden das eigentliche Niedersimmental. Ihr Gebiet erstreckt sich von der Simmenfluh bis oberhalb Pfaffenried. Die südliche Talseite von der Burgfluh. bis zur Einmündung des Kirels in die Simme gehört der Gemeinde Diemtigen an. Oberhalb davon greifen die drei Gemeinden auf beide Talflanken über und dehnen sich nordwärts bis zur Wasserscheide zwischen Sense und Simme und südwärts bis ins Einzugsgebiet von Narrenbach und Fildrich aus.

Die Anlage des Tales in westöstlicher Richtung bringt es mit sich, daß wir einen ausgesprochenen Sonnenhang und einen ebenso ausgeprägten Schattenhang vor uns haben. Dazu kommt, daß die Sonnseite des Tales reicher terrassiert ist als der gegen Norden abfallende Talabhang. Diese zwei Ursachen veranlaßten die viel dichtere Besiedlung der Sonnseite. 
1. Die obere Grenze der Dauersiedlungen auf der rechten Talseite

Die erste, hochgelegene Siedlung findet sich auf dem Diemtigbergli und gehört noch in die Gemeinde Diemtigen. Ihre Lage ist orographisch sehr günstig, ist doch das Diemtigbergli eine dem präglazialen Burgfluhniveau entsprechende Verflachung, die sich gut ausgebildet zwischen Diemtigtal und dem Simmental vorschiebt und dadurch der Insolation in günstiger Weise ausgesetzt ist. Von hier aus fällt die Kurve infolge der nun für die Sonnenbestrahlung ungünstig werdenden Gesamtexposition der rechten Talflanke auf 700-735 m hinunter. In dieser Höhe, also nur 30-40 m über dem Talboden, liegen erst wieder auf dem großen Schuttkegel des Steinibaches dauernd bewohnte Bauernhöfe. Es sind dies die von Steini (Nr. 1 und 2) auf der rechten und die von Seewlen (Nr. 3) auf der linken Seite des Baches. Die Talflanke weist oberhalb dieser Siedlungen eine etwas geringere Neigung als anderswo auf. Vereint mit der tiefen und breiten Kerbe des Steinibaches sind hier die Besonnungsverhältnisse ziemlich günstig. Der nächste Hof ist Junkernweiden in $765 \mathrm{~m}$ Höhe (Nr. 4), der sowohl in orographischer wie in klimatischer Hinsicht als schattige Hangsiedlung benachteiligt ist.

Von Junkernweiden an talaufwärts ist die rechte Talseite bis in die Umgebung des ehemaligen Klosters Därstetten wenig gegliedert und weist zudem überall eine größere Steilheit auf, so daß Dauersiedlungen fehlen. Erst bei der Oertlichkeit Kloster ist der Talhang in seinen untern Partien schwach geneigt und besitzt zahl reiche Verflachungen. Auf ihnen sind mehrere Bauerngüter entstanden, von denen die nachfolgend beschriebenen die Grenze der Dauersiedlungszone bestimmen. Die drei Terrassensiedlungen (Nr. 5, 6, 7) haben Nordexposition und stehen in 720-830 m Höhe. Am ungünstigsten ist Nr. 7 gelegen, weil sich wenige Meter dahinter ein mit Wald bewachsener Steilhang erhebt. Um die Ungunst der Nordexposition einigermaßen auszugleichen, richten die Häuser ihre Fensterfronten nach S oder W.

Fünfhundert Meter weiter westlich weicht der Hang in südwestlicher Richtung zurück und bildet eine tiefe und breite Ausbuchtung. Daraus hervor rauscht der Klosterbach, der einen großen Schuttkegel aufgebaut hat, der an seinem Außenrande durch eine schmale Flyschzone von der Simme getrennt ist. Seine Ausdehnung und seine Erhebung von fast $100 \mathrm{~m}$ über dem heutigen Talboden machen ihn zu einem der sonnigsten Gebietsstücke der rechten Talseite. Deshalb liegen auf seiner Oberfläche zahlreiche Einzelhöfe. Auf der rechten Bachseite steht in einer Waldlichtung der Einzelhof «Steini» (Nr. 8) in $830 \mathrm{~m}$ Höhe, links des Baches trifft man auf die Bauernhäuser von Witmoos, Zur Obern und Scheidwegen (Nr. 9) in $875 \mathrm{~m}$ Höhe.

Ist der Talhang vom Diemtigbergli bis Zur Obern eine bald mehr, bald weniger von Runsen durchsetzte und geneigte Talflanke gewesen, so wird sie jetzt in westlicher Richtung durch den Oeygraben zerschnitten, so daß sich vor dem Anstieg gegen den Thurnen und die Buntelgabel der Lampernhubel erhebt.

Von Scheidwegen aus ist ein ziemlich steiler Anstieg zu überwinden, um auf die Terrasse zu gelangen, auf der das dauernd bewohnte Bauernhaus «Kästanne» (Nr. 10) steht. Es liegt in $1055 \mathrm{~m}$ Höhe in ziemlich sonniger Lage, weil der rückwärtige Hang erst in einiger Entfernung ansteigt und zudem SW-Richtung besitzt, so daß der Ausblick nach Westen frei ist.

In leichtem Anstieg führt dann ein Weg auf der rechten Seite des Oeygrabens zum Gastwirtschaftsbetrieb und bäuerlichen Heimwesen Roßberg (Nr. 11) in $1131 \mathrm{~m}$ Höhe. Damit ist der höchste Punkt der obern Dauersiedlungsgrenze auf der rechten Talseite des Niedersimmentales erreicht. Das Wohnhaus steht nach allen Seiten frei auf einem breiten Moränenwall des ehemaligen Simmegletschers. Die Siedlungsgrenze verläuft nun über das Bauerngut Längacker zu den Höfen von Oberried und Breiti. Bevor jedoch diese drei Siedlungen besprochen werden, soll eine Zusammenstellung die Siedlungen charakterisieren, die im Gebiet von Hintereggen stehen und die die obere Grenze am Lampernhubel angeben. 
Das Gebiet von Hintereggen weist nordöstliche Exposition auf und besitzt eine große Zahl von kleinen Terrassen, Eggen und Mulden, weshalb hicr eine ausgesprochene Streusiedlung entstanden ist. Die obersten Dauersiedlungen sind auf der Karte mit den Nr. 12 bis 19 eingetragen worden.

$\begin{array}{cccccc}\text { Haus Nr. } & \text { Art der Siedlung } & \text { Exposition } & \text { Höhe über Meer } & \text { Bodenunterlage } & \text { Relative Höhe } \\ 12 & \text { Wallsiedlung. . . . . } & \mathrm{N} & 785 \mathrm{~m} & \text { Flysch } & 25 \mathrm{~m} \\ 13 & \text { Wallsiedlung. . . . . } & \mathrm{N} & 790 \mathrm{~m} & \text { Flysch } & 30 \mathrm{~m} \\ 14 & \text { Terrassensiedlung. . . } & \mathrm{N} & 800 \mathrm{~m} & \text { Flysch } & 40 \mathrm{~m} \\ 15 & \text { Hangsiedlung . . . . } & \mathrm{NE} & 835 \mathrm{~m} & \text { Flysch } & 75 \mathrm{~m} \\ 16 & \text { Terrassensiedlung. . . } & \mathrm{NE} & 870 \mathrm{~m} & \text { Flysch } & 135 \mathrm{~m} \\ 17 & \text { Terrassensiedlung. . . } & \mathrm{NE} & 900 \mathrm{~m} & \text { Flysch } & 135 \mathrm{~m} \\ 18 & \text { Terrassensiedlung. . . } & \mathrm{NE} & 970 \mathrm{~m} & \text { Flysch } & 200 \mathrm{~m} \\ 19 & \text { Eggsiedlung. . . . . } & \mathrm{NE} & 1000 \mathrm{~m} & \text { Flysch } & 230 \mathrm{~m}\end{array}$

Die große Terrasse des Roßberges, an derén Rande das Bauerngut Längacker liegt, hat gegen Westen einen völlig freien Ausblick. Die Gehänge gegen die Buntelgabel hinauf sind im allgemeinen wenig geneigt, so daß die Sonne sogar im Winter über den Kamm weg auf die Fläche des Roßberges zu scheinen vermag. Trotz der günstigen orographischen Voraussetzung und der sonnigen Lage sind bis anhin nur zwei Dauersiedlungen vorhanden gewesen, was auf die starke Versumpfung des Roßberges zurückzuführen ist. Durch seine Drainage im Jahre 1943 ist fruchtbares Land gewonnen worden, was vielleicht in den nächsten Jahren zum Entstehen neuer Dauersiedlungen führen wird.

Die Wohnstätte Längacker (Nr. 20) am Rande des Roßberges ist eine Hangsiedlung in $1120 \mathrm{~m}$ Höhe mit NW-Exposition. Die Fensterfront des Hauses schaut gegen Süden. Die Quelle für die Wasserversorgung entspringt in $100 \mathrm{~m}$ Entfernung. 60 Meter tiefer, am Wege nach der Siedlung Oberried, erhebt sich auf einer kleinen Terrasse der Einzelhof Nr. 21 in nördlicher Auslage. Von hier aus gelangt man über einen Zufluß des Ammerzenbaches zum Bauerngut Oberried (Nr. 22), das auf einer in $1050 \mathrm{~m}$ Höhe gelegenen' Terrasse steht und ebenfalls Nordexposition besitzt. Die Dauersiedlungen Nr. 20-22 liegen nach der Karte von RaBOwski auf Glazialschutt.

Die letzten Heimwesen auf der rechten Seite des Niedersimmentales befinden sich auf der ebenen Fläche von Breiti $(1000 \mathrm{~m})$ (Nr. 23), deren Untergrund aus Flysch besteht. Die Fensterfronten der Wohnhäuser von Breiti gehen nach W, E oder S. Die Quellen für die Brunnen werden in 100-600 m Entfernung gefaßt.

\section{Die obere Grenze der Dauersiedlungen auf der linken Talseite}

Die Wanderung auf dem klimatisch begünstigten linken Talhang beginnt an der politischen Grenze des Ober- und Niedersimmentales bei Wöschbrunnen (Nr. 24), einer Terrassensiedlung in $975 \mathrm{~m}$ Höhe mit SE-Exposition und rechts des Wüstenbaches, eines Zuflusses der Simme, gelegen. Es folgen jenseits, 100 Meter über dem Bett dieses Wildbaches, auf einer sonnigen Terrasse, die braungebrannten Häuser des Dörfchens Waldried in $1000 \mathrm{~m}$ Höhe (Nr. 25). Hier ist die obere Grenze der Dauersiedlungen orographisch gegeben; denn wenig hinter Waldried steigt der Talhang stark an und endigt vorerst in einigen Felsköpfen. Von Waldried aus führt ein Fußweg am Einzelhof Nr. 26 in $940 \mathrm{~m}$ Höhe vorbei hinunter nach Oberwil. Dieser Einzelhof ist nach der geologischen Karte Rabowskis eine Schuttkegelsiedlung, trotzdem heute dort kein Bach in unmittelbarer Nähe vorbeirauscht. Die Häuser des Dorfes Oberwil (Nr. 27) sind auf einer breiten und gut entwickelten Terrasse des Wyler bzw. Erlenbacher Systems erbaut worden. Die obere Grenze der Dauersiedlungen verläuft hier in bloß 870 m Höhe, weil die Terrasse von Oberwil, die in' der näheren Umgebung die günstigste Oberflächenform für Niederlassungen darstellt, diese an sich zieht. Zudem ist sie mit fruchtbarem Glazialschutt bedeckt. 
Ungefähr $1 \mathrm{~km}$ weiter östlich und nach Ueberschreitung des Hüpbaches gelangt man zur Hangsiedlung Riedmad (Nr. 28) in $915 \mathrm{~m}$ Höhe und mit Südexposition. Sie liegt hangwärts einer Schuttkegelsiedlung, nämlich des Weilers Weißenbach (Nr. 29). Unmittelbar dahinter steigt der Talhang ziemlich steil an und ist mit Tannenwald bewachsen. 100 Meter höher weist er eine deutliche Verflachung auf, die von Alphütten besetzt ist. Auf der andern Seite des Baches setzt sich diese Verflachung als ausgesprochene Terrasse fort. Auf ihr, die zum Kirchetniveau gehört, stehen 4 Dauersiedlungen: Ried (Nr. 30, 31 und 32) und Zelg (Nr. 33) in 1000 bzw. dreimal $1010 \mathrm{~m}$ Höhe. Die obere Grenze ist hier wiederum orographisch bedingt; denn die Talflanke geht wenige Meter oberhalb in die Flühe des Gsäßgrindes über, an deren Fuß sich eine mit Tannenwald bewachsene Geröllhalde gebildet hat. Die Terrasse endigt im Osten mit einem felsigen Absturz zum Bunschenbach, der in einer tief eingeschnittenen Schlucht, die teilweise sogar als Klamm ausgebildet ist, die Talflanke durchbricht. Jenseits des Bunschenbaches geht es neuerdings in steilem Anstieg hinauf nach Weißenburgberg (Nr. 34), einem Weiler, der auf einer breiten Verflachung, die die Fortsetzung der Terrasse von Ried und Zelg darstellt, in $995 \mathrm{~m}$ bis $1000 \mathrm{~m}$ Höhe gelegen ist. Der Weiler ist hier aber nicht die oberste Dauersiedlung, sondern nach einer Gefällsstufe erfolgt höher oben eine weitere, sehr ausgeprägte Verflachung, auf der sich das oberste, dauernd bewohnte Heimwesen der linken Seite, nämlich Stigenmad $(1120 \mathrm{~m}$ ) (Nr. 35), befindet. Die Terrasse von Stigenmad ordnet sich dem Burgfluhniveau ein. Auch hier wird die obere Grenze der Siedlungen durch orographische Verhältnisse bestimmt; denn darüber beginnt die Kalkzone des Flühberges, wodurch das Gelände sehr abschüssig und von Kalkflühen durchsetzt wird.

Von Stigenmad aus gelangt man in ziemlich steilem Abstieg zu der östlich von Weißenburgberg, in $1015 \mathrm{~m}$ Höhe gelegenen Hangsiedlung Steinacker (Nr. 36). Von hier aus führt der Weg durch eine Runse hinauf nach Sulzi. Es sind zwei Einzelhöfe: der erste (Nr. 37) eine Hangsiedlung in $1080 \mathrm{~m}$ Höhe, der zweite (Nr. 38) eine Eggsiedlung in $1055 \mathrm{~m}$ Höhe. Die Talflanke, die sich ob den drei zuletzt genannten Siedlungen hinzieht, steigt stark geneigt und wenig gegliedertzum Loherenspitz an. Sie istdicht mit Tannenwald bewachsen. So wird die obere Grenze wiederum orographisch bedingt.

Von Sulzi fällt die Kurve hinunter zum Einzelhof Wolfacker (Nr. 39), der auf einer schmalen Terrasse in $980 \mathrm{~m}$ Höhe liegt. Von da aus verläuft sie über den Weiler Nitfluh (Nr. 40), der auf einer schwach und vielfach gestuft ausgebildeten Terrasse in $930 \mathrm{~m}$ Höhe steht, über die Terrassensiedlung Nr. 41 in $930 \mathrm{~m}$ Höhe nach dem zum gleichen Siedlungstypus zählenden Heimwesen Nr. 42 in 1020 m Höhe, das nach der Ueberquerung einer kleinen, aber steilen Bachrunse erreicht wird. Dieser Einzelhof steht am westlichen Ende der Balzenbergallmend, die dem Burgfluhniveau angehört. Etwas tiefer erstreckt sich der langgezogene Weiler Balzenberg (Nr. 43) auf einer schmalen Terrasse in $975 \mathrm{~m}$ Höhe. Man folgt nun dem Fahrsträßchen und kommt nach wenigen Minuten nach Eschlen, wo 4 Heimwesen (Nr. 44), eng beieinander, in einer breiten Mulde in $905 \mathrm{~m}$ Höhe liegen. Sie bilden hier die obere Grenzlinie der Dauersiedlungen. Hier gabelt sich auch das Sträßchen, das von Erlenbach her nach Balzenberg und Moos führt. Wir folgen ihm Richtung talauswärts und gelangen zunächst zur Terrassensiedlung Nr. $45^{\circ}$ in $925 \mathrm{~m}$ Höhe, dann zum Weiler Moos (Nr. 46) in $905 \mathrm{~m}$ Höhe, der den gleichen Siedlungstypus darstellt. Ueber diesem Weiler, wieder auf einer Terrasse, die zum Burgfluhniveau zu rechnen ist, liegt das Bauerngut Oberberg (Nr. 47) in $975 \mathrm{~m}$ Höhe. Der Talhang wird erneut durch eine Bachrunse zerschnitten, die oberhalb Oberberg teilweise schluchtartigen Charakter annimmt. Sie wird überschritten, und im Abstieg nach Thal geht man an der Terrassensiedlung Nr. 48 in 915 m Höhe vorbei. Dreißig Meter tiefer breitet sich der genannte Weiler (Nr. 49) auf einer zum Kirchetniveau gehörenden Terrasse aus. Von hier hebt sich die Kurve ein letztes Mal zu den Siedlungen von Winklen (Nr. 50 und 51) in $915 \mathrm{~m}$ Höhe empor, um dann über 
den Weiler Allmenden (Nr. 52), der auf einer zum Kirchetniveau zählenden Terrasse in einer durchschnittlichen Höhe von $850 \mathrm{~m}$ erbaut worden ist, zu den obersten Heimwesen der Schuttkegelsiedlung Latterbach (Nr. 53) abzusinken. Dieses Dorf steht auf einem der Wyler bzw. Erlenbachterrasse aufgesetzten Schuttfächer. Die zwei letzten Siedlungen (54 und 55) talauswärts liegen auf einer sich lang hinziehenden Terrasse, die dem gleichen System angehört, in $680 \mathrm{~m}$ Höhe.

Auf der ganzen Strecke von Sulzi bis Außerlatterbach wird die obere Grenze der Dauersiedlungen durch die orographischen Verhältnisse bestimmt. Ueberall beginnt der Talhang in geringer Entfernung von den Siedlungen infolge des Auftretens von Kalkgesteinen eine so starke Neigung anzunehmen, daß die Dauersiedlungen fern bleiben. An vielen Orten, aber ganz besonders bei Außerlatterbach streben $150-200 \mathrm{~m}$ hohe Kalkflühe und Felswände empor.

Die Wasserversorgung der linksseitigen Siedlungen zeigt, daß wir uns nahe von Kalkzonen befinden. Entspringen die Quellen, die für die einzelne Dauersiedlung genügend Wasser liefern, am nördlich geneigten Talhang durchschnittlich $50 \mathrm{~m}$ bis $150 \mathrm{~m}$ vom Wohnhaus entfernt, so muß hier die Wasserfassung oft 300-1000 m weit weg erfolgen, um eine Quelle mit einem beständig genügenden Ausfluß zu besitzen. Die Bewohner von Außerlatterbach haben sich der Wasserversorgung von Latterbach angeschlossen, weil ihre Quellen den Bedarf in Trockenzeiten nicht zu befriedigen vermögen.

\section{Ergebnisse für die Dauersiedlungen}

a) Die Siedlungslagen

Im Niedersimmental bilden 37 Terrassen-, 8 Hang-, 8 Schuttkegel-, 1 Egg- und 1 Muldensiedlung die Punkte, die den Verlauf der obern Grenze der Dauersiedlungen festlegen. Diese Angaben vermitteln insofern ein ungenaues Bild, weil die Dörfer und Weiler jeweils als eine Siedlung gerechnet worden sind. Hätten wir jedes einzelne Haus darin gezählt, so würden die Terrassensiedlungen noch mehr überwiegen.

Die Siedlungen sind in diesem Talabschnitt ausschließlich auf Flysch, Glazialdepot, Schuttkegeln und Liasmergeln entstanden. Die Kalkzonen werden der Steilheit ihrer Hänge, der Felsköpfe und Felswände, der magern Ackerkrume und ihres Wassermangels wegen durchgehend gemieden. Die Wohnhäuser sind bei jeder Witterung erreichbar, weil sie verhältnismäßig nahe der Talsohle bleiben.

\section{b) Die Siedlungsarten}

Die Schattseite zeigt fast ausnahmslos die Einzelhofsiedlung. Diese gibt überall die Grenzpunkte für die Höhenkurve. Auf der Sonnseite dagegen liegen oft stattliche Dörfer und Weiler, wie Waldried, Oberwil, Nitfluh, Balzenberg, Eschlen, Allmenden und Latterbach, an der obern Grenze der Dauersiedlungen.

c) Mittlere Höhengrenze

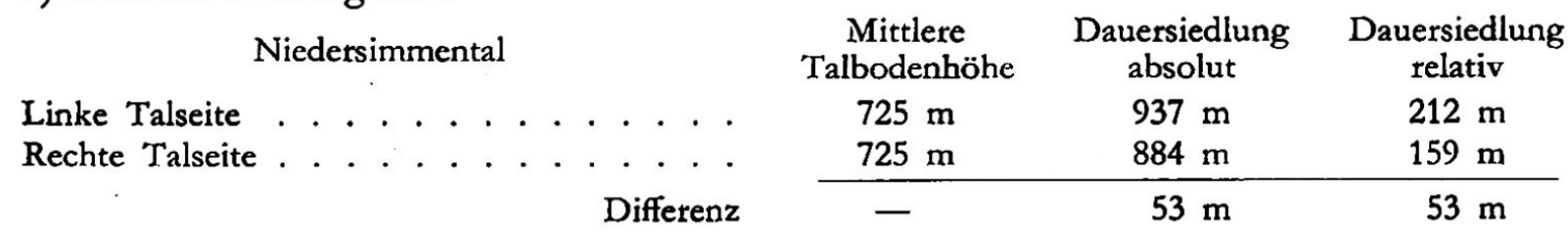

Wie erwartet, weist die linke Talflanke als Sonnseite den größeren, mittleren Höhenwert auf als die rechte. Diese Tatsache wird im allgemeinen bestätigt, wienn wir die Höhenlagen der Dauersiedlungen nach Expositionen ordnen.

$\begin{array}{cccccccc}\text { NE } & \text { N } & \text { NW } & \text { W } & \text { SW } & \text { S } & \text { SE } & \text { E } \\ 915 & 861 & 1120 & - & 1000 & 934 & 957 & -\end{array}$


Die auffällig hohe Zahl der NW-Exposition stammt von der Dauersiedlung Längacker (Nr. 20), während der geringe Wert der Südexposition durch die Siedlungen bei Außerlatterbach bewirkt wird.

Jede Dauersiedlung ist so angelegt worden, daß sie an ihrem Standort ein Höchst$\mathrm{maß}$ an Sonneneinstrahlung empfängt.

Die höchstgelegene Siedlung des Niedersimmentales, nämlich Roßberg, findet sich überraschenderweise auf der Schattseite und nicht am besonnten, nach Süden geneigten Talhang. Dies ist hier ausschließlich auf die orographischen Bedingungen zurückzuführen, die der Dauersiedlung auf der Sonnseite ein Höhersteigen verwehren.

Die obere Grenze besteht nicht aus einer waagrecht verlaufenden Linie, sondern diese buchtet, ständig wechselnd, bald nach oben, bald nach unten aus, was in erster Linie durch die Bodengestalt bewirkt wird. Wo diese nicht zur Erklärung genügt, muß die Grenze der Dauersiedlungszone in landwirtschaftlichen Ursachen gesucht werden.

\section{d) Veränderungen in der obern Dauersiedlungsgrenze}

Wie bereits im Kapitel über die Bevölkerungsbewegung angetönt worden ist, werden wir kaum auf Wüstungen stoßen. Wir haben im Niedersimmental ein einziges verlassenes Wohnhaus an der obern Grenze der Dauersiedlungen gefunden. Es steht in Riedmad bei Weißenbach, ungefähr $20 \mathrm{~m}$ über dem heute dauernd bewohnten, obersten Wohnhaus und wird zu Speicherzwecken verwendet.

Ein Sinken der obern Grenze der Dauersiedlungen im Niedersimmental ist also nur an einer einzigen Stelle vorhanden, wobei diese aufgegebene Siedlung noch eine von den tiefstgelegenen ist.

\section{JV. DIE OBERE GRENZE DER DAUERSIEDLUNGEN IN DER}

\section{GEMEINDE DIEMTIGEN}

1. Die obere Grenze auf der rechten Talseite

Die Gemeinde Diemtigen umfaßt das ganze Diemtigtal und das rechte Simmeufer von der Burgfluh bis und mit Oey. Sie ist mit $131 \mathrm{~km}^{2}$ flächenmäßig die größte Gemeinde der ganzen Talschaft. Den Beginn der Dauersiedlungskurve haben wir unmittelbar hinter der Burgfluh gewählt, trotzdem die Siedlung Burgholz noch zur Gemeinde Wimmis gehört. Die zwei Wohnhäuser liegen auf dem Schuttkegel des Staldengrabens in $685 \mathrm{~m}$ Höhe. Talaufwärts, ungefähr $2 \mathrm{~km}$ entfernt, stehen die mit den $\mathrm{Nr} .1$ und 2 bezeichneten Höfe der Gemeinde Diemtigen auf einer Terrasse in $690 \mathrm{~m}$ Höhe. Die Terrasse fällt mit steiler Böschung gegen den heutigen Talboden ab. Sie entspricht derjenigen von Außerlatterbach und gehört daher zum Wyler bzw. Erlenbachniveau. Der Boden ist hier mit Gletscherschutt überkleistert. Es sei erwähnt, daß an der Südmauer des Hauses Nr. 1 Reben gezogen werden, deren Früchte reifen, was beweist, wie klimatisch begünstigt das Niedersimmental ist.

Die Häusergruppe Nr. 3, gebildet aus drei Heimwesen, ist eine Terrassensiedlung in $720 \mathrm{~m}$ Höhe in Nordexposition. Hasli (Nr. 4), bestehend aus 4 Bauernhöfen, gehört dem gleichen Typus an und liegt in $760 \mathrm{~m}$ Höhe. Beide Siedlungen haben eine gemeinsame Brunnenstube, die $30 \mathrm{~m}$ oberhalb Hasli erstellt worden ist und die von einer Quelle, die unterhalb Zäunegg entspringt, gespiesen wird.

Um zu den Siedlungen auf Zäunegg (Nr. 5 und 6) zu gelangen, ist ein mit Wald bestandener Steilhang, der auf die hier auftretenden Radiolarite zurückzuführen ist: zu überwinden. Die drei Wohnhäuser stehen auf der unruhig geformten Terrasse auf wallartigen, niedrigen Erhebungen. Der Boden und die morphologische Form deuten auf Glazialdepot hin. Die Terrasse breitet sich in $845 \mathrm{~m}$ Höhe aus. 
Oestlich davon, auf dem Schuttkegel des Höllengrabens, befindet sich in $855 \mathrm{~m}$ Höhe das Gut Lochmatte (Nr. 7).

Bei diesen Siedlungen treten die Quellen, die für die Wasserversorgung benützt werden, 100 bis $200 \mathrm{~m}$ vom Wohnhaus entfernt aus.

Die erwähnten Bauerngüter liegen an der Nordabdachung der Niesenkette und somit auf der Schattseite des Haupttales. Ihre klimatischen Verhältnisse sind deshalb etwas verschieden von denen der Sonnseite. Der Schnee bleibt hier länger, so daß die winterlichen Fröste nicht unmittelbar auf den Boden einwirken. Im Frühling erfährt dieser Talhang durch den schmelzenden Schnee auch eine bessere Durchfeuchtung.

Die Siedlungen der Bäuerten Riedern, Horben und Bächlen breiten sich nicht mehr am eigentlichen Nordhang aus, sondern erhalten durch das Einschwenken der Niesenkette nach Süden eine Nordwest- bis Westlage. Die nach Norden gerichtete Abdachung der Niesenkette ist in den großen Zügen in der besiedelten Zone ruhig, im einzelnen jedoch sehr unruhig gestaltet. Morphologisch tritt in diesen Partien nur die von Riedern über Horben nach Bächlen verlaufende Terrasse hervor. Bereits BorNHAusER hat in seiner geologischen Arbeit über die Niesenkette darauf hingewiesen, daß diese Terrasse, die sich in 900 bis $1000 \mathrm{~m}$ Höhe erstreckt, als der Ueberrest eines ehemaligen Talbodens zu betrachten sei $(4,112)$. Diese Terrasse setzt sich über Rothbad bis zur Oertlichkeit Moos (1090 m) fort und trägt einen Teil der Höfe, die hier die obere Grenze bestimmen. Dieser Terrassenzug kann dem Burgfluhniveau eingeordnet werden.

Das von den Dauersiedlungen eingenommene Gebiet ist im übrigen durchsetzt von größeren und kleineren Terrassen, von Eggen, Mulden, Verflachungen und Buckeln. Die Abdachung wird zudem, wie bereits früher ausgeführt, von zahlreichen Bachgräben . zerschnitten.

Weil hervorstechende, orographische Merkmale fehlen, können die obersten Dauersiedlungen der Bäuerten Bächlen, Horben und Riedern in einer Tabelle wiedergegeben werden.

\begin{tabular}{|c|c|c|c|c|c|}
\hline $\begin{array}{l}\text { Siedlung } \\
\text { Nr. }\end{array}$ & Oertlichkeit & $\begin{array}{l}\text { Morphologische } \\
\text { Siedlungslage }\end{array}$ & $\begin{array}{l}\text { Höhe } \\
\text { über Meer }\end{array}$ & Exposition & $\begin{array}{l}\text { Relative Höhe } \\
\text { ca. }\end{array}$ \\
\hline 8 & - & Terrasse & $890 \mathrm{~m}$ & NW & $195 \mathrm{~m}$ \\
\hline 9 & Vechismad & Terrasse & $880 \mathrm{~m}$ & NW & $185 \mathrm{~m}$ \\
\hline 10 & Vechismad & Terrasse & $880 \mathrm{~m}$ & NW & $185 \mathrm{~m}$ \\
\hline 11 & Vechismad. & Egg & $925 \mathrm{~m}$ & NW & $205 \mathrm{~m}$ \\
\hline 12 & Vechismad & Terrasse & $905 \mathrm{~m}$ & NW & $195 \mathrm{~m}$ \\
\hline 13 & - & Terrasse & $930 \mathrm{~m}$ & NW & $210 \mathrm{~m}$ \\
\hline 14 & Buchacker & Terrasse & $945 \mathrm{~m}$ & NW & $205 \mathrm{~m}$ \\
\hline 15 & Löh & Terrasse & $985 \mathrm{~m}$ & NW & $230 \mathrm{~m}$ \\
\hline 16 & Sagi & 'Terrasse & $1020 \mathrm{~m}$ & NW & $240 \mathrm{~m}$ \\
\hline 17 & Widacker & Terrasse & $1040 \mathrm{~m}$ & NW & $240 \mathrm{~m}$ \\
\hline 18 & Rüti & Terrasse & $1060 \mathrm{~m}$ & NW & $260 \mathrm{~m}$ \\
\hline 19 & Bodenmatte & Terrasse & $1045 \mathrm{~m}$ & NW & $245 \mathrm{~m}$ \\
\hline 20 & Bodenmatte & Eigg & $1020 \mathrm{~m}$ & NW & $220 \mathrm{~m}$ \\
\hline 21 & Winklen & Hang & $1040 \mathrm{~m}$ & NW & $240 \mathrm{~m}$ \\
\hline 22 & Walkenmatte & Terrasse & $1020 \mathrm{~m}$ & NW & $170 \mathrm{~m}$ \\
\hline 23 & - & Egg & $1140 \mathrm{~m}$ & NW & $290 \mathrm{~m}$ \\
\hline 24 & Egg & Egg & $1175 \mathrm{~m}$ & NW & $275 \mathrm{~m}$ \\
\hline 25 & Springboden & Terrasse & $1335 \mathrm{~m}$ & NW & $415 \mathrm{~m}$ \\
\hline 26 & Halten & Egg & $1220 \mathrm{~m}$ & NW & $290 \mathrm{~m}$ \\
\hline 27 & - & Terrasse & $1170 \mathrm{~m}$ & NW & $240 \mathrm{~m}$ \\
\hline 28 & - & Hang & $1155 \mathrm{~m}$ & NW & $225 \mathrm{~m}$ \\
\hline 29 & Schlipfenplatten & Mulde & $1165 \mathrm{~m}$ & NW. & $235 \mathrm{~m}$ \\
\hline 30 & Hubel & Terrasse & $1160 \mathrm{~m}$ & NW & $170 \mathrm{~m}$ \\
\hline 31 & Pletschen & Hang & $1175 \mathrm{~m}$ & NW & $155 \mathrm{~m}$ \\
\hline 32 & Pletschen & Terrasse & $1180 \mathrm{~m}$ & NW & $160 \mathrm{~m}$ \\
\hline
\end{tabular}


Die Wasserversorgung geschieht nur bei den Siedlungen Bodenmatte (Nr. 19) und Pletschen (Nr. 31, 32) genossenschaftlich. Alle übrigen haben eigene Quellen. Bei diesen schwankt die Entfernung der Quelle vom Wohnhaus durchschnittlich zwischen 100 bis $150 \mathrm{~m}$; bei jenen ist sie, weil sie ergiebigere Quellen beanspruchen, auf $600 \mathrm{bzw}$. über $1 \mathrm{~km}$ angewachsen.

Vom Hof Löh (Nr. 15) bis zur Siedlung Walkenmatte (Nr. 22) verharrt die Siedlungskurve in ungefähr der gleichen Höhe. Es ist das vordere Stück des von BorNHAuSER erwähnten Terrassenzuges. Nachher schnellt die Grenze plötzlich um $120 \mathrm{~m}$ hinauf und zeigt kein gleichmäßiges Ansteigen mehr, auch dann nicht, wenn der Extremfall des Springbodens (Nr. 25) ausgeschaltet wird.

Von Pletschen senkt sich die Kurve ins Kireltal, wo vor der Einmündung des Pletschenbaches in den Kirel das oberste Heimwesen (Nr. 33) wenig über dem Flußbett auf einer schmalen Terrasse in $1050 \mathrm{~m}$ liegt. Es besitzt Westexposition.

Die Nr. 34 bezeichnet die Streusiedlung Entschwil, die sich auf einer großen Terrasse ausbreitet. Zwei Einzelhöfe stehen am Abhang des Kienberges gegen das Kirel-

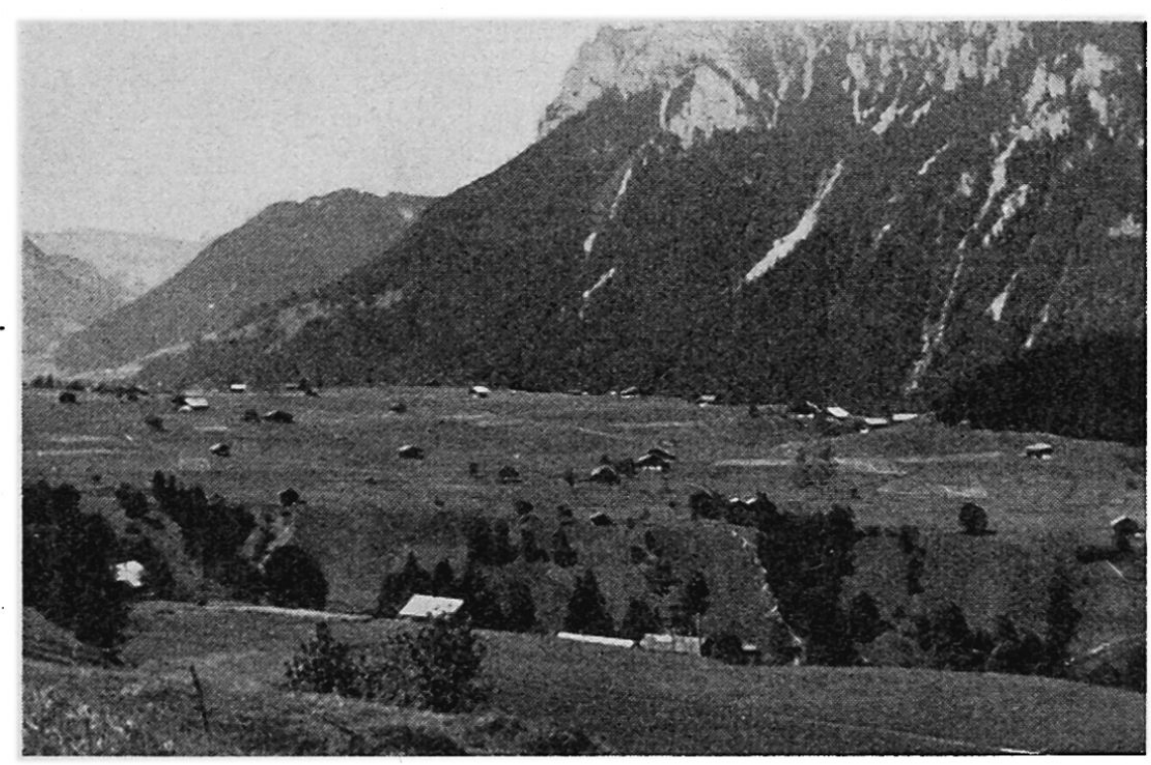

Abb.1. Terrasse v. Entschwil mit Abhang zum Kirelgraben. Im Vordergrund die Terrasse von Moos mit der gleichen Höhenlage wie die von Entschwil. Beide Terrassen gehören dem Burgfluhniveau an. (Photo P. Köchli) tal (Nr. 35, 36). Die tiefstgelegene Siedlung ist die Hangsiedlung $\mathrm{Nr} .36$ in $1000 \mathrm{~m}$ Höhe; die Hauptsiedlung weist einen Durchschnitt von $1090 \mathrm{~m}$ auf, und die oberste, im Unterberg, erreicht die Höhenkurve von 1110 m. Die Wasserversorgung von Entschwil ist genossenschaftlich organisiert, und das Wasser wird aus ungefähr $4 \mathrm{~km}$ Entfernung aus dem Kirelgraben hergeleitet. Das Haus Nr. 37 steht westlich Entschwil in $1125 \mathrm{~m}$

Höhe und gehört dem Typus der Hangsiedlungen an. Die Terrasse von Entschwil setzt sich bald als breitere, bald als schmälere Leiste, auf der ein Fußweg verläuft, bis zum Schuttkegel von Ennetkirel fort, in dem sie sich dann verliert. Ennetkirel besteht aus vier Wohnhäusern (Nr. 38 bis 41), die in $1100 \mathrm{~m}$, in $1050 \mathrm{~m}$ und in $1031 \mathrm{~m}$ Höhe liegen. Ihre Nordexposition bewirkt, daß die Fensterfronten nicht gegen das Diemtigtal blicken, sondern westwärts oder südwärts gegen den Hang.

Auf der rechten Talseite fehlen nun die Dauersiedlungen bis zur Tiermatte, weil die Abdachung der Hohmad gegen das Diemtigtal zufolge ihrer Steilheit siedlungsfeindlich ist. Tiermatten (Nr. 42) ist eine Schuttkegelsiedlung in $1070 \mathrm{~m}$ Höhe mit Westexposition. Der auf der linken Talseite steil aufragende Mäniggrat nimmt den tiefer gelegenen Heimwesen einen großen Teil der abendlichen Sonneneinstrahlung weg. Diese ungünstigen Besonnungsverhältnisse zwingen die Häuser, ihre Fensterfront gegen S oder $\mathrm{E}$ zu richten. Die Wasserversorgung funktioniert schlecht, so daß die Siedler in Trockenzeiten Wasser aus dem Bach holen. Die Quelle entspringt oben im Hängetal der Gurbs.

Die gleichen Verhältnisse weist auch das Heimgut Nr. 43 auf. 


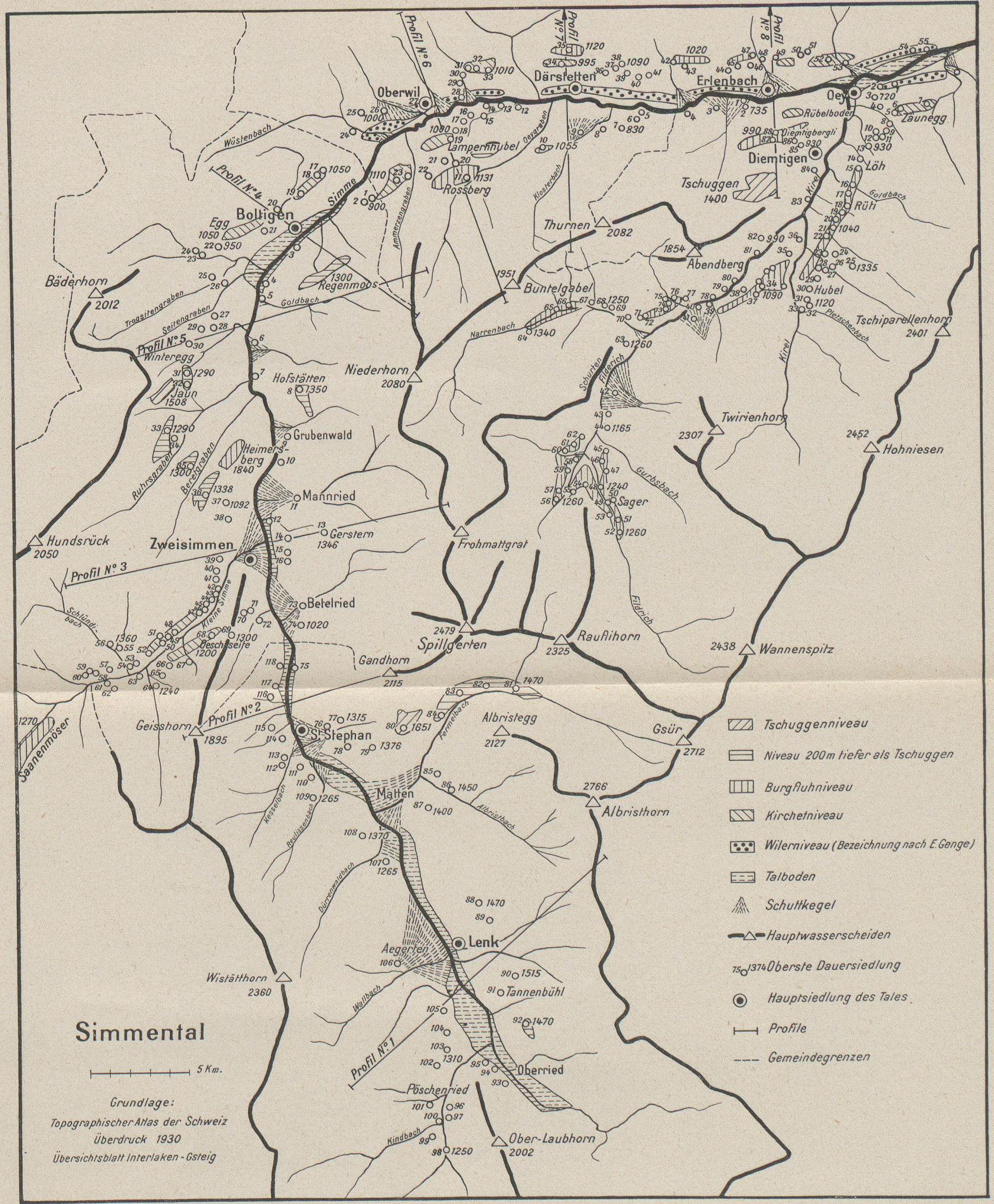

Kartenbeilage 
Schlatt (Nr. 44) ist eine Terrassensiedlung auf Glazialboden und erreicht die Höhenlinie von $1165 \mathrm{~m}$. Für seine Wasserversorgung ist es einer Genossenschaft von 28 Teilnehmern aus der Bäuert Schwenden angeschlossen, die ihre Quelle oben im Gurbs besitzt.

\section{Die obere Grenze im Talhintergrund}

Ein Kilometer oberhalb von Schlatt, nachdem sich der Gurbsbach in den Fildrich ergossen hat, wird das Tal durch den breiten Rücken des Stierengrimmis geteilt. Rechts dieses Rückens fließt der Fildrich, links der Grimmibach. Längs den Talhängen ziehen sich überall in ungefähr gleicher Höhe bald breitere, bald schmälere Terrassen hin. Ohne Zweifel handelt es sich um die Ueberreste eines ehemaligen Talbodens, die wir dem Burgfluhniveau zugeteilt haben. Auf diesem Terrassenzug liegt nun eine stattliche Anzahl von Einzelhöfen, deren Merkmale anschließend in einer Tabelle angegeben werden. Die Nummern 45 bis 52 sind rechts des Fildrichs, dann geht die Kurve über ihn hinüber und zieht sich nach der Egg (Nr. 54) hin, die auf dem Ausläufer des Rückens des Stierengrimmis erbaut worden ist; von da verläuft sie in südlicher Richtung am Westhang dieses Rückens, um bei Senggi den Grimmibach zu schneiden und nun talauswärts umzubiegen.

\begin{tabular}{|c|c|c|c|c|c|}
\hline $\begin{array}{l}\text { Haus } \\
\text { Nr. }\end{array}$ & Oertlichkeit & $\begin{array}{l}\text { Morphologische } \\
\text { Siedlungslage }\end{array}$ & $\begin{array}{c}\text { Höhe } \\
\text { über Meer }\end{array}$ & Exposition & $\begin{array}{l}\text { Relative Höhe } \\
\text { ca. }\end{array}$ \\
\hline 45 & Hutten. & Terrasse & $1240 \mathrm{~m}$ & W & $70 \mathrm{~m}$ \\
\hline 46 & - & Terrasse & $1220 \mathrm{~m}$ & W & $50 \mathrm{~m}$ \\
\hline 47 & Warttannen & Terrasse & $1210 \mathrm{~m}$ & W & $40 \mathrm{~m}$ \\
\hline 48 & Giebelegg & Terrasse & $1240 \mathrm{~m}$ & $\mathbf{W}$ & $40 \mathrm{~m}$ \\
\hline 49 & Sager & Terrasse & $1250 \mathrm{~m}$ & $\mathbb{W}$ & $20 \mathrm{~m}$ \\
\hline 50 & Sager & Terrasse & $1250 \mathrm{~m}$ & W & $20 \mathrm{~m}$ \\
\hline 51 & Grunholz & Terrasse & $1260 \mathrm{~m}$ & W & $25 \mathrm{~m}$ \\
\hline 52 & Grunholz & Terrasse & $1260 \mathrm{~m}$ & W & $20 \mathrm{~m}$ \\
\hline 53 & Grunholz & Terrassc & $1260 \mathrm{~m}$ & $\mathrm{E}$ & $20 \mathrm{~m}$ \\
\hline 54 & Egg & Terrasse & $1250 \mathrm{~m}$ & $\mathbf{N}$ & $40 \mathrm{~m}$ \\
\hline 55 & Senggi & Terrasse & $1250 \mathrm{~m}$ & W & $25 \mathrm{~m}$ \\
\hline 56 & Senggi & Terrasse & $1250 \mathrm{~m}$ & $\mathrm{E}$ & $20 \mathrm{~m}$ \\
\hline 57 & Senggi & Terrasse & $1250 \mathrm{~m}$ & $\mathrm{E}$ & $20 \mathrm{~m}$ \\
\hline 58 & - & Schuttkegel & $1180 \mathrm{~m}$ & $\mathrm{E}$ & -- \\
\hline 59 & - & Egg & $1250 \mathrm{~m}$ & $\mathrm{E}$ & $80 \mathrm{~m}$ \\
\hline 60 & Schlunegg & Terrasse & $1230 \mathrm{~m}$ & SE & $60 \mathrm{~m}$ \\
\hline 61 & Schlunegg & Terrasse & $1230 \mathrm{~m}$ & E & $60 \mathrm{~m}$ \\
\hline 62 & Schlunegg & Terrasse & $1200 \mathrm{~m}$ & $\mathrm{E}$ & $40 \mathrm{~m}$ \\
\hline
\end{tabular}

Sämtliche Siedlungen, mit Ausnahme von Nr. 58, liegen auf Glazialdepot.

3. Die obere Grenze auf der linken Talseite

Talauswärts ragt links des Fildrichs schroff die Wand des Mäniggrates empor. Erst beim Weiler Narrenbach, wo sich der Mäniggrat stark senkt und schließlich in den nach Norden gerichteten Hang des Mäniggrundes mündet, erhebt sich auf einer großen, vorspringenden Egg der Einzelhof Nr. 63 in 1160 m Höhe oder 120 m über dem Talboden in Ostexposition.

Von hier aus steigt die Kurve unmittelbar in den Mäniggrund hinauf. Die oberste Dauersiedlung befindet sich hier in der Halbstierenweid in $1340 \mathrm{~m}$ Höhe auf der Schattseite. Infolge der dort schwachen Neigung des Bodens und des Zurückweichens des rückwärtigen Hanges ist die Besonnung noch so günstig, daß es die einzige Stelle im Mäniggrund ist, wo auf der Schattseite Heu gewonnen wird. Sonst ist die ganze Nordabdachung Weide- und Waldgebiet. 
Die Häuser Nr. 65 und 66 stehen auf der Sonnseite des Mäniggrundes auf kleinen Schuttkegeln. Sie erheben sich nur wenig über den Talboden, in dem der Narrenbach fließt. Alle drei Wohnstätten erhalten das Quellwasser vom Näßli. Die Höhenlage beträgt $1280 \mathrm{~m}$.

Talauswärts folgt auf einer kleinen Egg die Siedlung Rain (Nr. 67) in $1270 \mathrm{~m}$ Höhe. Flysch bildet hier die Unterlage. Etwas tiefer liegt die Siedlung Schwand (Nr. 68, 69). Sie gehören zum Typus der Terrassensiedlungen und haben Südexposition.

Die Heimwesen von Hasli, Brunnen und Geißegg sind auf einer zum Burgfluhsystem gehörenden Terrasse erbaut worden. Die Wohnhäuser (Nr. 70 bis 76) liegen zwischen 1160 und $1120 \mathrm{~m}$ Höhe in Südexposition und beziehen ihr Wasser aus einer Quelle der Hegiweid, die der Wasserversorgungsgenossenschaft von Tschuepis gehört. Das Haus Nr. $77(1110 \mathrm{~m})$ zählt noch zur Geißegg, ist aber eine Hangsiedlung, weil die Terrasse vorher geendet hat.

Nun wird die Südflanke des Diemtigtales sehr siedlungsfeindlich. Die aus Malm und Trias gebildeten Kalkflühe des Abendberges streben in geringem Abstande vom Fildrich empor. Der Siedlung bleibt daher nur ein relativ schmaler Geländestreifen, der bald als Talboden, bald als die untersten, ansteigenden Gehängepartien ausgebildet ist. Die meisten Niederlassungen besitzen ihre Quelle auf der nach Norden gerichteten Talseite und leiten das Wasser über den Bach zum Wohnhaus hin. Diejenigen Höfe, die ihre Quelle auf der Sonnseite haben, leiden in Trockenzeiten an Wassermangel.

$\begin{array}{ccccccc}\text { Haus } & \text { Oertlichkeit } & \begin{array}{c}\text { Morphologische } \\ \text { Siedlungslage }\end{array} & \begin{array}{c}\text { Höhe } \\ \text { über Meer }\end{array} & \text { Relative Höhe } & \text { Exposition } & \text { Quelle } \\ 78 & \text { Riedli } & \text { Terrasse } & 1010 \mathrm{~m} & 5 \mathrm{~m} & \text { SE } & \text { N.-Seite } \\ 79 & \text { Riedli } & \text { Terrasse } & 1015 \mathrm{~m} & 25 \mathrm{~m} & \text { SE } & \text { S.-Seite } \\ 80 & - & \text { Terrasse } & 1010 \mathrm{~m} & 20 \mathrm{~m} & \text { SE } & \text { S.-Seite } \\ 81 & \text { Wampflen } & \text { Terrasse } & 930 \mathrm{~m} & 10 \mathrm{~m} & \text { SE } & \text { N.-Seite } \\ 82 & \text { Eggetli } & \text { Egg } & 990 \mathrm{~m} & 70 \mathrm{~m} & \text { SE } & \text { S.-Seite } \\ 83 & \text { Loch } & \text { Talboden } & 800 \mathrm{~m} & - & \text { SE } & \text { N.-Seite }\end{array}$

Von der Siedlung Loch springt die obere Grenze hinauf zum Bauernhof Emmit (Nr. 84) in $880 \mathrm{~m}$ Höhe. Es ist eine Terrassensiedlung mit Südostexposition. Wir lassen Diemtigen rechts liegen und steigen zum Diemtighubel hinauf. Dort finden sich einige Hofsiedlungen. Das Haus Nr. 85 ist eine Eggsiedlung in einer Höhe von 930 m. Das nächste Heimwesen, Nr. 86, steht auf einer schwach geneigten Terrasse in $960 \mathrm{~m}$ Höhe.

Die zwei Bauernhöfe auf dem Diemtigbergli $(\mathrm{Nr} .87,88)$ sind bereits am Nordhang, der gegen das Niedersimmental abfällt. Sie befinden sich in $1000 \mathrm{~m}$ bzw. in $991 \mathrm{~m}$. Höhe. Für die Wasserversorgung von Diemtigen, Diemtighubel und Diemtigbergli besteht eine Genossenschaft, die eine Brunnstube in $1030 \mathrm{~m}$ Höhe besitzt.

\section{Ergebnisse für die Dauersiedlungen}

Sie lauten für das Diemtigtal:

a) Die Siedlungslagen

An der obern Grenze der Dauersiedlungen sind hier 57 Terrassen-, 11 Schuttkegel-, 10. Egg-, 6 Hang-, 4 Talbodensiedlungen und eine Muldensiedlung vorhanden. Die Terrassensiedlungen überwiegen weitaus in dieser Gemeinde. Auffallend sind die zahlreichen Schuttkegelsiedlungen, die darauf hindeuten, daß an etlichen Orten die obere Grenze der Dauersiedlungen nahe an den Talboden herangerückt ist.

Im Diemtigtal ruhen die Siedlungen auf Glazialdepot, Niesenflysch, Schuttkegelmaterial und an einigen wenigen Stellen auf Flysch. Ueberall aber wird die Kalkzone und der Gehängeschuttstreifen am Fuße der Kalkflühe gemieden. Die Gründe dafür sind bereits in den Ergebnissen des Niedersimmentales angegeben worden. 


\section{b) Die Siedlungsarten}

Im Diemtigtal sind nur zwei Dörfer, nämlich Oey und Diemtigen, und zwei Weiler, Bächlen und Wattfluh, zu finden. Alles andere ist zerstreut angeordnete Einzelhofsiedlung. Die obere Grenze wird überall durch solche Heimwesen bestimmt.

\section{c) Mittlere Höhengrenzen}

Im morphologischen Ueberblick ist gezeigt worden, daß das Diemtigtal in vier Abschnitte eingeteilt werden muß. So kann folglich nicht ein Mittelwert für das ganze Tal errechnet, sondern es müssen die Werte für die angegebenen Talabschnitte eingesetzt werden.

1. Abschnitt

Linke Talseite

Rechte Talseite.

2. Abschnitt

Linke Talseite . . . . . . . . . . . .

Rechte Talseite.

3. Abschnitt

Linke Talseite . . . . . . . . . . .

Rechte Talseite.

4. Mäniggrund

Linke Talseite . . . . . . . . . . .

Rechte Talseite.

Mittlere H
der Dauersied
$952 \mathrm{~m}$
$997 \mathrm{~m}$
$1061 \mathrm{~m}$
$1064 \mathrm{~m}$
$1223 \mathrm{~m}$
$1210 \mathrm{~m}$
$1280 \mathrm{~m}$
$1340 \mathrm{~m}$

Differenz zwischen linker und rechter Talseite

$45 \mathrm{~m}$

$3 \mathrm{~m}$

$13 \mathrm{~m}$

$60 \mathrm{~m}$

Die Höhe des Talbodens in den einzelnen Abschnitten und die Mittelwerte der relativen Höhe sind in der Schlußzusammenstellung auf Seite 59 angegeben. Es sei hier bloß vorausgeschickt, daß sich diese Werte für den vordersten Talabschnitt nicht verwenden lassen. Ein Beispiel möge dies erläutern. Hier beträgt der Höhenunterschied von der Einmündung des Kirels bis zur obersten Dauersiedlung im Kireltal rund $400 \mathrm{~m}$. Die durchschnittliche Talbodenhöhe berechnet sich auf $900 \mathrm{~m}$. Nehmen wir die Höfe auf dem Diemtigbergli, so lägen sie nach diesen Zahlen ungefähr $90 \mathrm{~m}$ über dem Talboden, im Gelände aber sind es $300 \mathrm{~m}$. Die mittlere Talbodenhöhe führt hier zu unrichtigen Vorstellungen und kann deshalb nicht gebraucht werden. Für die drei restlichen Talabschnitte lassen sich dagegen die Mittelwerte verwenden.

$\mathrm{Zu}$ der obenstehenden Tabelle ist zu bemerken, daß die Durchschnittszahlen für den zweiten Talabschnitt den Besiedlungsgang ungenau widerspiegeln. Der kleinere Wert des linken Talhanges, der Sonnseite, ist einzig auf orographische Verhältnisse zurückzuführen. Sobald Raum für die Niederlassungen da ist, wie in der Bäuert Oeyen, liegen die Heimwesen auf der Sonnseite höher oben als auf der Schattseite.

Ordnen wir die Ergebnisse für die Dauersiedlungen nach den Expositionen, so ergeben sich folgende Durchschnittswerte:

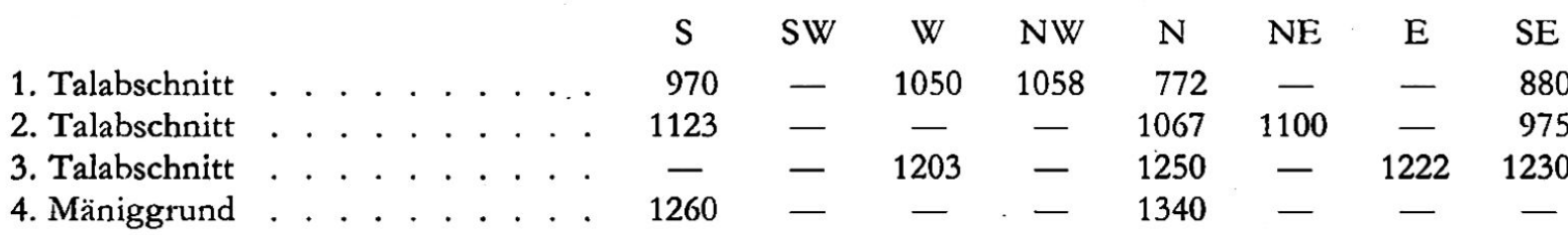

Im Diemtigtal steigt die Dauersiedlungsgrenze talaufwärts an. Diese Tatsache kann hier aber nicht mit der Massenerhebung erklärt werden, weil diese zu gering ist. Wie im wirtschaftlichen Teil gezeigt werden wird, befinden sich die Dauersiedlungen viel näher der obern Grenze des Ackerbaus als im vordern Diemtigtal. 


\section{d) Veränderungen der obern Grenze der Dauersiedlungen}

In den letzten Jahren sind im Diemtigtal nur zwei Bauernhöfe aufgegeben worden. Der eine ist jetzt eine Vorsaß und liegt in der Bäuert Riedern "Auf dem Hubel» in $1160 \mathrm{~m}$ Höhe. Es befinden sich heute dort noch zwei Dauersiedlungen, so daß kein Fallen der obern Grenzlinie stattgefunden hat. Der andere ist eine Wüstung bei Wampflen und hat auf der Bachegg gestanden und vor einigen Jahren den Besitzer gewechselt. Der ehemalige Besitzer ist ausgewandert, und der neue benützt es nicht, weil er bereits einen eigenen Hof besitzt. Trotz dieser Wüstung ist die Kurve nicht gesunken; denn wenige Meter davon erhebt sich das Wohnhaus «Eggetli» in $990 \mathrm{~m}$ Höhe.

\section{DIE OBERE GRENZE DER DAUERSIEDLUNGEN IN DEN GEMEINDEN BOLTIGEN UND ZWEISIMMEN}

\section{Die obere Grenze auf der rechten Talseite}

Die ersten für die Untersuchung wichtigen Dauersiedlungen in der Gemeinde Boltigen sind Fuchshalten (Nr. 1) und Fürsteini (Nr. 2). Diese steht in $900 \mathrm{~m}$, jene in $960 \mathrm{~m}$ Höhe. Die beiden Wohnhäuser liegen auf der von Breiti im Niedersimmental herziehenden Terrasse. Diese senkt sich talaufwärts von $200 \mathrm{~m}$ auf $100 \mathrm{~m}$ über der Talsohle und verliert sich in der Richtung nach Mißlisboden im Hang.

Das Heimwesen Nr. 3, das sich in der ersten-Schleife der Fahrstraße von Boltigen nach Regenmoos befindet, ist eine Hangsiedlung in $880 \mathrm{~m}$ Höhe und nur $60 \mathrm{~m}$ über der Talsohle. In der südlich Boltigen einsetzenden Talkrümmung ist der rechte Talhang wenig gegliedert und so steil, daß er überall von Tannenwald bewachsen ist, der bis nahe an die Simme hinabreicht. Die Dauersiedlung Nr.4, die Häuser von Gryden (Nr. 5), von Klein-Weißenbach (Nr. 6) und von Senki (Nr. 7) liegen nur wenig über der Talsohle. Nr. 4 ist eine Talbodensiedlung, Nr. 5 und Nr. 6 sind Schuttkegelsiedlungen; während Nr. 7 dem Typus der Hangsiedlungen entspricht. Ihre Höhenlagen schwanken zwischen $835 \mathrm{~m}$ und $880 \mathrm{~m}$.

Von hier aus schnellt die obere Grenze auf die große Terrasse von Hofstätten (Nr. 8) hinauf, wo 5 Bauernhöfe in 1240 bis $1260 \mathrm{~m}$ ständig bewohnt sind. Ihre Lage ist außerordentlich günstig; denn sie ist nach SW gerichtet. Die Terrasse von Hofstätten wird gegen den Grubenwaldbruch hin schmäler, bricht dann am Tobel ab und setzt sich jenseits davon nicht mehr fort. An ihrer Stelle erscheint der hier über $850 \mathrm{~m}$ hohe, steil abfallende Berghang des Grubenwaldes. Deshalb sinkt die Kurve auf 946 m, zum Dörfchen Grubenwald (Nr. 9), hinab, das sich auf dem linken Schuttkegelteil des gleichnamigen Baches ausbreitet. Das Dörfchen ist vor Wildbachschuttüberführungen durch Wald geschützt. Nach einigen Angaben von Einheimischen soll sich das Tobel erst in den letzten 100 Jahren zum heutigen bedeutenden Wildbachgraben, der seinen Einzugstrichter ständig vergrößert, entwickelt haben.

Grubenwald besitzt westliche Exposition; denn das Simmental hat unmittelbar talabwärts die Krümmung beendigt und verläuft nun von $S$ nach $N$.

Die nächste Siedlung (Nr. 10) heißt «Im Loch». Es ist eine Talbodenniederlassung in $920 \mathrm{~m}$ Höhe. Ihr Name deutet darauf hin, daß sie in der Sonnenbestrahlung benachteiligt ist. Die Mittagssonne wird ihr durch einen vorspringenden, bewaldeten Geländesporn des Grubenwald-Waldes weggenommen. Jetzt weitet sich das Tal zum breiten Becken von Zweisimmen, das überall, mit Ausnahme der eigentlichen Talsohle, dicht besiedelt ist. Mannried (Nr. 11) ist eine Schuttkegelsiedlung, die sich beidseitig des in den Schuttfächer eingeschnittenen Bachbettes erstreckt. Die rechts gelegene Dorfseite ist stärker entwickelt als die linksseitige. Die Häuser sind hier gegen die Kegelspitze angelegt worden. Das oberste Haus des Dorfes steht in $1020 \mathrm{~m}$, der Dorfkern in $1000 \mathrm{~m}$ und die untersten Wohnstätten in $950 \mathrm{~m}$ Höhe. 


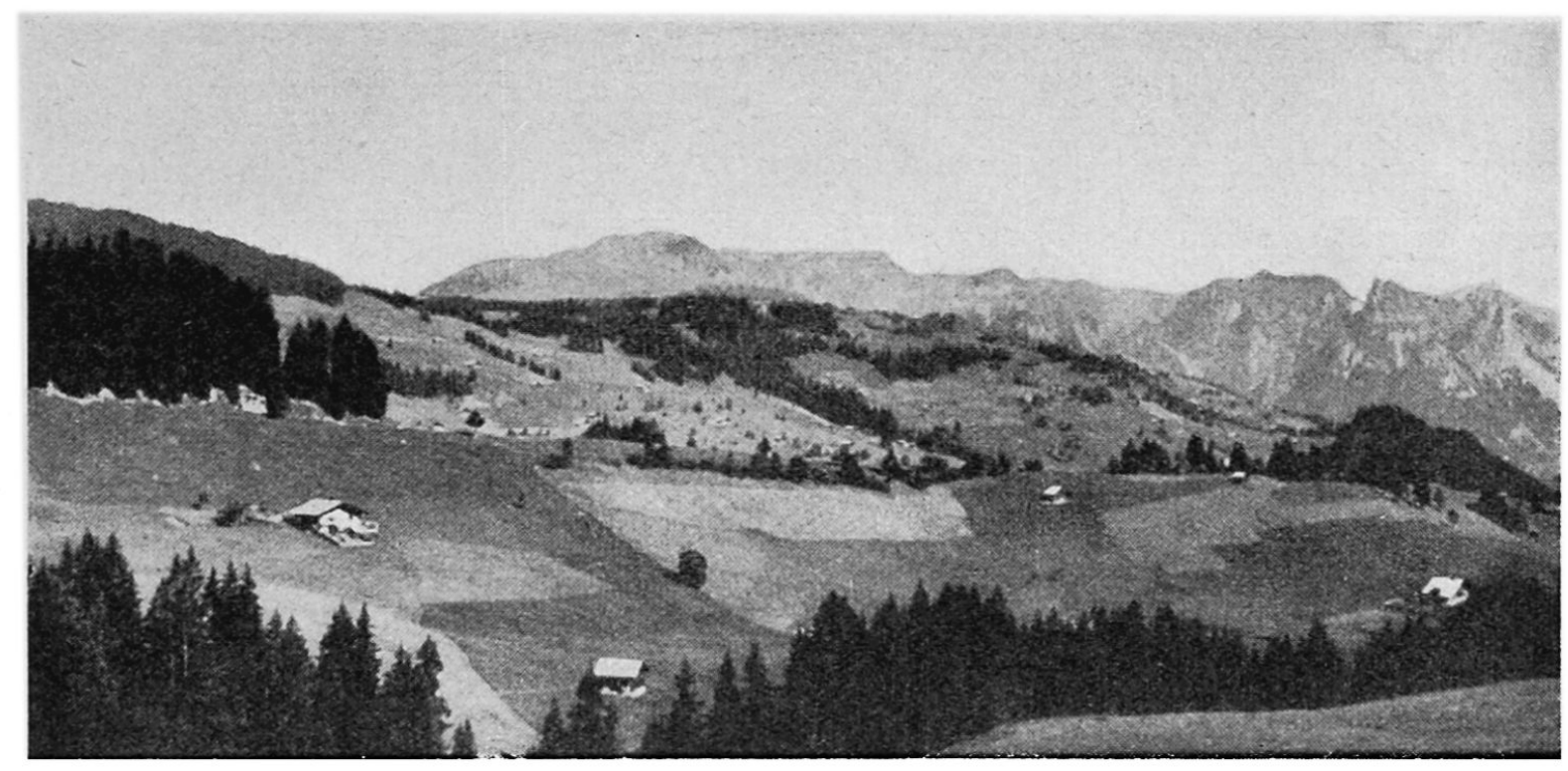

Abb. 2. Panorama des Jaunpaßgebietes. Aufgenommen "Auf den Eggen» ob Zweisimmen mit Blick gegen Norden. Im Hintergrund von links nach rechts: Bäderhorn, Krachihorn, Klushorn, Kienhorn, Mittagfluh. Im Abstieg vom Jaunpaß ins Simmental in der Mulde vor dem bewaldeten Hügel Bühl die Dauersiedlung Sommerau. Der lange Rücken im Vordergrund ist Beret mit den Siedlungen Saarweid und Zimmerboden. (Photo P. Köchli)

Der Schuttkegel von Mannried ist bereits der Terrasse aufgesetzt, die sich nachher in Richtung Egg fortsetzt. Eine gleich hoch liegende Terrasse, auf der Tüll und Bolgen stehen, erstreckt sich auf der gegenüberliegenden Talseite. Dieser Terrassenzug läßt sich in keines der erwähnten Terrassensysteme einordnen, so daß ihre Entstehung nicht mit den maßgebenden Zügen der Talbildung im Simmentảl erklärt werden kann.

Auf dieser Terrasse stehen in Westexposition als oberste Dauersiedlungen die Höfe Nr. 12 in 965 m; die von Oberried und Schlatt (Nr. 14, 15, 16) in 1030 m, 1010 m und $1020 \mathrm{~m}$ Höhe; Nr. 12 liegt unmittelbar südlich des Loosbächlis; Nr. 16 hat von allen den ungünstigsten Standort, weil sich unmittelbar dahinter der steil ansteigende Bettelriedwald bis auf $1364 \mathrm{~m}$ erhebt und dadurch der Siedlung viel Schatten gibt.

Hoch über der eigentlichen Dauersiedlungszone in $1346 \mathrm{~m}$ Höhe findet sich das Heimwesen "Gerstern» (Nr. 13), eine Terrassensiedlung, die nach $400 \mathrm{~m}$ Aufstieg erreicht wird. Es ist insofern ein Sonderfall, als diese Anordnung der Siedlungen erst in den Gemeinden St. Stephan und Lenk häufiger auftritt.

\section{Die obere Grenze auf der linken Talseite}

Die erste Siedlung nach der Amtsbezirkgrenze zwischen dem Niedersimmental und dem Obersimmental heißt Bettelegg (Nr. 17). Sie liegt in $1050 \mathrm{~m}$ Höhe oder ungefähr $250 \mathrm{~m}$ über der Talsohle in südöstlicher Lage. Unfern davon steht der Hof Nr. 18 mit derselben Höhe und Lage. Beide Bauernhöfe sind Hangsiedlungen. Anschließend folgt dann das Straßendörfchen Adlemsried (Nr. 19), das sich in einem ungefähr $1 \mathrm{~km}$ langen, schwach ausgeprägten und waagrecht verlaufenden Tälchen in $1040 \mathrm{~m}$ Höhe hinzieht. Von hier aus geht man in südlicher Richtung weiter, verliert einige Meter an Höhe und gelangt nach Taubenthal (Nr. 20), das in $960 \mathrm{~m}$ Höhe auf der rechten Seite des Baches, der das Tälchen von Adlemsried entwässert, in Ostexposition liegt. Bei Taubenthal biegt das erwähnte Tälchen rechtwinklig gegen das Haupttal um und mündet mit einer Stufe von ungefähr $140 \mathrm{~m}$ in dieses ein. 
Anschließend steigt das Gelände in westlicher Richtung bis zum Punkt 1082 an. Am Südhang dieser Erhebung ist das Wohnhaus Nr. 21 auf einer schmalen Terrasse in $970 \mathrm{~m}$ Höhe erbaut worden.

Dann öffnet sich das Tal des Reidenbaches in WNW-ESE-Richtung. $40 \mathrm{~m}$ über dem heutigen Bachbett scharen sich auf einer Terrasse die Häuser von Schwarzenmatt (Nr. 22) in $930 \mathrm{~m}$ Höhe. Der oberste Hof steht etwas abseits in $950 \mathrm{~m}$ unmittelbar unter dem Wald, der auf der Schutthalde der Portfluh wächst. Im Tälchen des Reidenbaches, der die Terrasse von Schwarzenmatt begrenzt, breiten sich dann noch die Heimstätten von Farni (Nr. 23, 24) aus. Sie werden durch einen Kalkfelsen, hinter dem sich eine Furche durchzieht, vor den von der Portfluh niederstürzenden Felstrümmern geschützt. Farni ist eine Terrassensiedlung mit Südexposition, wie Schwarzenmatt übrigens auch. Der Weiler steht in $990 \mathrm{~m}$ Höhe.

Von Schwarzenmatt bis Farni wird die obere Grenze der Dauersiedlungen durch die steil aufstrebenden Flanken der Schaffluh, der Mittagfluh, des Kienhorns und der Portfluh vorgezeichnet.

Westlich des Reidenbaches beginnt nun das ausgedehnte Flyschgebiet des Jaunpasses, in dem die Einzelhofsiedlung herrscht. Sie wird bedingt durch die im einzelnen unruhige Geländegestaltung. Charakteristisch für diese Gegend sind die vielen vorspringenden Rücken, zwischen denen sich Wildbachgräben, wie Sitengraben, Trogsiten-, Ruhrs- und Beretgraben, eingeschnitten haben. Die Siedlungen liegen größtenteils im obern Teil der Südostabdachung der Rücken, während der nach Nordwesten gerichtete Hang und die untern Partien der Wildbachgräben von Tannenwald bewachsen sind.

Die Merkmale der einzelnen Siedlungen können hier gut in einer Aufstellung wiedergegeben werden, weil die beigelegte Karte den Standort zeigt.

\begin{tabular}{|c|c|c|c|c|c|}
\hline $\begin{array}{l}\text { Haus } \\
\text { Nr. }\end{array}$ & Oertlichkeit & $\begin{array}{l}\text { Morphologische } \\
\text { Sicdlungslage }\end{array}$ & Exposition & $\begin{array}{l}\text { Höhe } \\
\text { über Meer }\end{array}$ & $\begin{array}{l}\text { Höhe über } \\
\text { dem Talboden }\end{array}$ \\
\hline 25 & Weid & Terrasse & SSE & $1030 \mathrm{~m}$ & $200 \mathrm{~m}$ \\
\hline 26 & Studmatt & 'Terrasse & E: & $965 \mathrm{~m}$ & $135 \mathrm{~m}$ \\
\hline 27 & Eschimatten & Terrasse & $\mathrm{E}$ & $1080 \mathrm{~m}$ & $240 \mathrm{~m}$ \\
\hline 28 & bei Eschiegy & Terrassc & E: & $1130 \mathrm{~m}$ & $290 \mathrm{~m}$ \\
\hline 29 & - & Hang & $\mathrm{E}$ & $1200 \mathrm{~m}$ & $360 \mathrm{~m}$ \\
\hline 30 & Husstocki & Terrasse & $\mathrm{E}$ & $1280 \mathrm{~m}$ & $430 \mathrm{~m}$ \\
\hline 31 & Sommerau & Terrasse & $\mathrm{E}$ & $1270 \mathrm{~m}$ & $400 \mathrm{~m}$ \\
\hline 32 & - & Terrasse & $\mathrm{E}$ & $1290 \mathrm{~m}$ & $420 \mathrm{~m}$ \\
\hline 33 & Ruhren & Terrasse & SE: & $1290 \mathrm{~m}$ & $390 \mathrm{~m}$ \\
\hline 34 & Ruhren & 'Terrassc & SE: & $1260 \mathrm{~m}$ & $360 \mathrm{~m}$ \\
\hline 35 & Saarweid & Terrasse & SE & $1300 \mathrm{~m}$ & $370 \mathrm{~m}$ \\
\hline 36 & Auf den Eggen & Terrasse & SE & $1.338 \mathrm{~m}$ & $408 \mathrm{~m}$ \\
\hline 37 & Riedwegen & Terrasse & ESE & $1092 \mathrm{~m}$ & $162 \mathrm{~m}$ \\
\hline 38 & Obegg & Terrassc & $E$ & $1071 \mathrm{~m}$ & $146 \mathrm{~m}$ \\
\hline 39 & Pfaffenmattc & Hang & $\mathrm{E}$ & $1050 \mathrm{~m}$ & $105 \mathrm{~m}$ \\
\hline 40 & - & Terrassc & $\mathrm{E}$ & $1050 \mathrm{~m}$ & $105 \mathrm{~m}$ \\
\hline
\end{tabular}

Die obere Grenze der Dauersiedlungen wird in diesem Abschnitt des Flyschgebietes durch wirtschaftliche und nicht durch orographische Bedingungen bestimmt.

\section{Die obere Grenze im Einzugsgebiet der Kleinen Simme}

Der Untergrund des Flühwaldes, der sich von Obegg an bis zur Einmündung des Schlündibaches in die Kleine Simme hinzieht, besteht aus Gesteinen der Simmendecke, die viel Kalk enthält. Diese Kalkgesteinszone setzt durchschnittlich $120-150 \mathrm{~m}$ über der Talsohle ein und bildet einen mit Flühen durchsetzten, stark geböschten Hang, der fast überall von dichtem Tannenwald bekleidet ist (Photo Nr. 3). 
An seinem untern Rand liegen die bereits erwähnten Siedlungen Nr. 38-40. Es folgt dann der auf einem kleinen Schuttkegel gelegene Weiler Mosenried in $1020 \mathrm{~m}$ Höhe mit Ostexposition (Nr. 41). Die nächsten sechs Siedlungen (Nr. 42-47) stehen in geringem Abstande links und rechts der Straße, die von Zweisimmen nach den Saanenmösern führt, am Abhang gegen die Kleine Simme zu auf schmalen Terrassen. Ihre Höhenlage beträgt $1010 \mathrm{~m}, 1010 \mathrm{~m}, 1025 \mathrm{~m}$, zweimal $1050 \mathrm{~m}$ und $1065 \mathrm{~m}$; ihre Exposition ist SE.

Anschließend springt die Kurve um $75 \mathrm{~m}$ hinauf und verläuft nun auf einer Leiste, die sich von Grubi bis Wärtli nach Vorderreichenstein hinzieht. Auf dieser Leiste kommen zahlreiche Einzelhöfe vor. Diese Leiste - die Bezeichnung ist im Sinne von LöwL angewandt - ergänzt sich mit den Terrassen von Oeschseite und Egg auf der gegenüberliegenden Talseite zu einem ehemaligen Talboden eines breiten V-förmigen Tales, in das sich die Kleine Simme in einem tiefen, schmalen Graben eingeschnitten hat.

Auf dieser Leiste sind die folgenden Siedlungen vorhanden:

$\begin{array}{cccccc}\begin{array}{c}\text { Haus } \\ \text { Nr. }\end{array} & \text { Oertlichkeit } & \begin{array}{c}\text { Morphologische } \\ \text { Siedlungsform }\end{array} & \text { Exposition } & \begin{array}{c}\text { Höhe } \\ \text { über Meer }\end{array} & \text { Relative Höhe } \\ 48 & \text { Grubi } & \text { Leiste } & \text { SE } & 1140 \mathrm{~m} & 80 \mathrm{~m} \\ 49 & \text { Grubi } & \text { Leiste } & \text { SE } & 1140 \mathrm{~m} & \\ 50 & - & \text { Leiste } & \text { SE } & 1140 \mathrm{~m} & \\ 51 & - & \text { Hang } & \text { SE } & 1170 \mathrm{~m} & \text { bis } \\ 52 & - & \text { Leiste } & \text { SE } & 1180 \mathrm{~m} & \\ 53 & \text { Vorderreichenstein } & \text { Leistc } & \text { SE } & 1185 \mathrm{~m} & \\ 54 & \text { Wärtli } & \text { Hang } & \text { S } & 1185 \mathrm{~m} & 120 \mathrm{~m}\end{array}$

Es sei erwähnt, daß bei den Heimwesen Nr. $45-51$ die Wasserversorgung den Bedürfnissen kaum zu genügen vermag, sobald eine längere Trockenzeit sich einstellt. Die Ursache ist die Kalkzone der Simmendecke.

Abseits des eigentlichen Siedlungsgebietes sind noch zwei Bauernhöfe anzutreffen, und zwar bei der Oertlichkeit Moos. Der erste Hof (Nr. 55) liegt $190 \mathrm{~m}$ über der Talsohle in $1320 \mathrm{~m}$ Höhe; der zweite (Nr. 56) $230 \mathrm{~m}$ über dem Talboden in $1360 \mathrm{~m}$ Höhe. Dieser hat bei südwestlicher Exposition Terrassenlage, jener blickt nach Westen und ist eine Hangsiedlung.

In der Richtung der Saanenmöser bestehen noch vier Wohnstätten auf dieser Talseite. Nr. 57 ist eine Terrassensiedlung in $1250 \mathrm{~m}$ Höhe; Nr. 58 eine Hangsiedlung in $1260 \mathrm{~m}$; Nr. 59 ist eine der seltenen Muldensiedlungen $(1290 \mathrm{~m})$, und Nr. 60 steht wieder auf einer Terrasse $(1280 \mathrm{~m})$. Alle vier Häuser haben südöstliche Lage.

Damit ist die Grenze des Amtsbezirkes Obersimmental erreicht, und es beginnt das Gebiet von Saanen. Die Siedlungen steigen mit der allgemeinen Hebung der Talsohle gegen die Saanenmöser hin noch etwas an, ohne aber extreme Werte zu erreichen. Die Dauersiedlung hört hier ungefähr $100 \mathrm{~m}$ über der Talsohle auf. Wir begeben uns nun auf die rechte Talseite und beginnen die Wanderung in Richtung Zweisimmen. Der erste, dauernd bewohnte Hof befindet sich hier auf der Wäflernweid (Nr. 61). Es ist eine Terrassensiedlung in $1180 \mathrm{~m}$ Höhe. An der Terrassensiedlung Nr. 62 in $1225 \mathrm{~m}$ Höhe vorbei, kommen wir zur Eggsiedlung "Auf der Egg» in $1160 \mathrm{~m}$ Höhe. Dann steigt die Kurve neuerdings bis zur Hangsiedlung Nr. 64 in $1240 \mathrm{~m}$ Höhe, um sich dann zum Weiler Oeschseite, dessen Häuser auf der bereits genannten Terrasse zerstreut liegen, zu senken. Die zwei obersten Höfe (Nr. 65, 66) erreichen die Höhenquote von $1210 \mathrm{~m}$. Sämtliche bis jetzt erwähnten Wohnhäuser der rechten Talseite haben trotz der NW-Exposition eine sonnige Lage, weil sie im Sommer aus E und W unge- 
hindert bestrahlt werden. Auch der rückwärtige Hang besitzt vorerst wenig Steilheit, so daß die Sonne sogar im Winter für kurze Zeit über den Rinderberg hinüber auf den Weiler scheint.

Oberhalb Oeschseite liegt die Muldensiedlung Schafmaad (Nr. 67) in $1290 \mathrm{~m}$ Höhe, wobei allerdings die Mulde nicht sehr ausgeprägt ist. Von hier aus senkt sich die Kurve langsam zur Terrasse von Weiermatten, die unterhalb Fang ausläuft. Auf dieser Terrasse steht die Dauersiedlung Nr. 68 in 1220 m Höhe.

Dann wölbt sich der Hang zum Rücken des Rinderberges, der gegen Zweisimmen abfällt. Auf dem breiten Rücken steht in Nordexposition das Gehöft "Fang» (Nr. 69) in $1300 \mathrm{~m}$ Höhe. $150 \mathrm{~m}$ tiefer, in der gleichen Lage, befindet sich die Terrassensiedlung Nr. 70. Etwas östlich davon, bereits an der Flanke gegen das Haupttal, erhebt sich die Hangsiedlung Nr. $71(1100 \mathrm{~m})$. Noch weiter hinuntersteigend, wird die Schuttkegel-

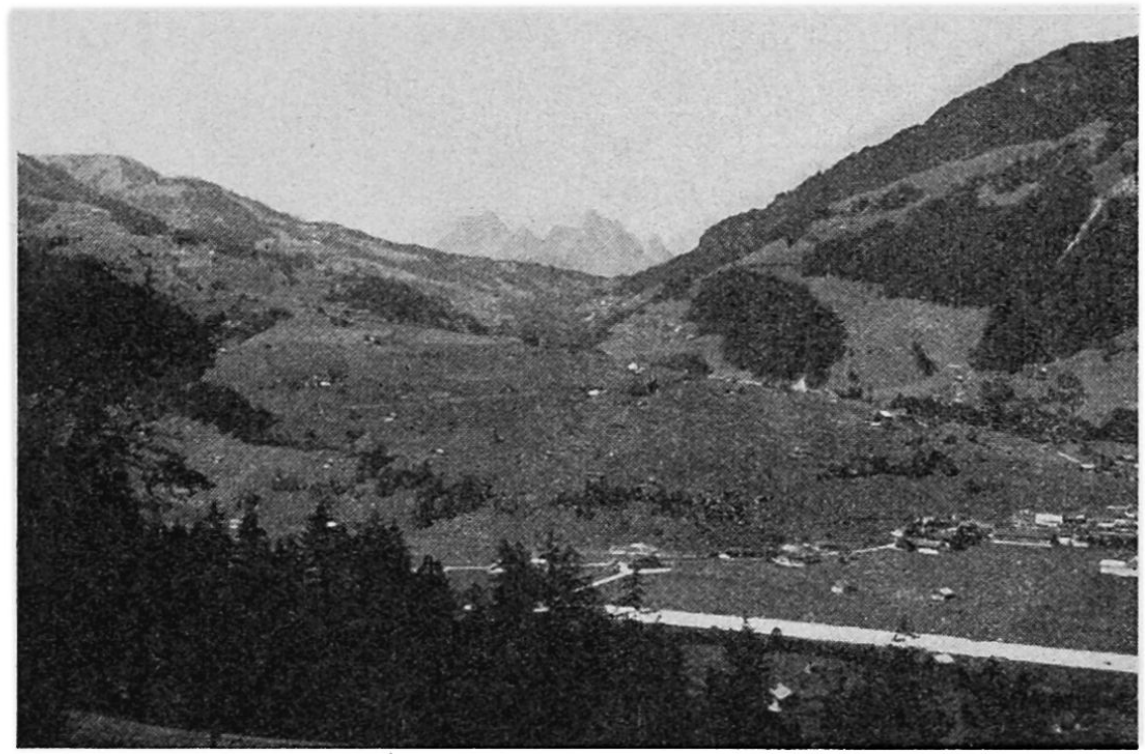

Abb. 3. Blick gegen den Rinderberg und die Saanenmöser, aufgenommen vom Aufstieg gegen Gerstern. Der breite Rücken des Rinderberges trägt Dauersiedlungen. Im Tal der Kleinen Simme ist die Terrasse von Oeschseite, die gegen die Saanenmöser ausläuft, sichtbar. Rechts Flühwald und darunter die obersten Dauersiedlungen in der gleichen Höhe wie die Terrasse von Oeschseite. (Photo P. Köchli) siedlung Moosbach (Nr. 72) in $960 \mathrm{~m}$ Höhe und SE-Exposition erreicht. Thre Lage ist ungünstig, weil die Lochfluh die Sonnenstrahlen aus westlicher Richtung auffängt.

Auf der andern Seite der Simme hat sich Bettelried (Nr. 73) auf dem Schuttkegel des Bettelriedbaches entwickelt. Die gesamte Siedlung steht rechts des Baches und gegen die Spitze des Schuttfächers hin, damit die ungünstige $\mathrm{Ex}-$ position möglichst verbessert werden kann. Diese wird durch die Nischenlage des Dorfes hervorgerufen, indem die steilen Gehänge des Maulenbergwaldes den Schuttkegel begrenzen und ihm einen großen Teil der Sonnenstrahlen enthalten. Die oberste Wohnstätte liegt in $1020 \mathrm{~m}$ Höhe bzw. $60 \mathrm{~m}$ über der Talsohle.

\section{Ergebnisse aus den Gemeinden Boltigen und Zweisimmen}

Die Einheitlichkeit des von den zwei Gemeinden erfaßten Gebietes erlaubt, die Angaben über die obersten Dauersiedlungen gemeinsam auszuwerten.

a) Die Siedlungslagen

Es finden sich hier an der obern Grenze 43 Terrassen-, 5 Leisten-, 2 Mulden-, 3 Egg-, 11 Hang-, 7 Schuttkegel- und 2 Talbodensiedlungen. Diese Zahlen sind nur mit der bereits früher erwähnten Einschränkung richtig. 
Die zwei Talbodenniederlassungen zeigen, daß im Obersimmental an zwei Orten das Resultat aus den klimatischen und orographischen Bedingungen sehr ungünstig ist. Auch hier lehrt die Untersuchung wieder, daß die Kalkgebiete von den Dauersiedlungen gemieden werden, und daß sie die Wasserversorgung erschweren.

\section{b) Die Siedlungsarten}

Die obere Grenze der Dauersiedlungen wird in diesem Teil des Obersimmentales durch alle drei Siedlungsarten gegeben. Bis Farni wird sie fast nur von wenig über dem Talboden gelegenen Dörfern und Weilern bestimmt, was durch die orographischen Verhältnisse bedingt ist. Die untern Partien des Talhanges von Simmenegg bis hinauf nach Reidenbach sind ziemlich steil, so daß sie von Aeckern und Mähwiesen eingenommen werden. Darüber befindet sich fast überall eine deutliche Verflachung, bevor die Talflanke in die steil aufragenden, aus Kalkschichten bestehenden Teile übergeht. Auf dieser Verflachung liegen die Siedlungen, die die obere Grenze bilden.

Auch auf dem Osthang formen Dörfer, wie Grubenwald, Mannried und Bettelried, Punkte der obern Grenzlinie, woran ebenfalls orographische Bedingungen schuld sind, indem der teilweise aus Kalkschichten aufgebaute, ungegliederte steile Hang der Besiedlung feindlich ist. An den meisten Orten wird aber trotz der zahlreichen Ausnahmen die obere Grenze der Dauersiedlungen durch Einzelhöfe bestimmt.

\section{c) Mittlere Höhengrenzen}

Der Durchschnitt für die dauernd bewohnten Heimwesen beträgt für die rechte Talseite $1069 \mathrm{~m}$, für die linke $1128 \mathrm{~m}$, was einem Unterschied von $59 \mathrm{~m}$ entspricht. Darin kommt vor allem die klimatische Begünstigung der Sonnseite des untersten Abschnittes des Obersimmentales zum Ausdruck, weil bei der SW-NE-Richtung des Tales die linke Talseite ausgesprochen sonnig ist, während die andere schattig bleibt. Zweitens ist darin aber auch die orographisch günstigere Gestaltung der linken Talflanke enthalten.

Ordnen wir die Höhenlagen der Siedlungen nach den Expositionen, so lauten die Werte:

$\begin{array}{cccccccc}\mathrm{S} & \mathrm{SW} & \mathrm{W} & \mathrm{NW} & \mathrm{N} & \mathrm{NE} & \mathrm{E} & \mathrm{SE} \\ 1029 \mathrm{~m} & 1286 \mathrm{~m} & 1043 \mathrm{~m} & 1095 \mathrm{~m} & 1077 \mathrm{~m} & - & 1111 \mathrm{~m} & 1140 \mathrm{~m}\end{array}$

Die mittlere Talbodenhöhe ist hier $918 \mathrm{~m}$, so daß auf der rechten Talseite die Dauersiedlungen durchschnittlich $151 \mathrm{~m}$, auf der linken $210 \mathrm{~m}$ darüber liegen.

\section{d) Veränderungen in der obern Grenze der Dauersiedlungen}

Wir haben in der Gemeinde Zweisimmen keine verlassenen Wohnstätten gefunden, wohl aber in der Gemeinde Boltigen. Die in der Gemeinde Boltigen aufgegebenen Höfe sind in Vorsassen umgewandelt worden und stehen im Gebiet des Jaunpasses, besonders in der Gegend von Vogelsang-Vorderhuen. Hier ist also die obere Grenze von $1422 \mathrm{~m}$ Höhe auf $1290 \mathrm{~m}$ gesunken.

Vogelsang (1454 m) ist insofern ein Sonderfall, als es in Jahren mit guten Heuerträgnissen bewohnt bleibt, während es in anderen infolge Viehfuttermangels nur periodisch benützt wird. Wir haben deshalb diese Siedlung nicht ins Verzeichnis aufgenommen.

Nach allen erhältlichen Angaben sind die Siedlungen nicht wegen Klima- oder Bodenverschlechterung aufgegeben worden, sondern psychologische Gründe sind ausschlaggebend gewesen. Die Leute wollten nicht mehr so abgelegen wohnen, weshalb die Güter in den achtziger Jahren verkauft wurden. 


\section{Allgemeiner Talcharakter, Siedlungsanordnung}

Das Obersimmental ist oberhalb des Riegels von Blankenburg als mehr oder weniger stark zerstörter, glazialer Taltrog ausgestaltet, dessen Sohle von Alluvionen aufgeschüttet ist, die infolge ihrer Grobheit keinen allzu fruchtbaren Boden abgeben. Als die Besiedlung erfolgte, war der Talboden weitgehend versumpft und von Ueberschwemmungen bedroht und heimgesucht. Die Talsiedlungen entstanden deshalb einmal auf kleinen Terrassen in den untersten Partien der Talflanke, vor allem aber auf den großen Schuttkegeln, wie St. Stephan und Grodey auf dem des Zelgbaches, Ried auf dem des Riedbaches, Matten auf dem des Fermelbaches und Aegerten auf dem des Wallbaches. Das Dorf Lenk ist eine Ausnahme, denn es liegt in der Talsohle. Aber durch OugSPURGER wissen wir, daß es im 17. Jahrhundert noch keine geschlossene Siedlung gewesen ist, sondern nur vereinzelte Heimstätten an den Rainen aufwies. Das Dorf ist erst in neuerer Zeit entstanden.

Neben diesen Talsiedlungen bestehen nun einzelne Höfe, die weit auseinander und verschieden hoch über der Talsohle liegen. Ihre Standorte sind vorwiegend Terrassen, breite Rücken, Eggen, die alle eine freie und daher sehr sonnige Lage aufweisen. Diese Dauersiedlungen sind für unsere Untersuchung maßgebend; denn sie beweisen, daß der Bauer noch in dieser Höhe die Ernährungsgrundlage findet.

Die steilen Flanken des Taltroges sind durchwegs unbesiedelt. Entweder sind sie von kleinen Wildbachrunsen stark zerschnitten, wie zwischen Aegerten und Dürrenwaldbach oder Brand und Oberried; oder sie sind mit dichtem Tannenwald bewachsen; oder sie haben einen ziemlich offenen Waldbestand wie von Obersteg bis Gütsch.

Die Gemeinden St. Stephan und Lenk unterscheiden sich durch ihren eigenen, auffälligen Siedlungscharakter vom übrigen Simmental: dichte Besiedlung im Tal, keine Siedlungen an den eigentlichen Talböschungen, einzelne, hochgelegene Siedlungen.

\section{Die obersten Siedlungen der rechten Talseite}

Die erste Siedlung talaufwärts von Bettelried befindet sich am Fuße des Dünkelwaldes, der ihr zum Teil die Mittagssonne wegnimmt. Sie liegt wahrscheinlich auf Gehängeschutt und nicht mehr auf dem Schuttkegel des Bettelriedbaches. Sie ist eine Hangsiedlung (Nr. 74) in $1020 \mathrm{~m}$ Höhe mit westlicher Auslage.

Die folgenden Niederlassungen kleben auf einer schmalen Terrasse, die sich bis zum Schuttkegel des Zelgbaches verfolgen läßt, wenige Meter über der Talsohle. Sie sind damit vor Ueberschwemmungen geschützt. Die erste davon ist Nr. 75 in $985 \mathrm{~m}$ Höhe und ungefähr $5 \mathrm{~m}$ über dem heutigen Talboden. Die restlichen Heimwesen, die links und rechts der Straße erbaut sind, haben wir nicht numeriert. Die Straße verläuft auf der erwähnten schmalen Terrasse und hebt sich bis auf $990 \mathrm{~m}$ Höhe empor. Es folgt der große Schuttkegel des Zelgbaches, auf dem sich St. Stephan ausbreitet. Die Grenze der Dauersiedlungen folgt dem Uebergang vom Schuttkegel zum Talhang. Die Kurve erreicht dabei eine Höhe von $1090 \mathrm{~m}$. Von hier aus klettert sie hinauf zum Bauernhaus Nr. 76, einer Hangsiedlung in $1170 \mathrm{~m}$ Höhe mit Westexposition. Nach steilem Anstieg wird die erste Hochterrassensiedlung, nämlich Neuenegg (Nr. 77), in $1375 \mathrm{~m}$ Höhe oder $375 \mathrm{~m}$ über der heutigen Talsohle erreicht. Die Lage ist nach Westen orientiert. Die Sonne scheint unbehindert aus S und SE hin, weil die Terrasse gegen $S$ zum Graben des Zelgbaches abfällt. Jenseits des Grabens liegt auf einer Terrasse der Einzelhof Ried (Nr. 78) in $1270 \mathrm{~m}$ Höhe. An der Terrassensiedlung Rütti (Nr. 79), in $1376 \mathrm{~m}$ und in südwestlicher Exposition gelegen, vorbeigehend, wird der Dachboden betreten, wo das höchstgelegene, ständig bewohnte Heimwesen (Nr. 80) 
des gesamten Simmentales in $1651 \mathrm{~m}$ Höhe (relative Höhe $650 \mathrm{~m}$ ) steht. Der Dachboden ist die Oberfläche eines breiten Rückens, der sich von der Mieschfluh her zwischen dem Graben des Zelgbaches und dem Fermeltal vorschiebt. Die Siedlung erhält infolge ihrer Lage außerordentlich viel Sonne, was das Entstehen einer Dauersiedlung in dieser Höhe wohl erst ermöglicht hat. Der Boden ist hier sehr fruchtbar, was im Sommer am dichten und üppigen Graswuchs festgestellt werden kann. Die Nachteile liegen in der weiten Entfernung vom Tale und in der etwas unzuverlässigen Wasserversorgung, weil nicht weit davon das Kalkgebiet der Mieschfluh beginnt.

Vom Dachboden aus führt die obere Grenze hinunter ins Fermeltal, das eine für sich abgeschlossene Talschaft bildet. Der Fermelbach durchbricht in einer breiten Schlucht und mit einer Gefällsstufe den eigentlichen Talhang. Die Siedlungen des Fermeltales liegen auf einer leicht geneigten Terrasse, die sich aus Gehängeschutt vom Rothorn, von den Spillgerten und von der Mieschfluh und aus $\mathrm{Ge}$ schiebematerial des Fermelbaches aufbaut. Der Bach hat sich heute wieder in die ehemalige Talsohle eingeschnitten. Das Fermeltal hat den Charakter eines ehemals vergletscherten Tales fast rein erhalten. Es hat eine sichelförmige Laàngserstrekkung. Sein oberer Teil verläuft NW-SE und sein unterer NE-SW.

Sämtliche Dauer-

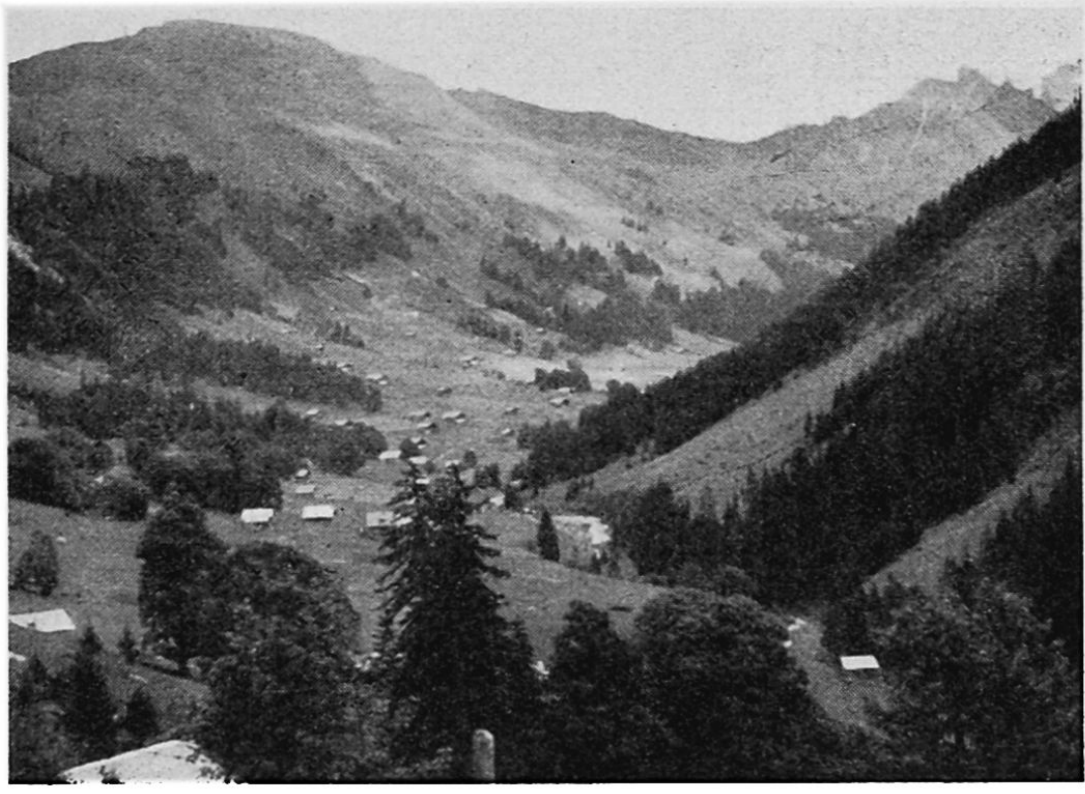

Abb. 4. Fermeltal. Blick von NW gegen SO. Rechte Talseite, im geographischen Sinne, mit Dauersiedlungen. Das Tal hat den trogförmigen, eiszeitiichen Charakter weitgehend bewahrt.

(Photo P. KöChLI) siedlungen des Tales stehen auf der rechten Talseite und ziehen sich gegen den obern Rand der Terrasse zurück, weil die tieferen Lagen infolge der Albristegg sehr schattig sind. Die oberste Dauersiedlung ist Gruben (Nr. 81) in $1470 \mathrm{~m}$ Höhe mit SW-Exposition. Die Karte gibt das Lagebild dieses Heimwesens insofern unrichtig wieder, als am Hang über Gruben Schutzwald wächst. Der Hang ist so steil und hat zudem eine ungebrochene Linie, daß der Schnee ohne den vorhandenen Wald abrutschen müßte.

Im Tal hat die Heimstätte Birchlauenen (Nr. 84) die geringste Höhenlage mit $1410 \mathrm{~m}$. Zwischen Gruben und Birchlauenen haben wir auswahlsweise noch die Heimwesen Nr. 82 und 83 aufgenommen. Sie besitzen eine Höhenlage von $1415 \mathrm{~m}$ mit SEExposition bzw. $1430 \mathrm{~m}$ und SSE-Exposition. Auf der ganzen linken Talseite reicht der Wald größtenteils bis an den Bach herunter.

Nach dieser Ausbuchtung ins Fermeltal greift die Kurve in einer zweiten in das Tal des Albristbaches hinüber. Es finden sich hier die Dauersiedlungen Eggen (Nr. 85) in $1350 \mathrm{~m}$ und $\mathrm{Zu}$ Hähligen (Nr. 86) in $1450 \mathrm{~m}$ Höhe. Das erste ist eine Egg-, das zweite eine Hangsiedlung; beide haben Westexposition. Nun schwingt sich die Grenze um den Weißenberg, der das Tal des Albristbaches vom Haupttal trennt, herum nach Obersteg (Nr. 87), das auf einer schmalen Terrasse in einem ziemlich abschüssigen Hang auf $1380 \mathrm{~m}$ in westlicher Auslage gelegen ist. Die relative Höhe beträgt $370 \mathrm{~m}$. 
Ungefähr $3 \mathrm{~km}$ weiter talaufwärts, nach Weißenberg-Bleiken, liegt oberhalb Gutenbrunnen in 1470 m Höhe oder 410 m über dem Talboden der Einzelhof Port (Nr. 88) auf einer Terrasse.

Bei Port setzt die schmale Flysch- und Liasmergelzone des Hahnenmoospasses ein. Die Auswirkungen davon auf die Geländegestaltung sind bereits früher besprochen worden. Es ändert damit aber auch das Siedlungsbild. Ausgenommen vom Dorf kern von Lenk, steigt an den Gehängen überall die Einzelhofsiedlung empor. Diese Zone erstreckt sich ungefähr bis zu einer Linie, die sich vom Hahnenmoospaß über Tannenbühl-Horlauenen hinüber zur Bettelegg zieht. Die Zone der Plaine-Morte-Decke zeigt mit ihren Schiefern eine etwas größere Widerstandsfähigkeit, so daß das oberste Stück des Obersimmentales und das Tal des Iffigenbaches wieder weitgehend den Charakter des Taltroges annehmen.

Eine Folge der Geländegestaltung bei Port besteht darin, daß bloß $70 \mathrm{~m}$ Höhenunterschied diese Siedlung trotz ihrer höheren Lage als Obersteg, Rütti oder Neuenegg von den tiefer gelegenen Bauernhöfen trennt.

Vom Wohnhaus Port führt der Weg nach Schwand (Nr. 89), das sich in $1400 \mathrm{~m}$ Höhe und $380 \mathrm{~m}$ über der Talsohle in westlicher Auslage befindet. Die Kurve schneidet nun die beiden Wildbäche, die vom Thierberg und Laveygrat herunterrauschen, und klettert dann über Seiten und Brand nach der Terrassensiedlung Brandegg (Nr. 90), die am Weg nach dem Hahnenmoos in $1515 \mathrm{~m}$ Höhe oder $495 \mathrm{~m}$ über der Lenk gelegen ist. Die Siedlung hat Westexposition und eine sehr sonnige Lage; denn das rückwärtige Gebiet ist sehr flach, und auch nach Süden ist der Ausblick vollständig frei.

Von der Brandegg aus geht es auf die Terrasse von Tannenbühl hinunter. Hier steht die Dauersiedlung Nr. 91 in bloß $1260 \mathrm{~m}$ Höhe bzw. $235 \mathrm{~m}$ höher als Oberried, Anschließend steigt die Kurve nach Metsch hinauf, wo sich die letzte hochgelegene. dauernd bewohnte Terrassensiedlung (Nr. 92) auf dieser Talflanke befindet. Ihre Höhenlage beträgt $1470 \mathrm{~m}$, die relative Höhe $440 \mathrm{~m}$. Dann senkt sich die Kurve bis zur Talsohle, die sie bei Oberried erreicht. Dieser Weiler hat eine durchschnittliche Höhe von $1090 \mathrm{~m}$.

\section{Die obere Grenze auf der linken Talseite und im Iffigental}

Am Ostabhang des Langerberges, der sich als breiter, trennender Rücken zwischen der Simme und dem Iffigenbach einschiebt, liegen drei Heimwesen auf Terrassen. Sie tragen die Nr. 93, 94, 95. Die erste hat $1150 \mathrm{~m}$ Höhe, die beiden andern $1100 \mathrm{~m}$. Sie erhalten infolge der Ostexposition nur wenig Abendsonne.

Nun biegt die Kurve um den Vorsprung des Langerberges und führt in die Bäuert Pöschenried. Die Merkmale der obersten Bauernhöfe werden im folgenden nach Talseiten geordnet wiedergegeben.

$\begin{array}{ll}\text { Rechte } & \text { Talseite } \\ \text { Haus } & \text { Oertlichkeit } \\ \text { Nr. } & \text { Distelboden } \\ 96 & \text { Schwand } \\ 97 & \text { Langernseiten } \\ 98 & \text { Talseite } \\ \text { Linke } & \text { Tal } \\ \text { Haus } & \text { Oertlichkeit } \\ \text { Nr. } & \text { Fluh } \\ 99 & - \\ 100 & \text { Bruch } \\ 101 & \text { Blatti } \\ 102 & \text { Blatti } \\ 103 & \text { Seefluh } \\ 104 & \end{array}$

Morphologische
Siedlungslage
Terrasse
Hang
Terrasse

Morphologische
Siedlungslage
Terrasse
Schuttkegel
Terrasse
Terrasse
Terrasse
Terrasse

$\begin{array}{ccc}\begin{array}{c}\text { Höhe } \\ \text { über Meer }\end{array} & \text { Exposition } & \text { Relative Höhe } \\ 1270 \mathrm{~m} & \text { WNW } & 75 \mathrm{~m} \\ 1310 \mathrm{~m} & \text { WNW } & 100 \mathrm{~m} \\ 1250 \mathrm{~m} & \text { W } & 10 \mathrm{~m}\end{array}$

$\begin{array}{ccc}\begin{array}{c}\text { Höhe } \\ \text { uber Meer }\end{array} & \text { Exposition } & \text { Relative Höhe } \\ 1300 \mathrm{~m} & \mathrm{E} & 75 \mathrm{~m} \\ 1210 \mathrm{~m} & \mathrm{E} & 30 \mathrm{~m} \\ 1370 \mathrm{~m} & \mathrm{E} & 75 \mathrm{~m} \\ 1310 \mathrm{~m} & \mathrm{E} & 190 \mathrm{~m} \\ 1270 \mathrm{~m} & \mathrm{E} & 150 \mathrm{~m} \\ 1170 \mathrm{~m} & \mathrm{E} & 60 \mathrm{~m}\end{array}$


Von der Seefluh aus sinkt die Siedlungsgrenze hinunter zu den obersten Häusern (Nr. 105) von dem Teil Lenks, der links der Simme gelegen ist. Diese erreichen die Höhenkurve von $1140 \mathrm{~m}$ und besitzen Ostexposition. Dann geht die obere Grenze über den Wallbach hinüber auf den großen Schuttkegel von Aegerten. Auf diesem Kegel stehen Bauernhäuser (Nr. 106) bis in die Höhe von $1287 \mathrm{~m}$. Nachher ist die linke Talseite von der Gegend des Schadauli an, unweit der Haltestelle Boden, für eine Besiedlung ungünstig gestaltet. Zahlreiche Runsen und Wildbachgräben haben den Talhang zerschnitten. Die Bauernhöfe befinden sich am äußern Rande der Talsohle. Erst bei Niederdorf bietet eine in $1225 \mathrm{~m}$ Höhe gelegene Terrasse einem ständig bewohnten Heimwesen Platz, das den Namen Stutz (Nr. 107) trägt und $115 \mathrm{~m}$ über dem Talboden steht. Die nächste Dauersiedlung, die aber erst seit zwei Jahren besteht, liegt jenseits des Dürrenwaldbachgrabens in $1370 \mathrm{~m}$ Höhe oder $360 \mathrm{~m}$ über dem Talboden. Diese Terrassensiedlung (Nr. 108) heißt "Auf dem Boden» und hat östliche Exposition.

Das folgende Heimwesen (Nr. 109) hat dieselbe Ortsbezeichnung, was auf eine gleiche Siedlungslage hinweist. Es steht links über dem Reulissenbach in $1265 \mathrm{~m}$ Höhe oder $270 \mathrm{~m}$ über der Talsohle und hat ebenfalls Ostexposition.

Dann fällt die obere Grenze wiederum, ohne daß es diesmal die orographische Geländegestaltung verlangte, und erreicht Schwarzbrand ( $\mathrm{Nr}$. 110) in $1050 \mathrm{~m}$ Höhe oder nur noch $5.5 \mathrm{~m}$ über der Simme. Es ist eine Terrassensiedlung. Sie ist eher schattig gelegen, weil die rückwärtige Böschung ziemlich steil und mit Wald bedeckt ist, so daß die Abendsonne fehlt. In freierer Lage erhebt sich das Wohnhaus Nr. 111 in $1020 \mathrm{~m}$ Höhe. Es folgen die vier Siedlungen Nr. 112-115. Die erste liegt auf der Studweid. Um sie zu erreichen, wird der Kesselbach überschritten und auf $1140 \mathrm{~m}$ hinaufgestiegen. Die zwei nächsten Heimwesen sind bei Schmitzenried in $1100 \mathrm{~m}$ bzw. in $1050 \mathrm{~m}$ Höhe anzutreffen. Die letzte endlich heißt Scheuergut und ist wie die drei genannten eine Terrassensiedlung in $1130 \mathrm{~m}$ Höhe.

Das Gelände wird wieder abschüssiger und ist daher mit Wald bewachsen. Die obere Grenze der Dauersiedlungen wird hinuntergedrückt. Das oberste Haus der Schuttkegelsiedlung Ried (Nr. 116) steht nur. noch in 1020 m Höhe. Der Riedwald und das Schlegelholz schieben sich nun gegen die Talsohle vor und lassen den Heimstätten nur den Talboden übrig. In $980 \mathrm{~m}$ Höhe liegen hier der Bauernhof Wirzacker (Nr. 117) und der keine Ortsbezeichnung tragende Hof Nr. 118.

Damit ist der Rundgang durch das Tal beendigt, und die obere Grenze der Dauersiedlungen kann bei der Siedlung Nr. 72 der Gemeinde Zweisimmen geschlossen werden.

\section{Ergebnisse aus den Gemeinden St. Stephan und Lenk}

Der einheitliche Talcharakter, einschließlich der schmalen Sattelzone, erlaubt die durchschnittliche Höhenzahl für den ganzen Talabschnitt zu berechnen. Die Höhenwerte aus den beiden kurzen Seitentälern, Fermeltal und Iffigental, dürfen auch berücksichtigt werden.

\section{a) Siedlungslagen}

Die 33 Terrassensiedlungen in den Gemeinden St. Stephan und Lenk bestätigen erneut den großen Vorsprung dieses Siedlungstypus. Die andern folgen erst in einem beträchtlichen Abstand mit 4 Talboden-, 4 Hang-, 3 Schuttkegelsiedlungen und 1 Eggsiedlung. Die vier Niederlassungen im Talboden weisen darauf hin, daß auch in diesen zwei Gemeinden das Ergebnis der klimatischen und orographischen Verhältnisse an einzelnen Stellen sehr ungünstig ist.

Die Siedlungen stehen hier entweder auf Glazialdepot, auf Niesenflysch, Flysch, Liasmergeln, Schuttkegelmaterial und vereinzelt auf Alluvionen. Ueberall aber bleiben sie dem Kalkgebiet fern. 


\section{b) Die Siedlungsarten}

Wie wir einleitend dargestellt haben, besitzt dieser Talabschnitt seinen besondern Siedlungscharakter. Deshalb wird die obere Grenze der Dauersiedlungen mit der einzigen Ausnahme von Ried durch Einzelhöfe gegeben.

c) Mittlere Höhenwerte

Die Zusammenstellung vermittle darüber einen Einblick:

Gemeinden St. Stephan und Lenk

Rechte Talseite. . . . . . . . .

Linke Talseite . . . . . . . . . .

Unterschied

\begin{tabular}{ccc}
$\begin{array}{c}\text { Mittlere } \\
\text { Talbodenhöhe }\end{array}$ & $\begin{array}{c}\text { Dauersiedlung } \\
\text { absolut } \\
1036 \mathrm{~m}\end{array}$ & $\begin{array}{c}\text { Dauersiedlung } \\
\text { relativ }\end{array}$ \\
$1036 \mathrm{~m}$ & $1162 \mathrm{~m}$ & $313 \mathrm{~m}$ \\
\hline- & $187 \mathrm{~m}$ & $126 \mathrm{~m}$ \\
\hline
\end{tabular}

Die rechte Talseite zeigt die höheren Mittelwerte, weil einmal die ganze Talseite in größere Höhen hinaufragt und weil eine geringe klimatische Begünstigung, die später begründet werden wird, vorliegt.

Die Mittel, zusammengestellt nach den Expositionen, erhärten die bereits früher gefundene Tatsache, daß die SW-Lage mit $1499 \mathrm{~m}$ den höchsten Betrag ergibt. Es folgen die SE-Lage mit $1418 \mathrm{~m}$, die W-Lage mit $1309 \mathrm{~m}$ und die E-Lage mit $1162 \mathrm{~m}$. Die übrigen Expositionen weisen keine Dauersiedlungen auf.

d) Veränderungen in der obern Grenze der Dauersiedlungen

Aus der Arbeit von Bernhard (49) über die Gemeinde Lenk ist zu entnehmen, daß 192747 Wohnhäuser unbewohnt gewesen sind und daß daneben noch 10 eigentliche Wüstungen bestanden haben.

An der obern Grenze der Dauersiedlungen haben wir nur eine Wüstung, und zwar im Sumpf ob Oberried, gefunden, während alle andern aufgegebenen Dauersiedlungen in Vorsassen umgewandelt worden sind. Einzelne davon stellen sogar wieder einen Uebergangstypus dar - sie befinden sich hauptsächlich in der Port bei Lenk -, indem sie heute in besonders ertragreichen Jahren während des ganzen Jahres bewohnt bleiben, sei es nun durch die Bauernfamilie selbst, oder sei es durch einen Knecht.

Die obere Grenze ist, soweit es sich feststellen läßt, seit langer Zeit unverändert geblieben, wenn auch die Siedlungsdichte in der Kampfzone in den letzten 80 Jahren abgenommen hat. Dieses Ergebnis wird auch durch die neuerdings wieder ständig bewohnte Siedlung Boden (Nr. 108) ob dem Dürrenwaldbach nicht verändert.

\section{UIBERBLICK UBER DIE ABHÄNGIGKEIT DER OBERN GRENZE DER DAUERSIEDLUNGEN VON DER BODENGESTALT}

Die Untersuchungen im Simmental zeigen, daß die orographischen Gegebenheiten nur streckenweise die obere Grenze der Dauersiedlungen bestimmen. Im Niedersimmental begrenzen sie das bewohnbare Gebiet von Außerlatterbach bis Latterbach, bei Stigenmad, Ried und Zelg, im Bergrutschgebiet des Korbwaldes, das sich von den Pfaffen herunterzieht, und in den verschiedenen Teilen des Diemtigtales, die wir erwähnt haben. Im Obersimmental verhindern sie das Vordringen der Dauersiedlungen beim Bettelriedwald und am Talabschluß, wo die steil aufragenden Flühe des Wildstrubelgebietes und die Flühe beim Iffigenfall eine eindeutige Grenze bilden.

In allen übrigen Gebieten fände die Siedlung günstige Standorte, sowohl was die Sicherheit wie die Zugänglichkeit anbetrifft. Denken wir nur an die Landschaften von Buntelgabel bis Niederhorn, Jaunpaß, Saanenmöser, Hahnenmoospaß usw. Hier sind es landwirtschaftliche Bedingungen, die der Siedlung ein weiteres Vordringen verwehren. 
Die tektonischen Verhältnisse und die Lagerung der Gesteinsarten zueinander verursachen im Simmental die Oberflächengestaltung. Vor allem spielt die Widerstandsfähigkeit der Gesteine bei bestimmter, gegenseitiger Lagerung eine Rolle. In einigen Gegenden sind die leicht verwitterbaren Schichten von Kalk unterlagert, der der Verwitterung einen solchen Widerstand entgegensetzt, daß sich das Gebiet in einer Höhe befindet, verursacht durch die Tektonik, daß eine Besiedlung ausgeschlossen ist; oder er läßt das $\mathrm{Ge}$ biet schwer zugänglich werden, so daß der Mensch auf dauernde Niederlassung verzichtet.

Bei der Abtragung erhalten die Gesteinsarten verschieden starke Böschungen, die, wenn sie eine gewisse Neigung überschreiten und zugleich wenig gegliedert sind, von der Siedlung gemieden werden, wie Teile der vordern Niesenkette, die Nordflanke der Hohmad, der Zwischenflühwald, der rechte Talhang des Obersimmentales von Boltigen bis Garstatt und die Flanken des glazialen Taltroges von Bettelried bis Oberried.

Dafür findet dann eine Anhäufung der Heimwesen in jenen Gegenden statt, die sich durch reiche Terrassierung, zahlreiche Schuttkegel, sanfte Rücken, durch eine leichte Zugänglichkeit und durch eine günstige Exposition auszeichnen.

Dort, wo nun die obere Grenze der Dauersiedlungen nicht durch die orographischen Verhältnisse erklärt werden kann, muß sie in landwirtschaftlichen obern Grenzen, die sich auf die Verbreitung der Kulturpflanzen, der Wiesen, des Waldes und der Weiden stützt, gesucht werden. In einem weiteren Kapitel sollen deshalb einzelne landwirtschaftliche Grenzen im Simmental besprochen werden.

VIII. BEZIEHUNGEN ZWISCHEN DER OBERN GRENZE DER DAUERSIEDLUNGEN UND ALPWIRTSCHAFTLICHEN UND NATURLICHEN HOHENGRENZEN

\section{Einleitung}

Die begrenzt zur Verfügung stehende Zeit und die dadurch bedingte Art der Begehung des Simmentales erlaubten es leider nicht, alle Beziehungen zwischen den Dauersiedlungen und den landwirtschaftlichen Grenzen eingehend zu untersuchen und zu würdigen. Trotzdem haben wir uns bemüht, die wenigen aufgenommenen obern Grenzen möglichst genau zu bestimmen. Im Gelände draußen bietet dies etwelche Schwierigkeiten, weil Wald, Weiden, Wiesen und Aecker fortwährend abwechseln, was eine genaue Festlegung der Grenzen erschwert.

Für die Beziehung zwischen der Mähwiesengrenze und der Dauersiedlungsgrenze ist festzuhalten, daß unter dem Begriff «Mähwiese» hier eine regelmäßig gedüngte Wiese verstanden wird, die nur zur Heugewinnung benützt und jährlich mindestens zweimal gemäht wird. Heu wird im Simmental aber nicht nur auf den Mähwiesen gewonnen, sondern auch noch auf den Vorsassen, Weiden und in den Wildheumähdern, um den Bedürfnissen der hochentwickelten Viehzucht zu genügen. Das Wildheu dient vorwiegend zur Verbesserung von magerem Winterfutter; das in den Einschlägen der Alpweiden geerntete Heu zur Fütterung des sömmernden Viehs während der Tage eines Wettersturzes; das auf den Vorsassen gedörrte Futter wird entweder dort verbraucht oder im Winter zum Heimgut hinuntergeschlittelt. Wird es in den Vorsassen verfüttert, so bleibt das Vieh ungefähr bis Januar dort, um nachher in das Heimgut hinuntergetrieben zu werden. Manchmal bleibt die ganze Bauernfamilie bis in den Januar in der Vorsaß, manchmal nur ein Knecht, oder dann steigt der Bauer, sofern sein Heimgut nicht zu weit entfernt ist, zweimal im Tage in die Vorsaß hinauf, um die Kühe zu besorgen.

Im weiteren darf nicht vergessen werden, daß die letzten drei Jahre für den Ackerbau sehr günstig gewesen sind. Vereint mit der vermehrten Anbaupflicht an Ackerfrüchten, wie Getreide, Kartoffeln und Gemüse, hat sich auch im Simmental der Ackerbau ausgedehnt. Diese Entwicklung wird wahrscheinlich in normalen wirtschaftlichen Zeiten und in Zeiten mit kühlerem und feuchterem Witterungsverlaufe einen Rückschlag zugunsten der Graswirtschaft, die das Gegebene ist, erleiden. 


\section{Landwirtschaftliche Grenzen im Niedersimmental}

a) Obere Grenzen von Kulturpflanzen

Im gesamten Niedersimmental, mit Ausnahme des 1943 noch nicht drainiert gewesenen Roßberges, folgte die Getreidegrenze den obersten Dauersiedlungen. Der Ertrag genügt jedoch der Nachfrage lange nicht, so daß keine Selbstversorgung mit Getreide, wie sie die Forscher in den Ostalpen festgestellt haben wollen, vorhanden ist. Es werden vor allem Roggen, Hafer und Weizen angebaut. Der Weizen blieb in den tiefern Lagen zurück. Der Hafer war ungefähr gleich verbreitet wie der Roggen, kam aber in höheren Lagen vor.

Die Kartoffel konnte ebenfalls bei allen obersten Heimwesen festgestellt werden. Sie wurde auch auf dem Roßberg in $1120 \mathrm{~m}$ Höhe angepflanzt, wo das Getreide bereits fehlte. Ihr Anbau hat in den letzten Jahren stark zugenommen, wenn schon die Ernte oft nicht den erhofften Erfolg gebracht hat. Der Boden ist infolge des regnerischen Klimas meist zu feucht. An ihrer obern Verbreitungsgrenze wird sie von Spätfrösten im Frühling und von Frühfrösten im Herbst bedroht.

Kleinere Gemüsegärten sind heute überall zu finden, in denen meistens Kohl, Kabis, Salat, Rüben, Suppengemüse, Rhabarber und Beerensträucher, wie Johannisbeeren und Stachelbeeren, gezogen werden.

Die Obstbäume, vorwiegend Apfelbäume mit den Sorten Lebel und Klaräpfel, bringen nur in den tiefern Lagen des Niedersimmentales alljährlich einen guten Ertrag. Nach der Obstbaumzählung von 1929 wächst folgende Anzahl von Obstbäumen im Niedersimmental:

$\begin{array}{cccccccc}\text { Gemeinden } & \begin{array}{c}\text { Apfel- } \\ \text { bäume }\end{array} & \begin{array}{c}\text { Birn- } \\ \text { bäume }\end{array} & \begin{array}{c}\text { Kirsch- } \\ \text { bäume }\end{array} & \begin{array}{c}\text { Zwerschgen-, } \\ \text { Pflaumenbäume }\end{array} & \begin{array}{c}\text { Quitten- } \\ \text { bäume }\end{array} & \begin{array}{c}\text { Nuß- } \\ \text { bäume }\end{array} & \begin{array}{c}\text { Aprikosen- } \\ \text { bäume }\end{array} \\ \text { Erlenbach .. . } & 2954 & 987 & 1316 & 1528 & 52 & 218 & 37 \\ \text { Därstetten . . } & 1307 & 556 & 790 & 731 & 21 & 60 & 8 \\ \text { Oberwil . . . } & 1985 & 785 & 1167 & 1025 & 6 & 36 & 3\end{array}$

Die Obstbaumpflege hat erst in den letzten Jahren richtig eingesetzt. Wo sie gewissenhaft durchgeführt wird, hat sich der Ertrag beträchtlich gesteigert. Die obere Grenze der Obstbäume zieht sich in ungefähr $1000 \mathrm{~m}$ Höhe auf der Sonnseite, in $900 \mathrm{~m}$ Höhe auf der Schattseite hin.

\section{b) Die obere Grenze der Mähwiesen}

Die Mähwiesen breiten sich meistens in der Nähe der Dauersiedlungen aus und liegen unter der mehr oder weniger zusammenhängenden Tannenwaldzone. Bei Außerlatterbach zieht sich ihre obere Grenze in $710 \mathrm{~m}$ Höhe hin, um dann sprungweise, entsprechend der Verbreiterung der Flyschzone, emporzurücken. Bei Latterbach erreicht sie $810 \mathrm{~m}$ Höhe, bei Eschlen $940 \mathrm{~m}$, um dann bis auf $1000 \mathrm{~m}$ Höhe zu steigen. Erst nach Balzenberg geht sie neuerdings hinauf bis auf $1050 \mathrm{~m}$. Die höchstgelegenen Mähwiesen haben wir bei Stigenmad in $1150 \mathrm{~m}$ Höhe festgestellt. Jenseits des Bunschenbaches zieht sie sich nur noch in $1080 \mathrm{~m}$ hin, was durch die orographischen Verhältnisse bedingt wird. Sie behauptet diese Höhe bis oberhalb Riedmad, um nachher auf einen Durchschnitt von $1000 \mathrm{~m}$ zu fallen, den sie bis zum Uebergang ins Obersimmental beibehält.

Auf der Schattseite beginnen wir bei Breiti, wo sie sich in $1050 \mathrm{~m}$ hinzieht. Dann erfolgt eine Zunahme auf $1170 \mathrm{~m}$ beim Roßberg, worauf sie längs des Oeygrabens, an dessen rechter Seite sie sporadisch bestimmt werden kann, auf $1070 \mathrm{~m}$ sinkt. Die Mähwiesengrenze fällt dann entlang des Klosterbaches bis auf $870 \mathrm{~m}$ hinunter. Diese Höhe verändert sich erst wieder, wenn die Grenze in die Gegend des Diemtigberglis kommt, wo sie bei der erwähnten Oertlichkeit in $1070 \mathrm{~m}$ Höhe ins Diemtigtal hinübergeführt wird. 
Um die Mittelwerte zu errechnen, sind wir so vorgegangen, daß wir über jeder vorher bestimmten Dauersiedlung die Höhengrenze der Mähwiese eingesetzt haben. Die Mittel lauten dann für die Sonnseite $1017 \mathrm{~m}$, für die Schattseite $943 \mathrm{~m}$.

\section{c) Die obere Waldgrenze}

Die obern Grenzen des Waldes in den einzelnen Landschaftsgebieten der Schweiz sind von IмноF bestimmt worden. Wir können seine Ergebnisse nur teilweise benützen, weil er große Abschnitte zusammengefaßt hat. Werden die von IмноF (28) angegebenen Werte mit denen von FLüCKIGER (22) verglichen, der für die Berechnung der obern temporären Siedlungsgrenze im Simmental die 24 höchstgelegenen Sennhütten verwendet hat und dabei einen Durchschnitt von 1905 m erhält, so ergibt sich, $\mathrm{da} ß$ die Alphütten durchschnittlich $100 \mathrm{~m}$ über der Waldgrenze liegen. Begeht man dagegen das Simmental, so wird der aufmerksame Beobachter bald einmal feststellen, daß in einigen Talpartien die Sennhütten unter der Waldgrenze liegen. Diese Erscheinung tritt besonders da auf, wo die Erhebung des Gebietes nicht oder kaum die obere klimatische Waldgrenze erreicht. Die Sennhütten stehen nie auf einem Kamm, sondern immer in den Flanken der Gebirgszüge, auf Verebnungen, Terrassen oder gar in großen Mulden, wie beispielsweise die Rinderalp ob Oey-Diemtigen, oder in Karen. Die obere Grenze der Alphütten zieht sich in mehreren Talabschnitten des Niedersimmentales unter der Waldgrenze hin.

Auf der rechten Talseite finden sich die Alphütten, wie im folgenden Kapitel gezeigt wird, in den hochgelegenen Längstälchen, während sich noch Wald fleckenweise an den Talflanken ausbreitet. Die obere Waldgrenze liegt zwischen dem Stockhorn und der Kaiseregg in einer mittleren Höhe von $1700 \mathrm{~m}$.

Auf der andern Talseite, von Abendberg-Thurnen bis Niederhorn, erheben sich nur wenige Punkte über die Waldgrenze von durchschnittliç $1750 \mathrm{~m}$ Höhenlage. Die Sennhütten bleiben hier aus orographischen Gründen beträchtlich unter der Waldgrenze zurück.

\section{d) Die obere Grenze der Sennhütten}

Im folgenden werden die Standorte der Alphütten, die zur Berechnung des Mittelwertes gedient haben, angegeben.

Die Rinderalp wird hier zum Niedersimmental gerechnet, trotzdem sie im Einzugsgebiet von Fildrich und Kirel liegt. Der gesamte Gebirgszug zwischen dem Niedersimmental und dem Diemtigtal reicht in seiner Höhe nicht an die klimatische, obere Grenze des Weidegürtels heran. Die Alphütten wiederum sind in zentraler und gut zugänglicher Lage der Weidegebiete erstellt worden. Die erste, große Alp im Niedersimmental ist Tschuggen in einer durchschnittlichen Höhe von $1380 \mathrm{~m}$, dann folgt Feldmöser in der gleichen Höhenlage. Nach einem steilen Anstieg kommt die ausgedehnte Rinderalp in $1700 \mathrm{~m}$ Höhe, zu der als Weidegebiete der nach Süden gerichtete Hang der Pfaffenköpfe und die nach Norden schauende, sanfte Böschung des Abendberges gehören. Auf der Südabdachung des Thurnen liegen dann die Alphütten von Hinter- und Vorder-Tärfeten in $1804 \mathrm{~m}$ bzw. in $1807 \mathrm{~m}$ Höhe. Dann bildet die Wasserscheide die obere Grenze für die Alphütten. In einer kleinen Einsattelung steht die Hütte Hängert (1784 m), in einem deutlichen Einschnitt das Ramsli (1743 m). Nachher befindet sich die obere Grenze der Alphütten nördlich der Wasserscheide. Sie zieht sich über die Buntelalp (1820 m), Rite $(1620 \mathrm{~m})$ nach der Bunfalalp $(1870 \mathrm{~m})$, um dann ins Obersimmental hinüberzuführen. Der Mittelwert für die obere Grenze der Sennhütten ergibt für die rechte Talseite $1690 \mathrm{~m}$.

An der nach Süden gerichteten Talflanke des Niedersimmentales liegen die hauptsächlichsten Alpweidegebiete in den kurzen, parallel zum Simmental laufenden, hochgelegenen Längstälchen. Nur vereinzelte Alphütten stehen noch höher oben. Von der Grenze zwischen dem Obersimmental und dem Niedersimmental aus erreichen wir 
zuerst die Hinter-Richisalp in $1780 \mathrm{~m}$ Höhe, dann, nachdem der Kamm von der Hohmad $(1875 \mathrm{~m})$ zur Scheibe $(2152 \mathrm{~m})$ überschritten ist, Alpiglen in $1700 \mathrm{~m}$ Höhe und östlich davon Neuenberg $(1630 \mathrm{~m})$, schließlich Domeren $(1680 \mathrm{~m})$ im Tälchen des Hüpbaches, der bei Oberwil in die Simme mündet. Von hier aus gelangen wir in nördlicher Richtung ins Einzugsgebiet des Morgetenbaches. An seinem obern Ende liegt Riprechten in $1700 \mathrm{~m}$ Höhe. Die Kurve hält sich auf der rechten Talseite und führt an der Alp Morgeten $(1650 \mathrm{~m})$ vorbei über Kneubossen $(1860 \mathrm{~m})$ auf den Morgetengrat hinauf. Von da aus sehen wir auf die große Alp Im Kessel $(1830 \mathrm{~m})$ und auf Schitterwang hinunter. Żwei Kilometer weiter östlich dehnt sich das Weidegebiet von Kühlauenen $(1580 \mathrm{~m})$ aus, anschließend das von Walalp $(1700 \mathrm{~m})$. Am Fuße des Stockhorns liegen die Alpen bei den Stockenseelein (1660 und $1630 \mathrm{~m})$. Nachher schwingt sich die Kurve um die Walpersbergfluh herum nach dem Pfrundnacki $(1535 \mathrm{~m})$ und endet auf dem Heitiberg in $1490 \mathrm{~m}$ Höhe.

Der Mittelwert lautet für die Südflanke bloß $1673 \mathrm{~m}$. Es zeigt sich hier der nachtsilige orographische Einfluß, indem die steil aufragenden Kalkklötze und die Steilflanken der Gräte das Mittel hinunterzudrücken vermögen. Einen Einfluß können auch die etwas isolierte Lage und die ungünstigen Zugänge zu den Alpgebieten ausüben.

\section{Landwirtschaftliche Grenzen im Diemtigtal}

a) Obere Grenzen von Kulturpflanzen

Der Getreideanbau fehlt in dieser Talschaft vollständig im Mäniggrund und auf dem Springboden. Der Weizen bleibt auf das unterste Talstück, das das Klima des Niedersimmentales besitzt, beschränkt. Die letzten Roggenäckerchen breiten sich bei Zwischenflüh aus, während der Hafer in sonnigen Lagen bis in die Höhe von Senggi und Grunholz (1250 m) gedeiht. Die Ernte ist jedoch in dieser Höhenlage immer durch frühen Schneefall bedroht, der die.Halme zu Boden drückt und ein Ausfallen der Körner bewirkt. In feuchteren und kühleren Jahren muß der Bauer hier den Hafer unreif schneiden und dann auf der Vorlaube seines Hauses trocknen, wobei durch die Vögel ein beachtlicher Teil der Körner aufgepickt wird. Sonst stimmt die Getreidegrenze mit der obern Grenze der Dauersiedlungen überein. Von einer Autarkie in der Getreideversorgung kann aber keine Rede sein.

Die Kartoffel wird im ganzen Tale angepflanzt. Im Mäniggrund werden die kleinen Kartoffeläcker nur auf der Sonnseite angelegt. Die Kartoffel wird hier, wie auch in Senggi, Grunholz, auf dem Springboden durch Fröste oft geschädigt.

Die Gemüsegärten weisen dieselben Gemüsearten wie im Niedersimmental auf. Einzig die Stangenbohne, die eine längere Vegetationszeit beansprucht, steigt nicht bis zu den obersten Dauersiedlungen hinauf. Im Diemtigtal ist ihre obere Grenze im Talboden in der Bäuert Zwischenflüh in ungefähr $1100 \mathrm{~m}$ Höhe.

Am gleichen Ort haben wir auch die letzten Obstbäume festgestellt, deren es im Diemtigtal noch zahlreiche gibt, wie folgende Zahlen beweisen: Apfelbäume 1895, Birnbäume 791, Kirschbäume 1362, Zwetschgen- und Pflaumenbäume 530, Quittenbäume 15 und 63 Nußbäume. Die Obstbäume wachsen vorwiegend im vordern Teil des Tales und bringen nur dort einen nennenswerten Ertrag hervor.

b) Die obere Mähwiesengrenze

Sie setzt bei der Lochmatte in der Bäuert Bächlen in $900 \mathrm{~m}$ Höhe ein. Aber schon bei Vechismad ist sie auf $1030 \mathrm{~m}$ hinaufgerückt. Je mehr nun die Niesenflanke in die NW-Richtung übergeht, desto höher steigen auch die Mähwiesen. Bei Rütti erreicht die obere Grenze $1180 \mathrm{~m}$, um nachher bis zum Springboden emporzuklettern. Dann beginnt die Kurve infolge der zunehmenden Steilheit des Geländes zu sinken, um in $1260 \mathrm{~m}$ Höhe auf die andere Talseite des Kirelbaches hinüberzuwechseln. Am Schwarzenberg läßt sie sich in $1110 \mathrm{~m}$ Höhe verfolgen. Sie behält diese Höhe bei, bịs sie sich 
auf dem Schuttfächer von Ennetkirel auf $1200 \mathrm{~m}$ Höhe hebt. Anschließend setzt sie an der ganzen Flanke des Höllerberges aus und kann erst wieder auf dem Schuttkegel von Tiermatten eingezeichnet werden, wo sie in $1230 \mathrm{~m}$ Höhe verläuft. Sie steigt hierauf allmählich an, um bei Warttannen in $1290 \mathrm{~m}$, bei Grunholz in $1340 \mathrm{~m}$ sich hinzuziehen und diese Höhe an den beiden Flanken des Stierengrimmi zu bewahren. Auf der linken Seite des Grimmibaches senkt sie sich langsam über Schlunegg $(1260 \mathrm{~m})$ zum Fildrich hinunter, den sie bei Tiermatten in $1145 \mathrm{~m}$ Höhe erreicht. Sie folgt jetzt seinem Lauf. Erst kurz vor Narrenbach verläßt sie ihn und schwingt sich zunächst auf $1200 \mathrm{~m}$, dann auf $1270 \mathrm{~m}$ hinauf. Sie wird bis zum Stierenweidli im Mäniggrund unterbrochen, wo sie sich auf ein kurzes Stück in $1340 \mathrm{~m}$ Höhe feststellen läßt. Die ganze Schattseite des Mäniggrundes ist sonst von Wald und Weide eingenommen. Auf.der Sonnseite sind die Heuwiesen etwas zahlreicher. Der Mittelwert der obern Grenze ist hier $1350 \mathrm{~m}$. Die Kurve verliert neuerdings an Höhe und hat bei Schwand noch $1280 \mathrm{~m}$, bei Hasli $1200 \mathrm{~m}$ Höhe. Diese bleibt gleich bis Riedli; dann fällt sie plötzlich auf $1100 \mathrm{~m}$, auf $1065 \mathrm{~m}$, um nach wenigen hundert Metern Längserstreckung im Talboden angelangt zu sein. Dieses Fallen wird durch den Steilabrall des Abendberges bewirkt, der an seiner Basis eine ausgedehnte, mit Wald bekleidete Schutthalde besitzt. Die obere Grenze der Mähwiese wird nun bis zum Bauerngut Emmit unterbrochen $(930 \mathrm{~m})$ und führt hierauf zum Diemtigbergli $(1070 \mathrm{~m})$ hinauf, wo sie mit der des Niedersimmentales verbunden werden kann.

Die orographischen Verhältnisse verlangen, die vier bei den Siedlungen erwähnten Unterabteilungen des Diemtigtales beizubehalten.

\section{Abschnitt}

Oey-Zusammenfluß Kirel-Fildrich . . . . . . . . . . . Horboden-Zusammenfluß Fildrich-Narrenbach . . . . . Einzugsgebiet Fildrich und Grimmibach . . . . . . . . . Mäniggrund . . . . . . . . . . . . . . . . . .

Linke Talseite
$1035 \mathrm{~m}$
$1141 \mathrm{~m}$
$1252 \mathrm{~m}$
$1340 \mathrm{~m}$

Linke Talseite $1141 \mathrm{~m}$ $1252 \mathrm{~m}$

c) Die Waldgrenze

Im Diemtigtal schwankt die Waldgrenze je nach der Oberflächengestaltung und der Exposition von $1600 \mathrm{~m}$ bis maximal $1960 \mathrm{~m}$ Höhe. Fast auf der gesamten rechten Talseite liegt die Alphüttengrenze höher als die Waldgrenze. Eine Berechnung aus der Karte ergibt für die heutige, obere Waldgrenze auf der Schattseite des Tales einen ungefähren Durchschnitt von $1750 \mathrm{~m}$, womit wir einen Wert erhalten haben, der sich von dem von IMHOF mit $1880 \mathrm{~m}$ um $130 \mathrm{~m}$ unterscheidet. Auf der Sonnseite fanden wir ein Mittel von $1800 \mathrm{~m}$, also $50 \mathrm{~m}$ weniger, als IMHOF errechnet hat.

Die in niedrigerer Höhe verlaufende Waldgrenze der rechten Talseite ist wahrscheinlich teilweise auf die klimatisch ungünstigeren Bedingungen zurückzuführen, dann aber sicher auch auf den ausgedehnten Weidebetrieb an der Niesenkette, der mit der Sennerei verkoppelt ist. Auf der Sonnseite sind infolge der ungünstigen orographischen Bedingungen nur vereinzelte Alpweiden vorhanden. Sie liegen, wie auch die des Mäniggrundgebietes, meistens innerhalb des Waldgürtels und erreichen so in ihrer durchschnittlichen Höhe die obere Waldgrenze nicht.

\section{d) Die obere Grenze der Alphütten}

Im untersten Talabschnitt, der von Burgholz bis zur Einmündung des Kirels in den Fildrich reicht, finden sich alle Alpen an der Westflanke der Niesenkette in ungefähr $1800 \mathrm{~m}$ Höhe. Die Reihe beginnt mit der Niesenkumlialp $(1680 \mathrm{~m})$ und setzt sich über die Drunenalp (1750 m), Standalp (1790 m), Nizelalp (1800 m), Tschiparellenalp (1803 m), Mächlistalalp $(1845 \mathrm{~m})$, obere Meienfallalp $(1830 \mathrm{~m})$ zur Hohniesenalp $(1930 \mathrm{~m})$ fort und endet auf der Kirelalp im 'Talabschluß des. Kirelbaches in $1520 \mathrm{~m}$ Höhe. In diesem Teil des Diemtigtales haben sich zufolge der ungünstigen Oberflächenbedingungen auf der Sonnseite keine Alpweiden gebildet. 
Die Grenzen des mittleren Talstückes werden durch den Kirelbach und eine Linie von Narrenbach über die Hohmad nach dem Twirienhorn bezeichnet. Innerhalb dieser Linien wird die obere Alphüttengrenze auf der Schattseite durch folgende Punkte bestimmt: Schwarzwaldalp (1738 m), Bodenfluhalp (1604 m), Mettenberg (1846 m), Bütschi (1936 m), Ramsen (1435 m) und Vorderkirel (1480 m). Auf der Sonnseite haben wir einzig die Alp Blachli in $1620 \mathrm{~m}$ Höhe, weil die Rinderalp und Tärfeten trotz ihrer Lage zum Niedersimmental gerechnet worden sind.

Im dritten Talabschnitt, der sich von Narrenbach bis zum obern Talende erstreckt, stehen zahlreiche Alphütten in beachtlicher Höhe. Auf der rechten Talseite sind die der Twirienalp $(1856 \mathrm{~m}$ ) und in einer Entfernung von ungefähr $2 \mathrm{~km}$ die von Ober-Gurbs $(1955 \mathrm{~m})$ zu erwähnen. Es folgen die Hütten der Alp Schönen (1921 m), hierauf die von zwei Alpen am Fuße der Kirgelischeibe in $1796 \mathrm{~m}$ und $1718 \mathrm{~m}$ Höhe. Eingerahmt durch Kileischeibe, Männlifluh, Erbethorn und Wannenspitz sind die Sennhütten von Galm $(1980 \mathrm{~m})$, Oberthal $(2175 \mathrm{~m})$ und Oberberg $(1950 \mathrm{~m})$. Im engern Talabschlußgebiet sind die periodischen Siedlungen von Kumli $(1871 \mathrm{~m})$, Steinboden $(1770 \mathrm{~m})$, Neßli $(1580 \mathrm{~m})$, von Stierengrimmi $(1816 \mathrm{~m})$, Grimmi $(1805 \mathrm{~m}, 1841 \mathrm{~m}, 1741 \mathrm{~m})$, Nydegg $(1380 \mathrm{~m})$, Wildgrimmi $(1729 \mathrm{~m})$ und Alpetli $(1810 \mathrm{~m})$ als wichtige Punkte zu berücksichtigen.

Auf der linken Talseite kommen als Folge der ungünstigen Oberflächenformen vorwiegend 200-300 m hohe Kalkflühe, wie die des Frohmattgrates, des Seehorns, des Mäniggrates und der Schurten - bloß die Oberkumlihütte in $1700 \mathrm{~m}$ und die Hütten von Alp in $1480 \mathrm{~m}$ Höhe vor.

Der Mäniggrund bildet als Seitental den vierten Abschnitt. Auf seiner rechten Talseite wird die obere Grenze durch die Alphütten auf dem Mäniggrat (1869 $\mathrm{m}$ und $1854 \mathrm{~m})$, durch Hintermänigen $(1674 \mathrm{~m})$ und Seebergalp $(1805 \mathrm{~m})$, auf der linken Talseite durch die Untergestelenalp $(1716 \mathrm{~m})$, Vierzel $(1620 \mathrm{~m})$, Näßli $(1520 \mathrm{~m})$ und Brunstallmend (1590 m) gegeben.

Die Durchschnittswerte für die obere Grenze der Alphütten im Diemtigtal lauten:

Diemtigtal

1. Abschnitt . . . . . . . . . . . . . . . . . . .

2. Abschnitt . . . . . . . . . . . . . . . . . .

3. Abschnitt . . . . . . . . . . . . . . . . . . .

4. Mäniggrund . . . . . . . . . . . . . . . .
Linke Talseite

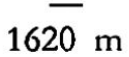

$1590 \mathrm{~m}$

$1611 \mathrm{~m}$
Rechte Talseite

$1772 \mathrm{~m}$

$1673 \mathrm{~m}$

$1816 \mathrm{~m}$

$1800 \mathrm{~m}$

4. Landwirtschaftliche Grenzen in den Gemeinden Boltigen und Zweisimmen

a) Obere Grenzen von Kulturpflanzen

Der Getreideanbau ist mit Sommerroggen und Hafer bis zu den höchstgelegenen Dauersiedlungen, die im Moos ob Vorderreichenstein stehen, vertreten. Bei Zimmernboden und Ruhren wird bei sonniger Südexposition Getreide angepflanzt, während es in gleicher Höhe Auf den Eggen ob Heimersmad im Begehungsjahr fehlte. Diese Tatsache muß darauf zurückgeführt werden, daß Auf den Eggen den Nordwinden ausgesetzt ist und daß bei der waagrechten Oberfläche die Wirkung der Sonnenstrahlen zufolge des schieferen Auftreffens geringer ist. In diesen obersten Lagen vermag der Sommerroggen aber nur in warmen, sonnenreichen Jahren zu reifen. In feuchten und kühlen Jahren bringt oft nicht einmal der anspruchslosere Hafer einen Ertrag.

Für die Kartoffel gilt dasselbe wie im Niedersimmental und im Diemtigtal. Neu kommt aber hinzu, daß neben den obersten Dauersiedlungen die ersten Vorsassen stehen, die ebenfalls einen kleinen Kartoffelacker wie auch einen Gemüsegarten mit den bereits genannten Gemüsen und Beerensträuchern aufweisen. 
Obstbäume kommen an der obern Grenze der Dauersiedlungen nur noch ganz vereinzelt vor, trotzdem sie, wie die Statistik beweist, noch ziemlich zahlreich vorhanden sind.

$\begin{array}{cccccccc}\text { Gemeinde } & \begin{array}{c}\text { Apfel- } \\ \text { bäume }\end{array} & \begin{array}{c}\text { Birn- } \\ \text { bäume }\end{array} & \begin{array}{c}\text { Kirsch- } \\ \text { bäume }\end{array} & \begin{array}{c}\text { Zwetschgen-, } \\ \text { Pflaumenbäume }\end{array} & \begin{array}{c}\text { Quitten- } \\ \text { bäume }\end{array} & \begin{array}{c}\text { Nuß- } \\ \text { bäume }\end{array} & \begin{array}{c}\text { Aprikosen- } \\ \text { bäume }\end{array} \\ \text { Boltigen . . } & 2336 & 768 & 1111 & 610 & 5 & 16 & 5 \\ \text { Zweisimmen : } & 2734 & 640 & 685 & 309 & 3 & 2 & 1\end{array}$

Klaräpfel und Lebel tragen in warmen Sommern reife Früchte bis in eine Höhenlage von $1350 \mathrm{~m}$, so wiederum bei Moos. Jährliche Ernten sind aber in diesem Teil des Obersimmentales, je nach der Lage, nur in $1000-1100 \mathrm{~m}$ Höhe als sicher zu erwarten.

Vereinzelte Kirschbäume wachsen noch bei den obersten, ständig bewohnten Heimwesen, so im Moos und bei Grünenwald ob Hinterreichenstein.

b) Die obere Grenze der Mähwiesen

Die Grenzlinie ist auf der rechten Talseite kaum feststellbar, weil diese stark bewaldet ist. Sie beginnt bei Breiti, wo sie im Niedersimmental geendet hat; und führt nachher über Fuchshalten-Fürsteini in leichtem Fallen zum Mißlisboden in $900 \mathrm{~m}$ Höhe. Dann verliert sie sich im Wald und taucht erst wieder im Aufstieg zum Regenmoos auf. Sie liegt etwa fünfzig Meter über dem Talboden. Eine längere, zusammenhängende Grenze ist auf der Terrasse von Hofstätten in $1330 \mathrm{~m}$ Höhe zu erkennen. Sie wird neuerdings durch Waldgebiet unterbrochen. Von Gschwend bis Gerstern kann ihre Höhenlage mit $1370 \mathrm{~m}$ angenommen werden. Dann bricht sie ab, weil bis Neuenegg ob St. Stephan eine dichte Waldbedeckung der Talflanke vorhanden ist.

Auf der linken Talseite setzt sie bei Wöschbrunnen ein und zieht über Bettelegg nach Adlemsried, wo sie in $1100 \mathrm{~m}$ Höhe liegt, nach Taubenthal, Schwarzenmatt, Farni und erreicht dann Weid. Sie verliert nach Adlemsried infolge der orographischen Verhältnisse an Höhe und sinkt auf ungefähr 1000 m, um gegen Weid wieder auf $1080 \mathrm{~m}$ anzusteigen.

Sie klettert im Gebiet des Jaunpasses bis auf $1460 \mathrm{~m}$ hinauf und fällt dann über Ruhren $(1410 \mathrm{~m})$, Beret $(1350 \mathrm{~m})$ nach Auf den Eggen auf $1320 \mathrm{~m}$ hinunter. Hierauf wird sie durch den Flühwald unterbrochen und setzt erst bei Moos in $1450 \mathrm{~m}$ Höhe ein. Diese Höhe bewahrt sie bis an die Grenze des Amtsbezirkes Saanen.

Auf der Schattseite des Tales der Kleinen Simme verläuft die Kurve von der Wäflernweid langsam ansteigend $(1260 \mathrm{~m})$ nach dem breiten Rücken des Rinderberges $(1300 \mathrm{~m})$, um auf der Seite gegen das Haupttal in $1200 \mathrm{~m}$ Höhe im Schlegelholz zu enden.

Der Mittelwert der obern Grenze beträgt in den zwei Gemeinden für die linke, sonnige Seite $1203 \mathrm{~m}$, für die rechte, schattige Talseite $1087 \mathrm{~m}$.

c) Die obere Waldgrenze

In den Gemeinden Boltigen und Zweisimmen reichen einzelne Teile der Wasserscheiden nicht über die obere Waldgrenze hinaus, so der Jaunpaß, die Oberegg und die Einsattelungen im Hugeligrat. Der Wald ist an seiner obern Grenze durch die intensive Weidewirtschaft und durch den Verbrauch von Brennholz im Sennereibetrieb stark aufgelockert worden. Die obere Waldgrenze zieht sich auf beiden Talseiten in durchschnittlich $1800 \mathrm{~m}$ Höhe hin.

d) Die obere Grenze der Alphütten

Die ganze rechte Talseite bleibt in ihrer Höhenentwicklung unter der obern Grenze der Weideregion zurück. Zudem besitzt diese Talseite in den zwei Gemeinden nur ganz ausnahmsweise Steilhänge und schroffe Gipfelformen. So dehnen sich die Alpweiden bis an die Wasserscheide aus, während die Alphütten meistens darunter, in windgeschützten Lagen zurückbleiben. 
Die erste, rechtsseitige Alp im Obersimmental ist die links des Niederhornkammes gelegene Hintere Niederhornalp in $1836 \mathrm{~m}$ Höhe. Es folgt dann in der Einsenkung zwischen dem Niederhorn (2080 m) und dem Bunschlergrat (2075 m) die obere Bunschleralp $(1805 \mathrm{~m})$. Auf dem südlichen Ausläufer des Niederhornes breitet sich die Luglenalp in $1910 \mathrm{~m}$ Höhe aus. Rechts der Wasserscheide zwischen dem Mänigbach und dem Mannriedbach, aber zum Obersimmental gehörend, liegt Obergestelen mit Alphütten in-1800 m Höhe. Dann zieht die obere Grenze über die Muntigenalp am Fuße der Geißfluh $(1750 \mathrm{~m})$, Stieren-Seeberg $(1864 \mathrm{~m})$ nach Gammerschal $(1860 \mathrm{~m})$, Bergli $(1764 \mathrm{~m})$ und Frohmatt $(1860 \mathrm{~m})$, die alle am Frohmattgrat zu finden sind. Die Kurve endet hier an einem der wild gezackten Ausläufer der Spillgertengruppe.

Auf der linken Talseite bestehen zunächst dieselben Verhältnisse wie im Niedersimmental. Die Alpweiden dehnen sich hinter der ersten, aus Kalkschichten bestehenden Kette aus. Sie liegen im allgemeinen in geringen Höhen wie die Aebialp (1548 m) hinter der Holzersfluh, wie Walop am Fuße der Kaiseregg (1678 m), Luchernalp am Rotenkasten (1976 m), Reidigenalp (1630 m), Fluhalp (1655 m) und Zytböden (1615 m), nördlich des Bäderhornes. Das Bäderhorn (2012 m) ist der letzte Ausläufer der Klippendecke im Simmental. Es beginnt das den Voralpen ähnliche Flyschgebiet, wo sich die Alpweiden bis zu den Wasserscheiden ausdehnen. Die Alphütten sind innerhalb des Weideareals erbaut worden und erreichen deshalb keine großen Höhenwerte. Die obere Grenze der Alphütten, die hier unter der Waldgrenze bleibt, wird talaufwärts durch folgende Punkte bestimmt: Bäderberg $(1650 \mathrm{~m})$, Winteregg $(1600 \mathrm{~m})$, Obereggalp $(1696 \mathrm{~m})$, Egghürli $(1800 \mathrm{~m})$, Neuenberg $(1800 \mathrm{~m})$, Erbetlaub $(1770 \mathrm{~m})$, VorderSchlündi $(1680 \mathrm{~m})$, Meiggen $(1700 \mathrm{~m})$, Wild-Eggli $(1770 \mathrm{~m})$ und Birren $(1800 \mathrm{~m})$.

Die Mittelwerte lauten für die rechte Talseite $1827 \mathrm{~m}$, für die linke Talseite, die dem Flyschgebiet entspricht, $1710 \mathrm{~m}$.

\section{Landwirtschaftliche Grenzen in den Gemeinden St. Stephan und Lenk}

a) Obere Grenzen von Kulturpflanzen

Der Getreidebau fehlt bei einigen obersten Dauersiedlungen, so bei Neuenegg, Ried, Rütti, Dachboden, Zu Hähligen, Obersteg, Port, Brandegg, Metsch und bei den obersten, dauernd bewohnten Heimwesen in der Bäuert Pöschenried. Dagegen ist heute der Getreideanbau im Fermeltal trotz des unsichern Ertrages wieder aufgenommen worden.

Die Kartoffel gedeiht bis zu den obersten Dauersiedlungen und wird auch bei den Vorsassen, die ungefähr in der gleichen Höhe liegen, angepflanzt. Aber auch hier ist sie wie im Mäniggrund, in Senggi und an andern Orten von Frostschäden bedroht.

Die Gemüsegärten mit den bereits genannten Gemüsearten fehlen bei keiner Dauersiedlung, sind allerdings oft von recht bescheidener Größe. Die Fruchtsträucher gedeihen in sonnigen Lagen bis in $1300 \mathrm{~m}$ Höhe, in schattigen bleiben sie unter $1200 \mathrm{~m}$. Als Durchschnitt ist $1200 \mathrm{~m}$ anzunehmen. Für die Stangenbohnen ist die Talsohle des Obersimmentales das oberste Verbreitungsgebiet.

Die Anzahl der Obstbäume hat stark abgenommen, wie die Statistik beweist. Die hier aufgeführten Bäume wachsen fast ausschließlich in der Talsohle und an den untersten Hangpartien, so besonders in der Bäuert Gutenbrunnen.

$\begin{array}{cccccccc}\text { Gemeinde } & \begin{array}{c}\text { Apfel- } \\ \text { bäume }\end{array} & \begin{array}{c}\text { Birn- } \\ \text { bäume }\end{array} & \begin{array}{c}\text { Kirsch- } \\ \text { bäume }\end{array} & \begin{array}{c}\text { Zwetschgen-, } \\ \text { Pflaumenbäume }\end{array} & \begin{array}{c}\text { Quitten- } \\ \text { bäume }\end{array} & \begin{array}{c}\text { Nuß- } \\ \text { bäume }\end{array} & \begin{array}{c}\text { Aprikosen- } \\ \text { bäume }\end{array} \\ \text { St. Stephan . . . } & 915 & 220 & 254 & 116 & 2 & 4 & 2 \\ \text { Lenk . . . . } & 1213 & 279 & 688 & 62 & 2 & 1 & -\end{array}$

In Neuenegg in $1313 \mathrm{~m}$ Höhe fanden wir den obersten Apfelbaum, und zwar einen Lebel; also tiefer als in der Gemeinde Zweisimmen. 


\section{b) Die obere Mähwiesengrenze}

Das erste kurze Stück der Grenzlinie ist bei Neuenegg in $1320 \mathrm{~m}$ Höhe festzustellen. Ein weiterer kurzer Teil zieht sich oberhalb Ried und Rütti in einer durchschnittlichen Höhe von $1370 \mathrm{~m}$ hin. In diesem Gebiet tritt der Sonderfall ein, daß nach einer Weidezone, die $230 \mathrm{~m}$ Höhendifferenz umfaßt, auf dem Dachboden und bei Gfell sich noch einmal kleine Mähwiesen ausbreiten. Sie haben SW-Exposition und eine durchschnittliche Höhe von $1600 \mathrm{~m}$. Anschließend sinkt die Kurve ins Fermeltal und zieht sich wenige Meter oberhalb der Siedlungen durch. An Höhenzahlen sind $1490 \mathrm{~m}, 1460 \mathrm{~m}$, $1460 \mathrm{~m}$ und $1450 \mathrm{~m}$ zu nennen. Die obere Grenze führt nachher hinüber gegen Eggen und $\mathrm{Zu}$ Hähligen, wo sie in $1400 \mathrm{~m}$ Höhe liegt. Bei Obersteg hat sie die gleiche Höhe. Der aufgelockerte Wald, der sich oberhalb der Bäuert Bleiken ausbreitet, vermag die Grenzlinie zu unterbrechen. Sie läßt sich gut feststellen in Port, wo sie sich in $1490 \mathrm{~m}$ Höhe befindet. Dann buchtet sie nach unten aus, um hierauf nach Brandegg $(1530 \mathrm{~m})$ hinaufzuklettern. Nach diesem zweiten, kleineren Maximum setzt sie sich über Tannenbühl $(1400 \mathrm{~m})$, Metsch $(1500 \mathrm{~m})$, Sumpf $(1460 \mathrm{~m})$ fort, um von dort in den Talboden hinunterzufallen $(1120 \mathrm{~m})$.

An der Ostseite des Langerberges hebt sich die Mähwiesengrenze auf $1170 \mathrm{~m}$ hinauf. $\Lambda$ ber erst im Iffigental erreicht sie wieder größere Höhen. Für die rechte, relativ kurze Talseite kann ein Mittelwert von $1290 \mathrm{~m}$ angenommen werden. Auf der gegenüberliegenden Seite setzt sie unterhalb der Iffigenfälle bei $1320 \mathrm{~m}$ ein, verliert dann $30 \mathrm{~m}$ an Höhe, um bei Stalden wieder die Höhenlinie von $1350 \mathrm{~m}$ zu gewinnen, und dann bis zur Seefluh auf $1230 \mathrm{~m}$ zu sinken. Dieser Isohypse folgt sie bis Aegerten, wo sie auf dem großen Schuttkegel in $1320 \mathrm{~m}$ Höhe verläuft. Infolge der Geländeverhältnisse tritt ein neuerlicher Höhenverlust ein, und sie zieht sich bis Niederdorf am Rande der Talebene zum Talhang hin. Von hier an liegt sie wieder in größeren Höhen, wo sie sich aber nur in kurzen Teilstücken bestimmen läßt, so bei Stutz in $1240 \mathrm{~m}$, bei Boden (Nr. 108) in $1380 \mathrm{~m}$, bei Boden (Nr. 109) in $1260 \mathrm{~m}$ Höhe. Dann schwankt sie um diese Höhenlinie herum, um vom Scheuergut an $(1140 \mathrm{~m}) \mathrm{zu}$ sinken und in einer durchschnittlichen Höhe von $1000 \mathrm{~m}$ am Schlegelholz zu enden.

Die Mittelwerte ergeben für die rechte Talseite $1390 \mathrm{~m}$, für die linke $1213 \mathrm{~m}$. Der größere Wert der rechten Talseite ist auf ihre klimatische Begünstigung zurückzuführen. Die Abendsonneneinstrahlung wirkt sich viel stärker auf die Schneeschmelze im Winter und Frühling und auf das Pflanzenleben im Frühling und Sommer aus, weil die Luft tagsüber erwärmt worden ist. Die Morgensonne, die den linken, nach Osten gerichteten Talhang bescheint, muß zuerst die nächtliche Kühle überwinden, bevor sich ihre Wärmewirkung bemerkbar macht. Dieser Unterschied der Sonneneinwirkung ist besonders gut im Frühling während der Ausaperung zu beobachten. Die linke Talflanke ist oft noch weit hinunter mit Schnee bedeckt, während die rechte bereits schneefrei ist.

c) Die obere Waldgrenze

In den Gemeinden St. Stephan und Lenk ist der Wald im allgemeinen in größeren, zusammenhängenden Beständen vorhanden als im übrigen Simmental. Die Erhebungen überragen hier die obere Waldgrenze. Sie läßt sich deshalb einwandfreier und genauer festlegen. Einzig im obern Talschluß wird sie durch die Flühe des Wildstrubelmassivs unter die klimatische, obere Waldgrenze hinabgedrückt. Die von Імноғ angegebene Höhe von $1820 \mathrm{~m}$ kann für beide Talseiten verwendet werden.

d) Die obere Grenze der Sennhütten

Die Unwirtlichkeit des Spillgertengebietes verhindert mit einer einzigen Ausnahme auf der rechten Talseite bis zum Fermeltal die Entstehung von Alpen. So findet sich nur die Alp Viehsattel mit einer Hütte in $1720 \mathrm{~m}$ Höhe. Die nächsten periodischen Siedlungen stehen erst wieder oberhalb der Dauersiedlung Gruben im Fermeltal. Ihre 
Verbreitung beschränkt sich auf die Sonnseite des Tales. Die obersten Sennhütten sind hier auf dem Blutlig (1984 m), Horn (2154 m), Muriboden (2000 m) und auf dem ausgedehnten Fermelberg in $1920 \mathrm{~m}$ Höhe. Zahlreiche Alpweiden liegen am Abhang gegen den Albristbach und nach Obersteg an der Haupttalflanke. Es gehören hierzu die Weidegebiete von Hüttenzaun $(1795 \mathrm{~m})$, Albristmäder $(1850 \mathrm{~m})$, Albrist $(1716 \mathrm{~m})$; Hinterberg $(1912 \mathrm{~m})$ - die Hütten von Weißenberg und Ober-Läger stehen bedeutend tiefer, Boden $(2050 \mathrm{~m})$, Seewelen $(1850 \mathrm{~m})$, Laveyalp $(2000 \mathrm{~m})$, Hahnenmoos (1960 m), Metschberg (1840 m) und Pommernalp (2040 m).

Im Talhintergrund unterscheiden sich das Haupttal und das Iffigental, was die Anlage von Alpen betrifft, sehr deutlich voneinander. In jenem liegen die Alpen des Trogschlusses wegen bedeutend tiefer als im gesamten übrigen Tal, so die Ammertenalp in $1560 \mathrm{~m}$ Höhe und der Räzliberg sogar nur in $1400 \mathrm{~m}$ Höhe, während im Iffigental der Ritzberg in $1740 \mathrm{~m}$ und Stieren-Iffigen in $2100 \mathrm{~m}$ Höhe sich ausdehnen. Auf dem breiten Rücken, der sich zwischen dem Simmental und dem Iffigental einschiebt, stehen die Alphütten von Langeralp $(1680 \mathrm{~m})$ und Langermatte $(1860 \mathrm{~m})$.

Auf der linken Talseite herrschen keine so ungünstigen orographischen Bedingungen wie in der Spillgertengruppe, an der Albristegg und im Talabschluß. Die obere Grenze der Sennhütten ist in ihrer Höhenlage viel regelmäßiger als auf der gegenüberliegenden Talflanke. Der Ausgangspunkt für die Grenze ist nördlich des Iffigenhornes gewählt worden, und sie führt dann talauswärts, Richtung Zweisimmen.

Die erste, für diese Linie maßgebende Alp ist Saanenstafel $(1860 \mathrm{~m})$, gefolgt von Ritzliberg (1920 m), Bettelbergmäder $(1940 \mathrm{~m})$, Tschäti $(1875 \mathrm{~m})$, Haslerbergmäder beim Trüttlisberg $(1920 \mathrm{~m})$, Lochberg $(1950 \mathrm{~m})$, Hinterberg $(1818 \mathrm{~m})$, Reulissen $(1700 \mathrm{~m})$ und von da in einem großen Sprung über Neßleren $(1591 \mathrm{~m})$ an die Flanke des Geißhornes; wo Hinterbergli in $1800 \mathrm{~m}$ und Gandlauenen in $1820 \mathrm{~m}$ Höhe liegen. Dann schwenkt die Kurve um den breiten Rücken des Rinderberges herum in das Gebiet der Saanenmöser.

Die Mittel der obern Grenze der Alphütten lauten für diesen Talabschnitt für die rechte Talseite - ohne Talabschluß - $1919 \mathrm{~m}$, für die linke $1835 \mathrm{~m}$. Sie zeigen, daß auf der rechten Talseite die Sennhütten durchschnittlich $100 \mathrm{~m}$ über der obern Waldgrenze liegen, was den von FlüCKIGER und IMHOF angegebenen Werten entspräche, auf der linken Talflanke dagegen bloß $15 \mathrm{~m}$ über der Waldgrenze. Diese Zahl stimmt mit denen der beiden genannten Autoren wiederum nicht überein. Dieser geringe Unterschied von $15 \mathrm{~m}$ ist auf die allgemein kleineren Höhen der links der Simme gelegenen Gebirgszüge zurückzuführen.

\section{ZUSAMMENFASSUNG DER ERGEBNISSE}

\section{Allgemeine Ergebnisse für die Besiedlungsfähigkeit eines Gebietes}

Die Orographie und das Klima sind in ihren Wechselbeziehungen zueinander die dafür entscheidenden Größen. Die eine kann die Besiedlung oft erlauben, während sie die andere am gleichen Ort verunmöglicht.

Die großen landschaftsgestaltenden Formen der Gebirgszüge und der Täler stimmen im Simmental im großen und ganzen mit der Tektonik überein. Sie bedingen, zusammen mit dem Wechsel der verschiedenen Gesteinsarten, die Ausdehnung der besiedlungsfähigen Zone. Innerhalb dieser Zone sind es nun aber die einzelnen kleinen Geländeformen, die die Standorte der Dauersiedlungen beeinflussen. Diese Standorte wie Terrassen, Eggen, Rücken, Mulden, sanfte Gehänge sind das Ergebnis einer langen Entwicklung, an der die Verwitterung, Fluß- und Gletschererosion, Denudation und Ablagerung teilgenommen haben. Alle diese Kräfte trugen dazu bei, die für die Siedlung wichtigen Einzelzüge in der Landschaft zu gestalten. Dabei ergab. 
sich, daß das Alter der Gesteine unwesentlich ist, weil der Kalk immer die charakteristischen Kalkverwitterungsformen, der Flysch, die Brekzien usw. die ihren zeigen.

Im Simmental ist die Tatsache - HAMmer hat sie bereits bewiesen $(6,77)-$, daß die Kalkgebiete von den Dauersiedlungen gemieden werden, sehr leicht feststellbar. Hier sind die Kalkgebiete überall durch schroffe Formen gekennzeichnet, und am Fuße der Kalkflühe sind meistens Schutthalden angelagert, so daß in diesem Gelände die Dauersiedlungen überall fehlen.

Gleich ungünstig auf die Entstehung von dauernd bewohnten Niederlassungen wirken sich ungegliederte, steile Hänge aus. Sogar sanfte Böschungen bleiben unbesiedelt, wenn sich in ihrer Nähe die bevorzugten Geländeformen wie Terrassen, Schuttkegel und Eggen befinden. Diese Erscheinung ist schon von den zahlreichen Forschern der österreichischen Alpentäler erläutert worden. Die Anlage der Siedlungen im Simmental beruht also auf den gleichen Ueberlegungen wie in den andern Alpentälern.

In jene Gebieten, in denen die Orographie die Besiedlung bis zur Kammlinie oder zur Wasserscheide erlaubte, bestimmt nun das örtliche Klima die obere Grenze der Dauersiedlungen. Die örtlichen klimatischen Einflüsse verändern das in der Schweiz herrschende Uebergangsklima vom ozeanisch-gemäßigten zum kontinental-gemäßigten Typus und das Gesetz der Temperaturabnahme mit der Höhe. Sie bringen ein unablässiges Schwanken der pflanzengeographischen Höhengrenzen zustande, von dem auch die Lage der Dauersiedlungen abhängig ist, bleiben doch die Bauern für ihre Existenz an die landwirtschaftlichen Möglichkeiten der Anpflanzung und der Ente gebunden. Im Simmental sind auf weite Strecken, weil keine orographischen Bedingungen die obere Grenze der Dauersiedlungen festlegen, diese pflanzengeographischen obern Grenzsäume von maßgebendem Einfluß.

\section{Ergebnisse in bezug auf die Siedlungslagen}

Bei der Vielgestaltigkeit des Simmentales sind die von LöwL erwähnten Siedlungslagen beinahe vollzählig vorhanden. Es überwiegen weitaus die Terrassensiedlungen, die von den Schuttkegel-, Talboden-, Leisten- und Hangsiedlungen gefolgt werden. Die Rundhöcker-, Staffel- und Haldensiedlungen fehlen im Simmental an der obern Grenze der Siedlungszone. Löws versteht unter dem Begriff «Halde» eine trockene Anlagerung von Felstrümmern (Schutthalde). Diese Halden sind hier, wie wir bereits erwähnt haben, durchwegs unbesiedelt.

Die Untersuchungen im Simmental zeigen, daß die Zahl der Siedlungstypen um zwei vermehrt werden kann, nämlich um die Eggsiedlung und die Muldensiedlung.

Die Egg - diese Bezeichnung ist in der Schweiz bekanntlich sehr verbreitet - ist eine im Gelände vorspringende Vollform von beschränkter Oberflächenausdehnung. Sie kommt entweder in einer von Bächen stark zerschnittenen Erosionslandschaft vor, wie zum Beispiel im Napfgebiet; aber auch im Simmental, wo sie mehr vereinzelt aus einem ziemlich steilen Hang vorspringt und wo es sich um eine Denudationsform handelt. Sie sind im allgemeinen der Besonnung, im Vergleich zum umliegenden Gelände, vorteilhaft ausgesetzt und werden weder von Wildwassern, Steinschlag noch Lawinen bedroht. Die Oberfläche der Egg ist meist ziemlich flach, so daß dort Gebäude errichtet werden können. Diese Eggen führten an verschiedenen Stellen zur Besiedlung, wo sie sonst wahrscheinlich fernbliebe, wie beispielsweise an der nordwestlichen Abdachung der Niesenkette, wo dieser Typus mehrmals vorkommt.

Bei der Muldensiedlung handelt es sich um ein Wohnhaus in einer kleinen Hohlform an einem sanften Abhange. Sie ist dreiseitig mehr oder weniger vom Hang eingeschlossen und weist daher Nachteile auf, so die der geringeren Besonnung und die der größeren Feuchtigkeit, die vom Boden aus leicht ins Haus eindringen kann. Als einzigen Vorteil besitzt sie einen ziemlich guten Windschutz, der aber die Nachteile nicht aufzuwiegen vermag. Die Muldensiedlung ist deshalb selten. 


\section{Ergebnissé in bezug auf die Wasserversorgung}

Die Untersuchung über die Dauersiedlungen im Simmental haben sich, soweit möglich, auch auf die Wasserversorgung erstreckt, um die Abhängigkeit der Anlage des Wohnhauses von den Quellverhältnissen zu bestimmen. Die Resultate wurden, um eine Eintönigkeit möglichst zu vermeiden, lange nicht bei allen aufgenommenen Dauersiedlungen angegeben.

Es ergibt sich nun, daß heute an der obern Grenze der Dauersiedlungen die genossenschaftlich organisierte Wasserversorgung von zwei bis fünf Mitgliedern am häufigsten vorkommt. Ziemlich zahlreich ist auch die Einzelwasserversorgung, die immer aus einer eigenen Quelle erfolgt, die durch ein Wasserrecht geschützt ist. Der Fall, daß eine ganze Bäuert sich zu einer Wassergenossenschaft zusammengeschlossen hat, ist ziemlich selten. Die Ursache liegt darin, daß die einzelnen Heimstätten an der obern Grenze der Dauersiedlungen zu weit auseinander stehen, um eine gemeinsame, bäuertweise organisierte Wasserversorgung aufzubauen.

Diejenigen Dauersiedlungen, die eine eigene Quelle besitzen, haben sie im Mittel in ungefähr $100 \mathrm{~m}$ Entfernung. Sprudelt erst weiter weg eine Quelle hervor, so ist sicher, daß im nähern Umkreis der Niederlassung ein Bach oder ein Bächlein vorbeirauscht, die in früheren Zeiten das notwendige $\mathrm{NaB}$ geliefert haben.

Bei den Genossenschaften, handle es sich um eine kleine oder größere, entspringen die Quellen meistens in größerer Entfernung, weil die angeschlossenen Mitglieder auf einen ergiebigeren Erguß angewiesen sind. Oft werden mehrere Quellen in einer Brunnstube zusammengeleitet, von wo aus dann das Wasser auf die einzelnen Wohnhäuser verteilt wird. Aber auch hier ist es ursprünglich so gewesen, daß immer in der Nähe der Niederlassung entweder eine kleine Quelle, ein Bach oder ein Bächlein ist, die einmal für die Wasserversorgung benützt worden sind.

Sämtliche Dauersiedlungen sind folglich in der näheren Umgebung von Wasser entstanden. - Die wenigen Orte, die bei den häufigen Niederschlägen, die das Simmental erhält, zeitweise an Wassermangel leiden, sind erwähnt worden. Sie liegen ausnahmslos in der Nähe von Kalkgebieten. Dieser Nachteil wird bei günstiger Exposition und zusagenden landwirtschaftlichen Bedingungen in Kauf genommen.

\section{Resultate in bezug auf die verschiedenen Höhengrenzen}

Die folgende Tabelle gibt eine Uebersicht über die obern Grenzen der Dauersiedlung, der Mähwiesen, des Waldes und der Alphütten; über die Differenzen dieser Linien $z$ wischen der rechten und der linken Talseite; über die Unterschiede zwischen der Dauersiedlungsgrenze zu den erwähnten Höhengrenzen und zum Talboden.

Aus nachstehender Zusammenstellung ist ersichtlich, daß sowohl im Simmental wie im-Diemtigtal talaufwärts die durchschnittliche Höhe der Dauersiedlungsgrenze und der Mähwiesengrenze zunimmt. Die Waldgrenze verharrt dagegen in ungefähr der gleichen Höhe, so daß es sich frägt, ob das Hinaufrücken dieser beiden Grenzen auf die Massenerhebung zurückzuführen ist. Wir möchten es verneinen, weil das Simmental wenig hochgelegene Talböden hat und weil die Gebirgszüge in keine großen Höhen hinaufragen. Aus dem talaufwärts im allgemeinen abnehmenden Unterschied zwischen der Mähwiesengrenze und der Dauersiedlungsgrenze wie auch zwischen dieser und der Wald- bzw. Sennhüttengrenze ist eher an ein Hinaufsteigen der dauernd bewohnten Heimstätten an die obere Grenze der Existenzgrundlagen überhaupt zu denken. Dabei dürfen die Eingriffe des Menschen in die natürlichen Verhältnisse - Eingriffe, die sich wahrscheinlich zu Gunsten einer Ausdehnung der Mähwiesen innerhalb ihrer Grenzen auswirkten - nicht unberücksichtigt gelassen werden. Vermutlich ist hier die Wechselbeziehung: mehr Wohnhäuser - mehr Mähwiesen — anzunehmen, während die Beziehungen zur Wald- und Weidegrenze unverändert geblieben sind. 
Die Hö̀henunterschiede zwischen den einzelnen Grenzen sind in beiden Tālern sehr unregelmäßig, was die verschiedenen orographischen und örtlichen klimatischen Bedingungen widerspiegelt.

Auffällig ist es, daß im Diemtigtal die mittlere Höhe der Dauersiedlungsgrenze mit einer einzigen Ausnahme nur wenig über dem Talboden liegt, wāhrend das ganze übrige Simmental ansehnliche Höhenunterschiede aufweist. Diese Tatsache ist durch die vielen und auf langen Strecken auftretenden Kalkflühe des Diemtigtales zurückzuführen, die die Siedlungsgrenze hinunterdrücken.

Es sei schließlich noch wiederholt, daß im Simmental und im Diemtigtal die Getreidegrenze und die Dauersiedlungsgrenze an einigen Orten nicht zusammenfallen, und daß in der Getreideversorgung - im Gegensatz zu den Tälern der Ostalpen - von einer Autarkie nicht gesprochen werden kann. Die übrigen erwähnten Kulturpflanzen, ausgenommen die Obstbäume, sind bis zu den obersten Dauersiedlungen anzutreffen.

\section{Niedersimmental}
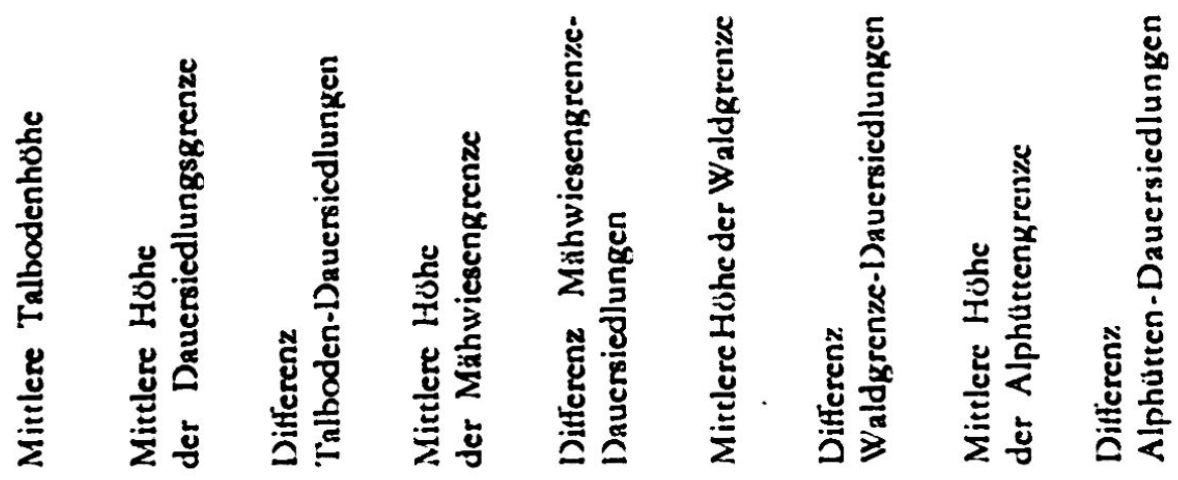

Rechte Talseite... 725

Linke Talseite ... 725

$\begin{array}{rrr}884 & 159 & 943 \\ 937 & 212 & 1017 \\ 53 & 53 & 74\end{array}$

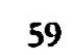

1800

916

1690

806

Differenz -

80

1700

763

1673

736

Diemtigtal

1. Abschnitt

Rechte Talseite . . . -

997 - 1136

-

100

17

2. Abschnitt

$$
\text { Differenz }
$$

Rechte Talscite . . .

Linke Talseite .. .
Differenz

965

45

-*

1035

139

1750

753

1772

775

3. Abschnitt

Differenz -

1064

101

83

1800

848

- -

Rechte Talseite . . 1185

Linke Talseite .. . 1185

$1064 \quad 99 \quad 1157$

93

50

3

$96 \quad 1141$

80

1750

686

1673

609

16

1800

739

1620

559

4. Mäniggrund

Differenz

1210

1223

1292

1252

82

50

540

53

1750

$540 \quad 1816$

$577 \quad 1590$

606

13

13

40

50

-

226

$1340 \quad 70$

1340

Rechte Talseite . . . 1270

1280

1350

1750

410

1800

1611

460

Differenz

60

60

10

1800

520

189

Obersimmental

Boleigen-Zweisimmen

Rechte Talseite . .

$918 \quad 1069$

Linke Talseitc . . .

$918 \quad 1128$

151

1087

1203

$$
18
$$

$1128 \quad 210$

116

St. Stephan-Lenk

Differen
-Lenk

Rechte Talscite . . . 1036

59

59

$1349 \quad 313$

1390

75

1800

$1710 \quad 582$

Linke Talseite . . . 1036

1162

126

1213

$41 \quad 1820$

$51 \quad 1820$

471
658

$1919 \quad 570$

$187 \quad 187$

17.

-

- -

1835

673

- Siche dazu die Eskblirung in Text auf Seite 35. 
Folglich bestimmen diese Kulturpflanzen im Verein mit den Mähwiesen die obere Grenze der Niederlassungen, wo sie nicht durch orographische Bedingungen gegeben wird.

Eine zweite Uebersicht zeigt noch einmal die gefundenen Mittelwerte für die obersten Bauernhöfe, geordnet nach Expositionen.

\begin{tabular}{|c|c|c|c|c|c|c|c|}
\hline $\begin{array}{c}\text { Gebiet } \\
\text { Niedersimmental. . . . }\end{array}$ & $\begin{array}{l}\mathrm{SE} \\
957\end{array}$ & $\begin{array}{c}S \\
.934\end{array}$ & $\begin{array}{c}S W \\
1000\end{array}$ & W & $\begin{array}{l}\text { NW } \\
1120\end{array}$ & $\begin{array}{l}N \\
861\end{array}$ & $\begin{array}{c}\mathrm{NE} \\
915\end{array}$ \\
\hline $\begin{array}{l}\text { Diemtigtal } \\
\text { 1. Abschnitt. . . . . . . . . } \\
\text { 2. Abschnitt. . . . . . . } \\
\text { 3. Abschnitt. . . . . . . . } \\
\text { 4. Mäniggrund } \\
\end{array}$ & $\begin{array}{r}880 \\
975 \\
1230 \\
-\end{array}$ & $\begin{array}{r}970 \\
1123 \\
\overline{1260}\end{array}$ & $\begin{array}{l}- \\
- \\
-\end{array}$ & $\begin{array}{c}1050 \\
\overline{1203} \\
-\end{array}$ & $\frac{1058}{-}$ & $\begin{array}{r}772 \\
1067 \\
1250 \\
1340\end{array}$ & $\begin{array}{l}\overline{1100} \\
- \\
-\end{array}$ \\
\hline $\begin{array}{l}\text { Obersimmental } \\
\text { Boltigen-Zweisimmen. . } \\
\text { St. Stephan-Lenk. . . . }\end{array}$ & $\begin{array}{l}1140 \\
1418\end{array}$ & $\begin{array}{c}1029 \\
-\end{array}$ & $\begin{array}{l}1286 \\
1499\end{array}$ & $\begin{array}{l}1043 \\
1309\end{array}$ & $\begin{array}{c}1095 \\
-\end{array}$ & $\begin{array}{c}1077 \\
-\end{array}$ & - \\
\hline
\end{tabular}

Es ist daraus zu ersehen, daß die SW-Exposition im allgemeinen die Höchstwerte hat und daß die Siedlungen in der Nordlage am tiefsten bleiben. Damit wird ein weiteres Ergebnis, das die Forscher in den ostalpinen Tälern gefunden haben, bestätigt. Die auffallend hohe Zahl für die Dauersiedlung, die in nördlicher Auslage im Mäniggrund liegt, bildet eine Ausnahme, auf die wir bei der Besprechung der einzelnen Wohnstätten hingewiesen haben.

Die Siedlungsdichte ist im Simmental bei südlicher Exposition am größten, gefolgt von der W-, SE- und NW-Exposition. Die Niederlassungen mit südwestlicher oder nordöstlicher Exposition sind infolge des Talverlaufes ziemlich selten.

Die Dauersiedlungsgrenze zieht sich im Simmental in größeren Höhen hin als in den Kantonen Unterwalden und Appenzell, die einen ihm ähnlichen Landschaftscharakter haben. Auch die höchsten Werte aus dem Entlebuch werden um $250 \mathrm{~m}$ überboten.

Die Siedlungskurve im Simmental liegt ungefähr gleich hoch wie die in den Tälern der Nordabdachung der Ostalpen. Dagegen steigen die Siedlungen südlich der Kammlinie der Ostalpen bedeutend höher hinauf, sowohl was die Durchschnitts- wie die Extremwerte anbelangt.

Verglichen mit den andern voralpinen Tälern der Schweizer Alpen, kann das Simmental als ein Uebergangsgebiet von den Voralpen zu den Hochalpen bezeichnet werden.

\section{Wirtschaftliche Ergebnisse}

Wir schieben zunächst eine Bemerkung ein, die wir der Arbeit von Paravicini über die Bodennutzungssysteme in der Schweiz $(54,36)$ entnommen haben. Nach seinen Angaben herrschen in den Alpentälern vorwiegend Kleinbauern- und kleine Mittelbauernbetriebe vor. $45,6 \%$ aller Höfe entfallen auf die Größenklasse von 3,1 bis 10 ha, und $35,5 \%$ auf diejenige von 0,5 bis 3 ha. Im Ober- und Niedersimmental ist die große Zahl der Betriebe, die 30 bis 70 und mehr Hektaren umfassen, auffällig. Die Ursache dafür ist, daß die Züchter versuchen, ihre Betriebe zu arrondieren, um in den Besitz großer Grundstücke zu gelangen, auf denen sie die jungen Zuchttiere weiden lassen.

Im Simmental befinden sich an der obern Grenze der Dauersiedlungen fast ausschließlich Kleinbauern, die 1 bis 8 Stück Rindvieh und einige Ziegen oder Schafe besitzen. In zahlreichen Fällen üben diese Kleinbauern, weil ihnen die Landwirtschaft das zum Leben Notwendige kaum gewährt, noch eine Nebenbeschäftigung als Forstgehilfe, Wegknecht, Holzhauer aus, oder sie arbeiten als Aushilfen bei den Großbauern.

Die landwirtschaftlichen obern Grenzen, die auf dem Vorkommen von Kulturpflanzen, Mähwiesen usw. beruhen, sind bereits im Kapitel über die Höhengrenzen besprochen worden, so daß auf eine weitere landwirtschaftliche Erörterung verzichtet werden kann. 
Der wirtschaftliche Aufbau im Simmental, wie er aus den geschichtlichen Quellen und den heutigen Verhältnissen erschlossen werden kann, ist beinahe unabhängig vom Ackerbau. Die obere Grenze des Ackerbaus und der Dauersiedlungen fallen seit Jahrhunderten nicht mehr zusammen. Die Rindviehzucht und die Milchwirtschaft sind von jeher die Grundlagen der Existenz gewesen. Dort, wo die Kühe und Rinder überwintert werden können, was nur innerhalb der Mähwiesenzone möglich ist, liegt die obere Grenze der Dauersiedlungen im Simmental. Darin unterscheidet es sich von den Tälern der Ostalpen, in denen der Getreidebau die obere Grenze bedingen soll. Dieser Umstand ist sicher teilweise auf die reichlicheren Niederschläge des Simmentales zurückzuführen, die dem Getreidebau hinderlich sind, dafür aber die Graswirtschaft begünstigen.

6. Ergebnisse in bezug auf die Verändèrungen der obern Dauersiedlungsgrenze

Die Begehung des Simmentales hat erlaubt, festzustellen, daß die obere Grenze der Dauersiedlungen beinahe unverändert geblieben ist. An einigen Orten ist ein geringer Verlust - so im Jaunpaßgebiet, im Diemtigtal in der Bäuert Riedern -, an andern dafür ein kleiner Gewinn - so in der Gemeinde St. Stephan - eingetreten. Die Dichte der dauernd bewohnten Häuser in der Kampfzone hat im Obersimmental abgenommen, im Diemtigtal zugenommen, und im Niedersimmental hat sie sich nicht verändert.

Im Obersimmental bewahrheitet sich der bekannte Satz, daß ein von einem Schienenstrang durchzogener Haupttalboden heute volksdichter sein kann als früher, während die seitlichen Hochtäler einen durch die positive Gesamtbevölkerungsentwicklung der zugehörigen Gemeinden verdeckten Siedlungsabbau aufweisen.

Der Verlust an der obern Grenze der Dauersiedlungen ist im Simmental nicht auf objektive Grundlagen, wie Klimaverschlechterung, Naturkatastrophen, Lawinenverheerungen, zurückzuführen, sondern auf subjektive Ursachen, wie in der zunehmenden Abneigung gegen die Härten des Landlebens im Gebirge und auf die gesteigerten Lebensansprüche, die aus der Kenntnis der Lebenshaltung im Bauernbetrieb des Flachlandes entstanden sind.

\section{LITERATURVERZEICHNIS}

(Es sind nur die wichtigsten der benützten Werke und Zeitschriftenartikel angegeben)

Geologie und Morphologie

1. BeCK, P.: Grundzüge der Talbildung im Berner Oberland. Eclog. geolog. Helvetiae, 16, 1921, 139-176.

2. -- Nachweis, daß der diluviale Simmegletscher auf den Kander-Aare-Gletscher hinauffloß. Mitteil. d. Naturf. Ges. Bern, 1921, 1-2.

3. - Eine Karte der letzten Vergletscherung der Schweizer Alpen. Mitteil. d. Naturf. Ges. Thun, $1,1926,3-53$.

4. Bornhauser, M.: Geologische Untersuchungen an der Niesenkette. Diss. Bern 1929.

5. Geologischer Führer der Schweiz. Basel 1934.

6. Hammer, W.: Der Einfluß der Eiszeit auf die Besiedlung der Alpentäler. Zeitschr. d. DeutschOesterreich. Alpenvereins, 45, 1914, 61-81.

7. Herm, AL.: Geologie der Schweiz. Leipzig 1922.

8. Lugeon, M.: Les hautes Alpes calcaires entre la Lizerne et la Kander. Matériaux pour la carte géologique de la Suisse. Nouv. Série, 30e livr., 1914/18, 1-360.

9. - Sur la géologie des Préalpes internes du Simmental. Eclog. geolog. Helvetiae, 16, 1920, 97-102.

10. - et Gagnebin, E.: Observations et vues nouvelles sur la géologie des Préalpes romandes. Mém. de la Soc. vaudoise des Sciences nat., 7, 1941, 1-90.

11. Nussbaum, F.: Die eiszeitliche Vergletscherung des Saanegebietes. Diss. Bern 1906.

12. - Die Täler der Schweizer Alpen. Eine geographische Studie. Bern 1910.

13. Penck, A., und Brückner, E.: Die Alpen im Eiszeitalter. Lcipzig 1901/1909.

14. Piwowar, A.: Ueber Maximalböschungen trockener Schuttkegel und Schutthalden. Diss. Zürich 1903.

15. Rabowski, F.: Les Préalpes entre le Simmental et le Diemtigtal. Matériaux pour la carte géologique de la Suisse. Nouv. Série, 35e liv., 1920, 1-130.

16. Richter, E.: Die Gletscher der Ostalpen. Stuttgart 1888.

17. Tschacritli, B. S.: Ueber Flysch und Couches rouges in den Decken der östlichen Préalpes romandes. Diss. Bern 1941. 
Höhengrenzen

18. BREtSCHNEIDER-GrütTER, H.: Umrisse einer Wirtschafts- und Siedlungsgeographie des Berner Juras. Diss. Bern 1914.

19. BüHler, A.: Das Meiental im Kanton Uri. Diss. Basel 1928.

20. BüHLER, J.: Veränderungen in Landschaft, Wirtschaft und Siedlung des Entlebuchs. Diss. Zürich 1937.

21. Burkr, CH.: Die Siedlungen des Rhonequertales in ihrer Abhängigkeit von den Formelementen des Tales. Diss. Leipzig 1911.

22. FlüCKIger, O.: Die obere Grenze der menschlichen Siedlungen, abgeleitet auf Grund der Verbreitung der Alphütten. Diss. Bern 1906.

23. FreY, H.: Das Emmental. Versuch einer geographischen Monographie. Diss. Bern 1910.

24. FrrTzsCH, M.: Ueber Höhengrenzen in den Ortleralpen. Wissenschaftl. Veröff. d. Vereins f. Erdkunde zu Leipzig, 2, 1895, 105-292.

25. GASTL, R.: Die Veränderungen der Dauersiedlungen in den höheren Lagen des bayrischen Allgäus. Forsch. z. Deutschen Landeskunde, 36, 1941, 1-126.

26. Hassinger, H.: Neuere Arbeiten zur Anthropogeographie der Schwéiz. Zeitschr. d. Ges. f. Erdkunde zu Berlin, 1924, 97-129.

27. Jegerlehner, J.: Die Schneegrenze in den Gletschergebieten der Schweiz. Diss. Leipzig 1902.

28. Iмног, E.: Die Waldgrenze in der Schweiz. Diss. Bern 1900.

29. Klengel, F.: Die historische Entwicklung des Begriffs der Schneegrenze von Bouguer bis auf A. von Humboldt, 1736-1820. Mitteil. d. Vereins für Erdkunde zu Leipzig, 1888, 105-190.

30. Krebs, N.: Länderkunde der österreichischen Alpen. Stuttgart 1913.

31. Lehmann, O.: Fortbildung des Begriffs der obern Grenze der Dauersiedlungen in den Alpen. Mitteil. d. Geogr. Ges. Wien, 63, 1913, 153-162.

32. Löws, F.: Siedlungsarten in den Hochalpen. Forsch. z. Deutschen Landes- und Volkskunde, 2, $1888,403-449$.

33. MAYER, R.: Die Verbreitung der Kulturflächen in den Ostalpen und ihre obere Grenze, geomorphologisch betrachtet. Geogr. Zeitschr., 33, 1927, 113-138.

34. Meissinger, E.: Almgeographie des Illerqueligebietes. Würzburg 1936.

35. Orт, A.: Die Siedlungsverhältnisse beider Appenzell. Diss. Zürich 1915.

36. Ratzel, F.: Anthropogeographie. Stuttgart 1912.

37. - Höhengrenzen u. Höhengürtel. Zeitschr. d. Deutsch-Oesterreich. Alpenvereins, 20, 1889, 102-135.

38. Ringwald, F.: Wirtschaft und Besiedlung des Kantons Obwalden. Diss. Zürich 1933.

39. Schindler, F.: Kulturregionen und Ackerbau in den Hohen Tauern. Zeitschr. d. Deutsch-Oesterreich. Alpenvereins, $19,1888,73-82$.

40. - Kulturregionen und Kulturgrenzen in. den Oetztaler Alpen. Zeitschr. des Deutsch-Oesterreich. Alpenvereins, 21, 1890, 62-84.

41. - Zur Kulturgeographie der Brennergegend. Zeitschr. d. Deutsch-Oesterreich. Alpenvereins, 23, $1893,1-20$.

42. SIEGER, R.: Zur Geographic der zeitweise bewohnten Siedlungen in den Alpen. Geogr. Zeitschr., $13,1907,361-369$.

43. StAuB, W.: Klimaschwankungen, Landschaftsform und Siedlungen, ihrc Beziehungen in der Vorgeschichte der Schweiz. Diss. Zürich 1900.

44. Walser, H.: Stand und Aufgabe der Siedlungsgeographie der Schweiz. Jahresbericht d. Vereins

-. Schweiz. Gymnasiallehrer, 43, 1913, 155-174.

45. W.ETtSTEIN, O.: Anthropogeographie des Safientales. Diss. Zürich 1915.

Bevölkerungspolitik und Wirtschaft

46. Ammann, H.: Ist die Entvölkerung der tessinischen Gebirgstäler eine Ausnahmeerscheinung? Zürich 1927.

47. BÄGGLI, W.: Betriebswirtschaftliche Bciträge zur Kenntnis der Landwirtschaft im simmentalischen Hochzuchtgebiet, insbesondere im Diemtigtal, mit spezieller Berücksichtigung der Verschuldungsverhältnisse. Diss. ETH. Bern 1937.

48. BernhaARd, H.: Grundlagen zu einer Erhebung über die schweizerische Gebirgsentvölkerung. Zeitschrift für schweiz. Statistik und Volkswirtschaft, 67, 1927, 201-234.

49. - Ergebnissc einer Bevölkerungsenquète in ausgewählten Gemeinden der Schweizer Alpen. Bern 1928.

50. - Bodenbenützungsform und Volksdichte. Deutsche Rundschau für Geographie, 37, 1914, 110-117.

51. Gutzwiller, K.: Die Alpwirtschaft in der Urzeit. Die Alpen, 13, 1937, 95-100.

52. HüsSER, P.: Die Entvölkerung der urschweizerischen Gebirgstäler. Einsiedeln 1927.

53. Koller, A.: Geographische Grundlagen der Entvölkerung in den Alpen. Diss. Zürich 1929.

54. Paravicini, E.: Die Bodennutzungssysteme in der Schweiz in ihrer Verbreitung und Bedingtheit. Erg.-H. Nr. 200 zu Peterm. Mitteil. Gotha 1928.

55. Schweiz. Bauernsekretariat: Die Bodennutzungssysteme in der Schweiz und ihre Verteilung. Brugg 1927.

56. WIRTH, P.: Die geographische Verbreitung der schweizerischen Viehwirtschaft. Diss. Bern 1942. 
Kanton Bern und Simmental

157. Fontes rerum bernensis. Bern $1903 \mathrm{ff}$.

58. Gempeler-sChletri, D.: Heimatkunde des Simmentales. Bern 1904.

59. Heimatkundevereinigung des Simmentales: Simmentaler Heimatbuch. Bern 1938.

60. JAHN, A.: Der Kanton Bern deutschen Theils, antiquarisch-topographisch beschrieben. Bern und Zürich 1850.

61. Isobersteg, J.: Das Simmental in alter und neuer Zeit. Bern 1874.

62. Jörin, E.: Der Kanton Oberland 1798-1803. Diss. Bern 1912.

63. Kasthofer, K.: Wanderung in das Siebenthal. Alpenrosen, ein Schweizer Almanach auf das Jahr 1813. Bern.

64. - Bemerkungen über die Wälder und Alpen des Bernerischen Hochgebirges. Aarau 1818.

65. Nussbaum, F.: Das Berner Oberland in J. J. FrüH, Geographie der Schweiz, Bd. 3, 1938.

66. Ougspurger, Kastran: Amtsbuch der Landschaft vom 7. April 1677. Staatsarchiv Bern.

67. V. Tscharner, L.: Die obersimmentalische Herrschaft Mannenberg. Neujahrsbl. d. histor. Vereins d. Kt. Bern. 1907.

68. V. TsChaRner, L. S.: Rechtsgeschichte des Obersimmentales bis zum Jahre 1798. Bern 1908.

69. Volkswirtschaftskammer des Berner Oberlandes: Landwirtschaft und Obstbau des Berner Oberlandes. Interlaken 1925.

70. Wurstemberger, J. L.: Geschichte der alten Landschaft Bern. Bern 1861.

71. WYss, J. R., der Jüngere: Ein Streifzug ins Siebenthal. Alpenrosen, ein Schweizer Taschenbuch auf das Jahr 1825. Bern.

Verschiedenes

72. Billwiller, R.: Die geographische und jahreszeitliche Verteilung der Regenmengen in der Schweiz. Schweiz. Zeitschr. f. Forstwesen, 1897. 217-225, 260-267.

73. BrockmanN-Jerosch, H.: Einfluß des Klimacharakters auf die Grenzen der Pflanzenareale. Vierteljahresschr. d. Naturf. Ges. Zürich, 58, 1913, 1-4.

74. - Die Vegetation der Schweiz. Beiträge zur geobotan. Landesaufnahme. Zürich/Bern 1925/29, 1-499.

75. Conz, J.: Statistik und Verbau der Lawinen in den Schweizer Alpen. Bern 1910.

76. FrüH, J. J.: Geographie der Schweiz, 3 Bde. St. Gallen 1930/38.

77. Geographisches Lexikon der Schweiz. Neuenburg 1902/10.

78. Maurer, J., Billwiller, R., jun., Hess, C.: Das Klima der Schweiz auf Grund der 37jährigen Beobachtungsperiode von 1864-1900. Frauenfeld 1909.

79. MeYer, A.: Ueber einige Zusammenhänge zwischen Klima und Boden in Europa. Diss. ETH. Zürich, Jena 1926.

80. Streun, G.: Die Nebelverhältnisse der Schweiz. Ann. d. Schweiz. Meteorolog. Zentralanstalt, 36, 1899, Anhang Nr. 6, 1-39.

81. V. TAvel, R.: Die wichtigsten Aenderungen in der Lebenshaltung der schweizerischen Hochgebirgsbewohner im Laufe des 19. Jahrhunderts. Diss. Heidelberg, Bern 1891.

82. Uttrnger, H.: Die Niederschlagshäufigkeit in der Schweiz in der Zeitperiode von 1901-1930. Ann. d. Schweiz. Meteorolog. Zentralanstalt Zürich, 69, 1932, Anhang 1, 1-8.

Statistische Werke

83. Annalen der Schweiž. Meteorolog. Zentralanstalt Zürich. 1930-1940.

84. Mitteilungen des Kantonalen Statistischen Bureaus Bern, 1902, 1918, 1921, 1925; N. F. Nr.9, 1931, 1941 (unveröffentlicht).

85. Schweizerische Anbaustatistiken, herausgegeben vom Eidg. Stat. Amt Bern, Jahrgänge 1917, 1919, 1926, 1929, 1934, 1943.

86. Schweizerische Arealstatistik 1923/24, herausgegeben vom Eidg. Stat. Amt Bern 1924.

87. Statistische Quellenwerke der Schweiz, herausgegeben vom Eidg. Stat. Amt Bern, Eidg. Volkszählungen 1930 und 1941. Heft 152, Nutztierbestände in der Schweiz 1941-1943.

Karten

Geologischer Atlas der Schweiz, 1:25000. Bern $1930 \mathrm{ff}$.

LugEON, M.: Karte Nr. 60 zum geologischen Atlas (siehe Literaturverzeichnis Nr. 8).

Rabowski, F.: Karte Nr. 69 zum geologischen Atlas (siehe Literaturverzeichnis Nr. 15).

Geotechnische Karte der Schweiz; Blatt 3.

Topographischer Atlas der Schweiz (Siegfriedatlas), Blätter 364, 365, 366, 367, 462, 463, 472, 481. Bern.

(Die einschlägigen Blätter der neuen Landeskarte durften zur Zeit der Feldaufnahmen auf Grund militärischer Verfügung nicht benützt werden.)

Topographischer Atlas der Schweiz, 1:50000, Uebersichtsblatt Interlaken-Gsteig.

Topographische Karte der Schweiz (Dufourkarte), 1:100000, Bl. 12.

WALSER, H.: Höhenregionen der Siedlung in der Schweiz.

BrockmanN-jerosch, H.: Regenkarte, publiziert mit der unter Nr. 69 erwähnten Arbeit.

Isothermenkarten aus dem Schweiz. Mittelschul-Atlas, 5. Auflage, Zürich 1928. 


\section{INHALTSVERZEICHNIS}

\section{A. Einleitung}

I. Zum Begriff der Höhengrenzen . . . . . . . . . . . . . . 1

II. Die obere Grenze der Dauersiedlungen . . . . . . . . . . . . 4

\section{B. Die obere Grenze der Dauersiedlungen im Simmental}

I. Natürliche Verhältnisse des Simmentales . . . . . . . . . 7

II. Anthropogeographische Verhältnisse . . . . . . . . . . . . 20

III. Die obere Grenze der Dauersiedlungen im Niedersimmental . . 25

IV. Die obere Grenze der Dauersiedlungen in der Gemeinde Diemtigen 30

V. Die obere Grenze der Dauersiedlungen in den Gemeinden Boltigen und Zweisimmen . . . . . . . . . . . . 36

VI. Die obere Grenze der Dauersiedlungen in den Gemeinden St. Stephan und Lenk . . . . . . . . . . . . . . . . . 42

VII. Ueberblick über die Abhängigkeit der oberen Grenze der Dauersiedlungen von geographischen Faktoren ......... 46

VIII. Beziehungen zwischen der oberen Grenze der Dauersiedlungen und alpwirtschaftlichen und natürlichen Höhengrenzen . . . . . . 47

1. Einleitung. . . . . . . . . . . . . . . . . . . . . . 47

2. Landwirtschaftliche Grenzen im Niedersimmental . . . . . 48

3. Landwirtschaftliche Grenzen im Diemtigtal . . . . . . . . 50

4. Landwirtschaftliche Grenzen in den Gemeinden Boltigen und Zweisimmen. . . . . . . . . . . . . . . 52

5. Landwirtschaftliche Grenzen in den Gemeinden St. Stephan und Lenk . . . . . . . . . . . . . . . . . . . . . 54

IX. Zusammenfassung der Ergebnisse . . . . . . . . . 56

1. Allgemeine Ergebnisse für die Besiedlungsfähigkeit eines Gebietes 56

2. Ergebnisse in bezug auf Siedlungslagen . . . . . . . . 57

3. Ergebnisse in bezug auf die Wasserversorgung . . . . . . . 58

4. Resultate in bezug auf die verschiedenen Höhengrenzen . . . 58

5. Wirtschaftliche Ergebnisse . . . . . . . . . 60

6. Ergebnisse in bezug auf die Veränderungen der oberen Dauersiedlungsgrenze ................ 61 
KARTE UBBER OBERE GRENZEN IM SIMMENTAL

Kartenbeilage ||

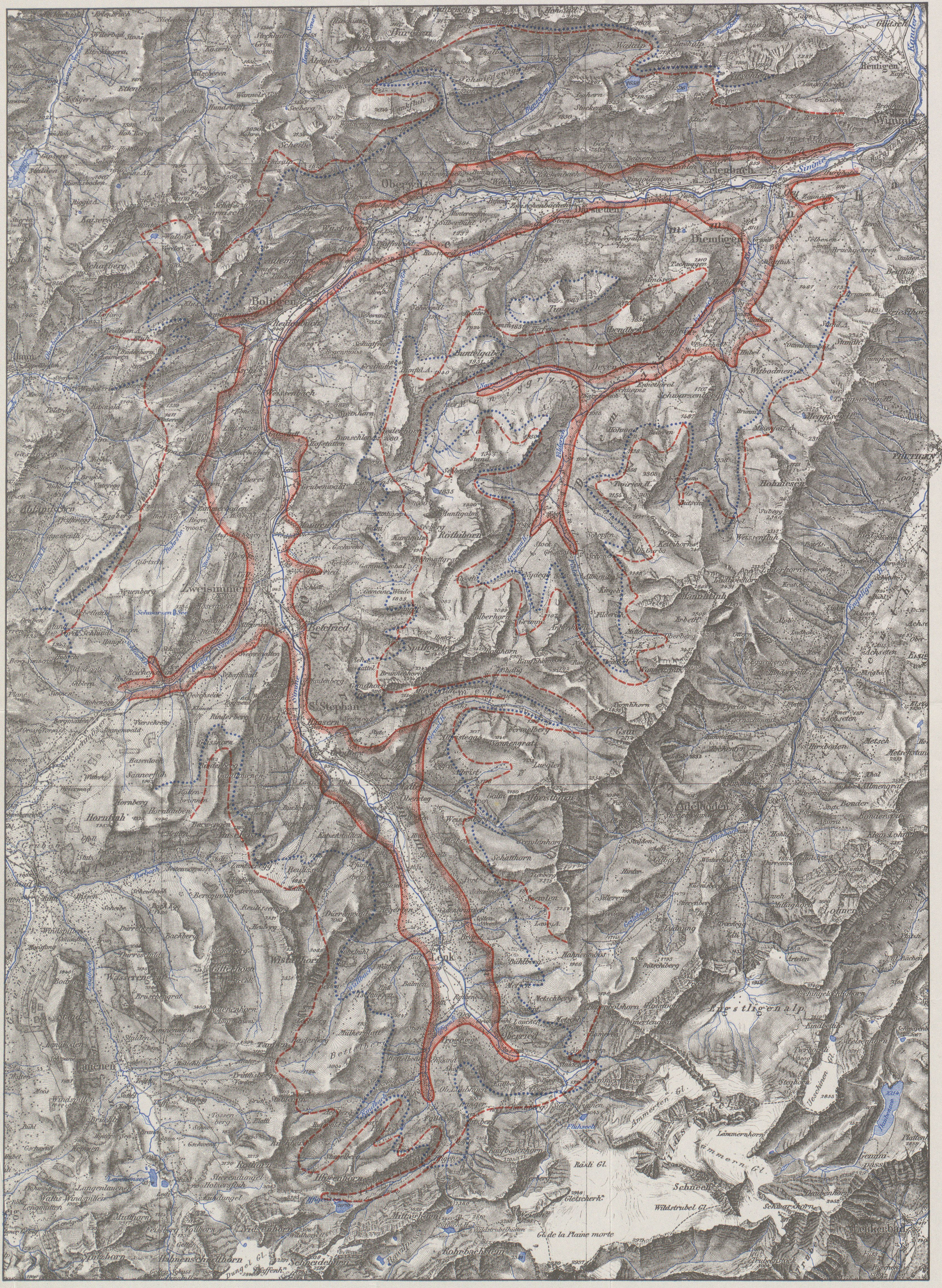




\title{
RÉSUMÉ
}

Le travail avait à fixer dans le Simmental la lisière supérieure des maisons habitées en permanence et de comparer ces résultats avec d'autres. Il est arrivé aux conclusions suivantes: La lisière supérieure de la zone peuplée est fixée, en maints endroits, par des pentes abruptes, formées de roches calcaires, notamment entre Ausserlatterbach et Boltigen, dans le Diemtigtal; partout où la limite n'est pas dictée par les conditions orographiques, elle est en rapport avec l'agriculture. Entre la limite des maisons constamment habitées et celle des prés fauchés il y a, dans le Niedersimmental, une différence de $100 \mathrm{~m}$., dans le Obersimmental, de $50 \mathrm{~m}$. La limite des prés fauchés, et non celle de la culture du blé, fixe l'extension de la zone peuplée. Les fermes habitées toute l'année sont toujours situées au-dessous de la limite des prés fauchés. La culture du blé cesse dès $1400 \mathrm{~m}$. Le paysan base son existence sur le seul élevage du bétail au Mäniggrund, au Dachboden, à Hähligen, etc. Il y a là une différence remarquable en comparaison des Alpes orientales, où la culture du blé délimite le peuplement. La limite de la zone peuplée du Simmental est restée pratiquement la mème dans les 70 dernic̀res années. La densité des fermes habitées à la limite a diminué dans l'Obersimmental. Elle est restée la mème dans l'Obersimmental; elle a augmenté dans le Diemtigtal. Les pertes, surtout aux environs de Lenk et du col de Bellegarde, ne s'expliquent pas par des catastrophes naturelles, mais bien par des faits d'ordre psychologique. L'altitude de l'habitation permanente est la même dans le Simmental et les régions septentrionales des Alpes orientales, elle reste au-dessous des moyennes des régions méridionales. En Suisse, le Simmental possède des moyennes ou des extrêmes élevés en comparaison avec d'autres vallées de la zone préalpine. Il représente une zone de transition entre les Préalpes et les Haut-Alpes calcaires et les Alpes centrales.

\section{RIASSUNTO}

I confini delle sedi umane vengono esaminati nel Simmental (Cantone Berna), la cui zona abitata si estende al di sopra della regione del Flysch e del Niesenflysch. I terreni calcarei vengono evitati; essi determinano in molti luoghi il confine orografico superiore, come per esempio tra Ausserlatterbach e Boltigen, nel Diemtigtal e cosi via. In altri luoghi è il limite superiore dei prati da fieno e non quello dei cereali che segna il confine superiore delle sedi abitate in modo permanente (il secondo si trova nel Niedersimmental circa $100 \mathrm{~m}$. sotto, nell'Obersimmental circa $50 \mathrm{~m}$. sopra il margine naturale dei prati $\mathrm{da}$ fieno). In conseguenza alla maggiore insolazione e alle precipitazioni più favorevoli, il versante con esposizione verso meridione ha abitazioni ad una altitudine superiore. Negli ultimi 70 anni il confine superiore delle sedi umane non ha subito un abbassamento. La densità della popolazione nelle vicinanze del confine stesso ha subito una diminuzione nell'Obersimmental, rimase invariata nel Niedersimmental e segnò un aumento nel Diemtigtal, di modo che nel complesso il Simmental rappresenta una eccezione.

\section{LES PASSAGES ALPESTRES}

\section{EN LIAISON AVEC LES ABBAYES, LES PÈLERINAGES ET LES SAINTS DE LA MONTAGNE}

\author{
par PaUl Girardin
}

Le grand obstacle aux communications, dans les Alpes, est moins au passage du col, au sommet de la chaîne, que dans la remontée des gorges d'accès, dont les roches à pic dominent parfois le torrent de 500 à 800 mètres (Schœllenen, Via Mala). Le passage luimême, qualifié parfois de "Mont» ou "Berg" - "Mont Iseran», "Lœtschberg" - ou de "Colline» (on a dit la "colline» du Mont Cenis - le Simplon s'est appelé "col des collines», concurremment à "Mons Briga») est souvent ouvert largement, sur le type de l'ensellement ou de la "Selle», mot qui revient fréquemment, comme "Sella»: exemples, Mont Cenis, Simplon, Grand- et Petit-Saint-Bernard, Saint-Gothard, l'Argentière, la Maloggia, col la Croix en Queyras. Il porte très souvent à son sommet un lac ou des lacs; la Maloggia en a une chaîne, comme le Reschen Scheidegg, Col de Resia. Ces caractères s'expliquent par l'origine morphologique du passage, qui est dû d'ordinaire à la «transfluence» d'un ancien glacier qui passait par-dessus (Brünig).

Les gorges d'accès furent longtemps inaccessibles, à cause de l'étroitesse du sillon creusé par le torrent, qui en est encore au stade de l'érosion verticale; les parois rocheuses, à pic ou surplombantes, sont si rapprochées qu'elles semblent se toucher. Parfois elles 